\title{
Conversion and Correction Factors for Historical Measurements of Iodine-131 in Hanford-Area Vegetation, 1945-1947
}

Hanford Environmental Dose Reconstruction Project

\author{
E. I. Mart \\ D. H. Denham \\ M. E. Thiede
}

May 1993

CEVED

Prepared for review and approval by the Technical Steering Panel and the Centers for Disease Control and Prevention under Contract 200-92-0503(CDC)/18620(BNW)
$1 \div 191833$

$00 \mathrm{TI}$

Battelle

Pacific Northwest Laboratories

Richland, Washington 99352 


\section{LEGAL NOTICE}

This report was prepared by Battelle as an account of sponsored research activities. Neither Sponsor nor Battelle nor any person acting on behalf of either:

MAKES ANY WARRANTY OR REPRESENTATION, EXPRESS OR IMPLIED, with respect to the accuracy, completeness, or usefulness of the information contained in this report, or that the use of any information, apparatus, process, or composition disclosed in this report may not infringe privately owned rights; or

Assumes any liabilities with respect to the use of, or damages resulting from the use of, any information, apparatus, process, or composition disclosed in this report.

Reference herein to any specific commercial product, process, or service by trade name, trademark, manufacturer, or otherwise, does not necessarily constitute or imply endorsement, recommendation, or favoring by Sponsor or Battelle.

Printed in the United States of America

Available to DOE and DOE contractors from the

Office of Scientific and Technical Information, P.O. Box 62, Oak Ridge, TN 37831; prices available from (615) 576-8401. FTS 626-8401.

Available to the public from the National Technical Information Service, U.S. Department of Commerce, 5285 Port Royal Rd., Springfield, VA 22161. 


\section{Preface}

In 1987, the U.S. Department of Energy (DOE) directed the Pacific Northwest Laboratory, which is operated by Battelle Memorial Institute, to conduct the Hanford Environmental Dose Reconstruction (HEDR) Project. The DOE directive to begin project work followed a 1986 recommendation by the Hanford Health Effects Review (HHER) Panel. The HHER Panel was formed to consider the potential health implications of past Hanford-Site releases of radioactive materials.

A December 1990 Memorandum of Understanding between the Secretaries of the DOE and the U.S. Department of Health and Human Services (DHHS) transferred responsibility for managing the DOE's dose reconstruction and exposure assessment studies to the DHHS. This transfer resulted in the current contract between Battelle Pacific Northwest Laboratories $(B N W)$ and the Centers for Disease Control and Prevention (CDC), an agency of the DHHS.

An 18-member Technical Steering Panel (TSP) was selected by the vice presidents for research at major universities in Washington and Oregon to direct the project work. The TSP consists of experts in the various technical fields relevant to HEDR Project work and representatives from the states of Washington, Oregon, and Idaho; Native American Tribes; and the public.

The purpose of the HEDR Project is to estimate the radiation dose that individuals could have received as a result of emissions since 1944 from DOE's Hanford Site near Richland, Washington. A major objective of the HEDR Project is to estimate doses to the thyroid of individuals who were exposed to iodine-131 by drinking milk obtained from cows that ate vegetation contaminated by iodine-131 released into the air from Hanford facilities.

To support this work, HEDR Project staff are developing a database of historical environmental measurements. This database will include iodine-131 concentrations for vegetation samples collected since 1945 around the Hanford Site. The quality of the historical measurements of iodine-131 in vegetation are examined by reconstructing and evaluating the vegetation sampling and analysis methods used at Hanford in 1945-1947 when air emissions of iodine-131 from Hanford were at their peak.

This effort includes compiling information on early vegetation monitoring methods and reconstructed conversion factors--the subject of this report. These conversion factors can be used to provide the best estimate of true iodine-131 activities in vegetation from 1945 through 1947. The uncertainty in these conversion factors is discussed in a companion report (Gilbert el al. 1992). Original beta counting data and historically reported radionuclide activity levels

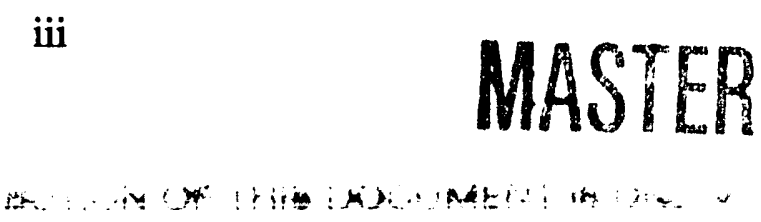


in vegetation will be provided in the Milestone 0501A final report which will soon be published. This report, presented for TSP and CDC review, will fulfill HEDR Project Milestone 0502A. 


\section{Summary}

This report is a result of the Hanford Environmental Dose Reconstruction (HEDR) Project whose goal is to estimate the radiation dose that individuals could have received from emissions since 1944 at the U.S. Department of Energy's (DCE) Hanford Site near Richland, Washington. The report describes in detail the reconstructed conversion and correction factors for historical measurements of iodine-131 in Hanford-area vegetation which was collected from the beginning of October 1945 through the end of December 1947.

\section{Scope of Work}

The scope of work is to quantify the appropriate conversion and correction factors that are necessary to reconstruct true iodine-131 activity level in vegetation for 1945-1947. This has been accomplished by 1) providing information on historical methods of vegetation sampling and analysis, 2) providing information on the assumed efficiency of the Geiger-Mueller (GM) detector, and 3) developing factors needed to convert original gross beta counting rate data and reported iodine-131 activity levels to estimates of iodine-131 activities as they would be measured today. The potential impacts on the conversion and correction factors that have been addressed are 1) the radioactive decay that potentially occurred between sample collection and measurement, 2) the measurement efficiency due to the geometry of the measurement system, 3) the sample weight and configuration, 4) the radiation absorption and scattering, and 5) the original assumption that all beta activity in vegetation was due to iodine-131.

Although this report addresses measurement techniques from the start of Hanford operations, the conversion and correction factors provided only apply to 1-gram sagebrush samples measured from October 1945 through December 1947. It is limited to one-gram sagebrush samples because these were the samples predominantly collected starting in October 1945.

\section{Technical Approach}

To determine the conversion and correction factors, BNW staff reviewed the historical records and interviewed veteran Hanford employees familiar with the respective vegetation sampling and measuring techniques. The objective was to learn from them as much as possible about how iodine-131 and other radionuclides dispersed once they were released from the stacks, and about the collection and measurement techniques, radiation-detector systems, original counting data, and historical conversion factors. Although counting data are available from the $1940 \mathrm{~s}$, calibration techniques were limited. Therefore, the conversion factors were developed by evaluating 1950 s research on calibration techniques to determine absolute or 
near-absolute beta activity. The 1950 s research involved the same thin-window (mica) GM counting systems as had been used in the 1940s to measure iodine-131 levels in vegetation. The research done in the 1950s is considered highly reliable for the counting samples and configurations for which they were developed. This reliability is evidenced both by the confidence expressed by the veteran Hanford employees and by several recorded accounts that show close agreement between independent Hanford-Site-activity determinations and those reported by the U.S. Bureau of Standards (USBS).

\section{Results and Conclusions}

The results produced by the research and included in this report are conversion factors which may be used to convert original counting data to numerical values that represent the best approximation of the actual (as they would be measured today) amounts of iodine-131 deposited onto vegetation at the Hanford Site and surrounding areas.

Three main factors affected the true iodine-131 activity in a vegetation sample measured from 1945 through 1947 . These factors are the measurement conversion factor $(M$, disintegrations per minute/counts per minute--dpm/cpm), the decay correction factor $\left(D_{c}\right.$, unitless), the iodine-131 assumption correction factor $\left(\mathrm{I}_{\mathrm{c}}\right.$, unitless). Both $\mathrm{D}_{c}$ and $\mathrm{I}_{c f}$ must be individually determined for a given measurement date and location. On the other hand, $M$ is generic for the type of vegetation pellet sample counted. The vegetation sampled was formed into pellets by hand until about mid-1946. Then, a hand-operated press was put into use to help ensure consistency in pellet dimensions. Thus, one value of $M$ can be applied to handformed pellets and another value for press-formed pellets. The uncertainty associated with each factor $\left(M, D_{c}, I_{c f}\right)$ is discussed in a companion report (Gilbert et al. 1992).

The factors developed in this analysis are approximations that can be used to derive best estimates of true iodine-131 activities in the historical vegetation samples. These conversion factors were developed by evaluating historical studies that developed parameters for absolute beta counting.

The results of this report must be viewed in light of the limitations in the scope of this report. While the results are necessarily approximations, they do provide a basis for estimating the overall uncertainty in the available vegetation data for 1945-1947. Although additional research would reduce the uncertainty in the conclusions, the uncertainty in the conversion factors (Gilbert et al. 1992) relative to the uncertainty in the models and model parameters being developed to predict radiation doses is small. Therefore, further refinement of these vegetation estimates is not deemed necessary. 


\section{Data Quality Objectives}

The information generated for this report was prepared before the implementation of formal data quality objectives (Shipler 1992). However, data quality was assessed in the manner described below.

\section{Accuracy and Precision}

The results of the research presented in this report are conversion and correction factors with which iodine-131 levels in vegetation can be reconstructed using historical data. The uncertainty of the reconstructed iodine-131 levels was addressed by Gilbert et al. (1992) when they assessed the uncertainty of the factors now being published in this report. They evaluated all parameters of the factors addressed in this report and developed a possible range of values and a best estimate of the true value for each parameter. They used appropriate models, approximated the uncertainty of model parameters, and propagated those parameter uncertainties through the models to obtain the uncertainty of the reconstructed iodine-131 levels.

\section{Completeness}

Any further review of historical documents is not expected to have a major impact on the results of this report. Original Hanford-Site documents were reviewed as well as documents from non-Hanford-Site research. The non-Hanford documents confirmed that Hanford had historically (starting in the 1950s) applied appropriate techniques. Enough information has been uncovered in the documents reviewed and from discussions with veteran Hanford employees to adequately understand the detector systems used and the measurement techniques employed. In addition, the reconstruction of cross-seasonal 1-gram sagebrush pellets (see Section 2.5) provided empirical information on rellet dimensions.

\section{Representativeness}

This report provides reconstructed conversion and correction factors with which iodine131 levels can be computed from historical data. The factors covered in this report are representative of those necessary for converting and correcting the historical data. 


\section{Comparability}

Comparability is not an issue because the objective of this research is to provide factors for converting and correcting historical data to our best estimates of actual iodine-131 levels. This report does not provide the reconstructed iodine-131 values in vegetation. No previous values other than those historically reported are available for comparison, and use of historical data for comparison is not valid because the historically reported iodine-131 levels could have been inaccurate by a factor of two or more. The report provides a technique of estimating actual values, even if they differ from those historically reported by more than a factor of two.

\section{Conclusions}

The uncertainty in the factors provided in this report and addressed by Gilbert et al. (1992) could be reduced by additional research. Additional reviews of documents and notebooks, empirical studies, and mathematical modeling could be used to further refine these estimates. However, such additional efforts are not expected to have a major impact on the values reported here nor on the end product of the HEDR Project. 


\section{Acknowledgments}

BNW staff held three meetings with veteran Hanford employees who provided valuable information by putting in context the methods and intent of the radiation measurements on vegetation during the period of this report. These meetings with the veteran Hanford employees greatly increased our understanding of how to interpret some of the documents. For example, they explained that certain reports were just summaries written to management which helped clarify why some of the historical documents were so brief and included little supplementary technical inrormation. In addition, the veteran Hanford employees provided recommendations on the development of conversion and correction factors for historical measurements of iodine-131 in the Hanford-area vegetation. The following veteran Hanford employees were invaluable in establishing what was done and why:
Z. E. Carey
H. J. Paas (deceased)
J. K. Soldat
C. C. Gamertsfelder
R. W. Perkins
C. W. Thomas
J. W. Healy
K. R. Price
R. C. Thorburn
P. O. Jackson
D. L. Reid
L. D. Turner

Along with the veteran Hanford employees, the following BNW staff are greatly appreciated for their assistance with the research for and publication of this report:

R. L. Dirkes - previous task leader and current environmental surveillance program manager

R. W. Hanf - measurements of reconstructed pellet dimensions

J. P. Duncan - measurements of reconstructed pellet dimensions

R. O. Gilbert - technical guidance and ad hoc reviews

L. K. Grove - editorial support (initial communic ition specialist)

S. D. Cannon - editorial support (succeeding communication specialist) 


\section{Definitions of Key Words}

Absorption Parameter, $F_{\mathrm{a}}$ : The parameter that corrects for absorption of beta particles after they leave the vegetation pellet and pass through cellophane, air, and the mica window. This correction depends on beta particle energy, the combined mass thicknesses of cellophane, air, and the mica window, and the iodine-131 beta-absorption coefficient. This is one of the parameters that affects the reconstructed measurement conversion factor.

Activity: The number of nuclear transformations (disintegrations).

Adjustment Factor, A: The unitless ratio of the reconstructed measurement conversion factor, $M(\mathrm{dpm} / \mathrm{cpm})$, to the inverse of the historical detector efficiency factors assumed (dpm/cpm). The adjustment factors correct the historically reported iodine-131 activity levels on vegetation ( $\mu \mathrm{Ci} / \mathrm{g}$ or $\mu \mathrm{Ci} / \mathrm{kg}$ ) for biased historical detector efficiency factors.

Backscatter Parameter, $F_{b s}$ : The parameter that compensates for an increase in the counting rate from betas being reflected back towards the Geiger-Mueller (GM) detector. The backscattering medium is typically the material upon which the source is mounted (e.g., a stainless steel planchet). The ratio of the measured activity in the source without the backing material to that of the same source with the backing material is the backscatter parameter $\left(F_{b s}\right)$. However, for the 1945-1947 vegetation pellets, the backscattering medium is the vegetation itself because the mass of the vegetation is large. This is one of the parameters that affects the reconstructed measurement conversion factor $(M)$.

Beta-Detection Parameter, $\mathbf{E}_{\boldsymbol{\beta}}$ : The parameter that considers those betas that entered the sensitive volume of a GM tube but did not generate counts.

Bias: An assumption, procedure, equipment, or process that skews results either greater than or less than the true value.

Burnup: The power, multiplied by the length of time at that power, that the given fuel has been subjected to in a reactor. The unit for burnup is MWD/ST (megap'itt days per short ton). Burnup indicates how much of the fuel is burned up (used) and, conversely, how much is left to sustain criticality. Fuel is used up once it reaches the discharge burnup goal.

Cellophane-Scatter Parameter, $\mathbf{F}_{\text {col }}$ : The parameter that accounts for an increase in the counting rate due to the cellophane that was placed directly on top of the vegetation pellets and deflected additional betas into the GM detector. This is one of the parameters that affects the reconstructed measurement conversion factor $(M)$. 
Coincidence and Dead-Time Parameter, $C_{d}$ : The parameter that considers the counts that were lost because a beta particle entered the GM tube's sensitive volume while it was recovering from a previous pulse (dead-time) or coincidentally with another beta.

\section{Conversion Factors:}

Historical Detector Efficiency: The relationship of cpm/dpm that was assumed from 1945 to 1947 in converting background corrected count rate (cpm) to disintegration rate (dpm). Note: From 1945 to 1947, the observed counts per minute registered by a mica-window GM detector for a 1 -gram vegetation pellet were divided by the assumed detector geometry (cpm/dpm) to obtain $\mathrm{dpm} / \mathrm{g}$. The dpm value was then divided by the standard relationship $\left(2.22 \times 10^{6} \mathrm{dpm} / \mu \mathrm{Ci}\right)$ to obtain $\mu \mathrm{Ci} / \mathrm{g}$. In February 1946, a selfabsorption factor was added to account for those betas absorbed by the vegetation pellet. At that time, the term "geometry" denoted both geometry and the selfabsorption factors.

Reconstructed Measurement Conversion Factor, M: The reconstructed estimate of the ratio of iodine-131 disintegrations per minute to counts per minute (dpm/cpm) for the historical measurement process and detector systems used. The measurement conversion factor $(M)$ does not include the iodine-131 assumption correction factor nor the iodine-131 decay correction factor. The unit for $M$ is dpm/cpm.

Reconstructed Total Conversion Factor, C: The factor to convert 1945-1947 iodine-131 cpm/g data to the best estimate of $\mu \mathrm{Ci} / \mathrm{kg}$ levels. The unit for $\mathrm{C}$ is $(\mu \mathrm{Ci} / \mathrm{kg}) /(\mathrm{cpm} / \mathrm{g})$. This factor is determined by evaluating all of the parameters that would have affected the percentage of the iodine-131 disintegrations that were registered as counts by the mica-window GM detectors used in the 1940s. It incorporates the reconstructed measurement conversion factor $(M)$, the decay correction factor $\left(D_{e}\right)$, and the iodine-131 assumption correction factor $\left(\mathrm{I}_{\mathrm{cf}}\right)$.

\section{Correction Factors:}

Decay Correction, $\mathbf{D}_{\mathbf{0}}$ : The exponential value that compensates for iodine-131 decay that occurred in the time interval between field sampling and laboratory counting.

Iodine-131 Assumption Correction, $\mathbf{I}_{\mathrm{f}}$ : The fraction of activity resulting from iodine-131 decay. This corrects for the historical assumption that all the counts registered by a mica-window GM detector were generated by iodine-131. 
Counter Resolving Time: The period of time during which ion-pairs from a previous ionization event render a GM detector unresponsive to additional radioactive particles.

Counting Rate: The number of counts registered by a detector per unit time, usually given in units of counts per minute. Counting rate is crnverted to disintegration rate by conversion factors that take into account the solid angle relationship between the source being counted and the detector dimensions, and other parameters such as scatter and absorption. Disintegration rate is converted to curies by the standard $2.22 \times 10^{12} \mathrm{dpm} / \mathrm{Ci}$.

Counts: Pulses registered by a radiation detector system. In this report, counts refer to electronic pulses with each pulse generated by an ion cascade that occurred in those micawindow GM detectors used from 1945 through 1947. Each pulse was then registered as a count. The total counts were collected and divided by the counting time to derive a counting rate in counts per minute (cpm).

Detection Parameter, $\mathbf{E}_{\mathrm{c}}$ : The parameter that accounts for the fraction of betas and gammas counted inside the GM tube, and for the coincidence/dead-time losses. This is one of the parameters that is considered in the reconstructed measurement conversion factor (M).

Disintegration: A spontaneous nuclear transformation (radioactivity) characterized by the emission of energy and/or mass from the nucleus. Disintegration rate is the number of disintegrations occurring per unit of time, which, in this report, is minutes.

Four-Pi $(4 \pi)$ Counting: Counting techniques in which the geometry approaches $4 \pi$. That is, almost every particle emitted is detected and recorded as a count. This is achieved by preparing extremely thin sources to minimize self-absorption and placing the thin source within a detector system so that every emitted particle has cise to a 100 percent chance of being detected.

Fuel-Cooling Time: The length of time elapsed between the cessation of fuel irradiation and the initiation of fuel dissolution.

Gamma-Detection Parameter, $\mathbf{E}_{\boldsymbol{\gamma}}$ : The parameter that $\mathrm{cc}$. asiders those gammas that generated counts. Because the source of the counts collected by a GM detector cannot be identified, counts originating from gammas would erroneously be interpreted as beta counts.

Half-Life: The time required for a radioactive substance to lose 50 percent of its activity by decay. Each radionuclide has a unique half-life. 
Mean Effective Distance, MED: The distance from within the vegetation pellet to the detector. At this distance, the corresponding point-source geometry parameter $\left(G_{p}\right)$ and sample-diameter parameter $\left(F_{d}\right)$ are representative of the entire pellet. The layers within the pellet, and thus the MED, are weighted by the fact that self-absorption occurred in the vegetation at a rate that increased with increasing pellet depth.

Original Counting Data: The historical data collected directly from the counting laboratory. Data refer to recorded counting rates (background corrected counts per minute). The counts were collected by a mica-window GM detector that was used for beta counting. Although these GM detectors were primarily beta detectors, they may also have detected some gamma rays, particularly those of low energy. The counting rate does not directly indicate activity in a given sample. Conversion and correction factors need to be applied to the counting rate to estimate the activity level in microcuries per gram.

Point-Source Geometry Parameter, $\mathbf{G}_{\mathrm{p}}$ : The ratio of the solid angle subtended by the aperture of the sensitive volume of the GM detector tube to the $4 \pi$ solid angle with point source at the origin. Thus, it is that fraction of beta particles emitted from a point source at a fixed distance from the detector that would reach the sensitive volume of the detector if there were no self-scatter, no self-absorption, no absorption in air, cellophane, or window, and no backing behind the source. This parameter compensates for vertical displacement and is one of the parameters that affects the reconstructed measurement conversion factor $(M)$.

Radium D, E, F Standards, RaDEF: Sources used historically for deriving parameters for absolute beta counting. $\operatorname{RaD}$ is lead-210; $\operatorname{RaE}$ is bismuth-210; and $\operatorname{RaF}$ is polonium-210.

Reconstructed Values: The historical data that has been converted and corrected, or adjusted if it was a reported activity, to provide the best estimate of actual iodine-131 levels on vegetation in 1945 to $: 947$.

Release Fraction: The amount of a radionuclide emitted to the environment relative to the initial amount. In this report, it refers to the fraction of a given radionuclide that was released to the environment as a result of the fuel-dissolution process.

Sample-Diameter Parameter, $F_{d}$ : The parameter that corrects for the change in geometry caused by the spreading out of activity such that the source (vegetation pellet) does not represent a point source. This parameter compensetes for horizontal displacement, whereas the point-source geometry parameter compensates for vertical displacement. This is one of the parameters that affects the reconstructed measurement conversion factor $(\mathrm{M})$. 
Self-Absorption Parameter, $\mathbf{F}_{\mathrm{sa}}$ : The measure of the absorption of iodine-131 beta particles by the vegetation. Historically, self-absorption was expressed as a multiplier by Healy and Eisenacher (1946) and as a fraction by Schwendiman (1954). In this report, $F_{s a}$ is expressed as the fraction of iodine- 131 betas not absorbed by passing through the vegetation pellet. This is one of the parameters that affects the reconstructed measurement conversion factor $(M)$.

Self-Scatter: The change in direction of iodine-131 betas during passage through the vegetation pellet. The scattered beta particles would also have been reduced in energy.

Standards: A solution or solid that contains a known amount of radioactivity (disintegrations per minute) at a given radionuclide per unit voiume, unit weight, or in the entire source. 


\section{Contents}

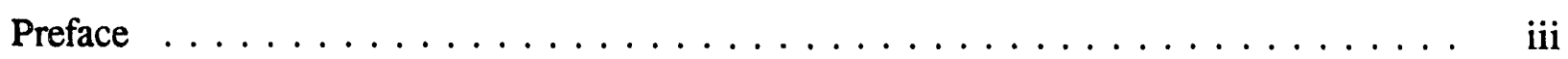

Summary $\ldots \ldots \ldots \ldots \ldots \ldots \ldots \ldots \ldots \ldots \ldots \ldots$

Data Quality Objectives $\ldots \ldots \ldots \ldots \ldots \ldots \ldots \ldots \ldots \ldots \ldots$ vii

Acknowledgments $\ldots \ldots \ldots \ldots \ldots \ldots \ldots \ldots \ldots \ldots \ldots \ldots$

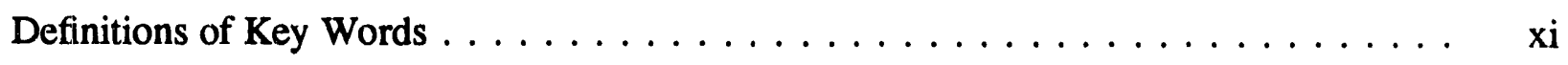

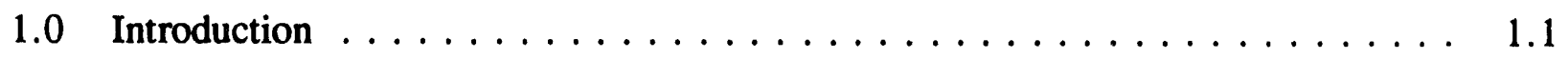

2.0 Historical Techniques and Background $\ldots \ldots \ldots \ldots \ldots \ldots \ldots \ldots$

2.1 Measurement Techniques and Instruments from

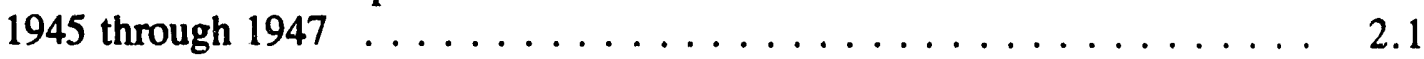

2.1.1 Initial 1945 Technique of Analyzing Vegetation $\ldots \ldots \ldots \ldots \ldots . . .4$

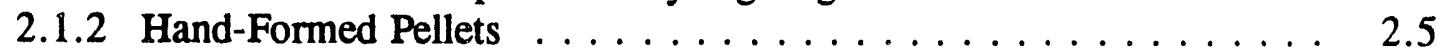

2.1 .3 Press-Formed Pellets $\ldots \ldots \ldots \ldots \ldots \ldots \ldots \ldots$

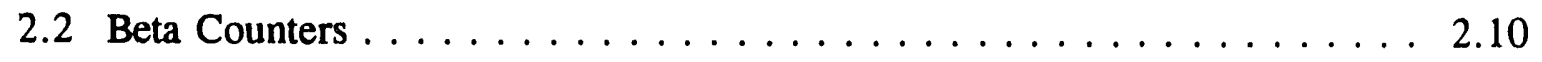

2.3 Iodine-131 and RaDEF Standards . . . . . . . . . . . . . 2.13

2.4 Historical Conversion Factors $\ldots \ldots \ldots \ldots \ldots \ldots \ldots$

2.5 Pellet Dimensions $\ldots \ldots \ldots \ldots \ldots \ldots \ldots \ldots \ldots \ldots$

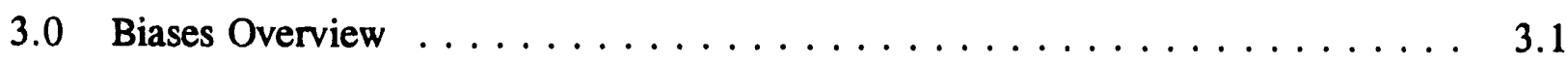

4.0 M: Reconstructed Measurement Conversion Factor . . . . . . . . . . . . 4.1

4.1 Equation for Measurement Conversion Factor, $M \ldots \ldots \ldots$

4.2 Self-Absorption Parameter, $\mathrm{F}_{\mathrm{sa}} \ldots \ldots \ldots \ldots \ldots \ldots$

4.3 Backscatter Parameter, $\mathrm{F}_{\mathrm{bs}} \ldots \ldots \ldots \ldots \ldots \ldots \ldots$

4.4 Cellophane, Air, and Mica-Window Absorption Parameter, $\mathrm{F}_{\mathrm{a}} \ldots \ldots \ldots$ 
4.5 Cellophane-Scatter Parameter, $\mathbf{F}_{\text {cel }} \ldots \ldots \ldots \ldots \ldots \ldots \ldots \ldots$

4.6 Point-Source Geometry Parameter, $G_{p}$, and Sample-Diameter

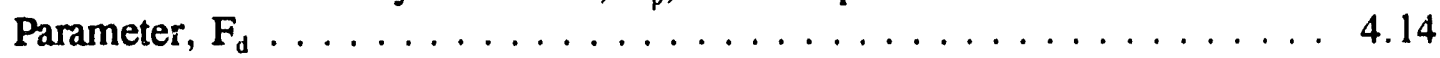

4.6.1 Determination of $G_{p} \ldots \ldots \ldots \ldots \ldots \ldots \ldots \ldots \ldots$

4.6.2 Determination of $F_{d} \ldots \ldots \ldots \ldots \ldots \ldots \ldots \ldots .16$

4.6.3 Determination of Mean Effective Distance, MED . . . . . . . . 4.17

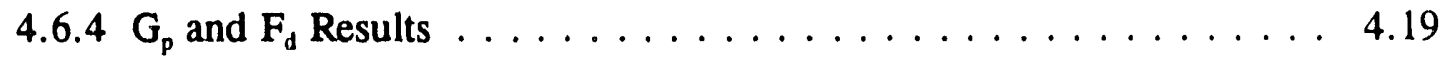

4.7 Parameters with Negligible or No Impact $\ldots \ldots \ldots \ldots$. . . . . . . . . . 4.19

4.7.1 Handling/Processing Losses . . . . . . . . . . . . . . . . . . . 4.19

4.7.2 GM Tube Detection Parameter, $\mathrm{E}_{\mathrm{c}} \ldots \ldots \ldots \ldots \ldots \ldots \ldots$

4.8 Limitations $\ldots \ldots \ldots \ldots \ldots \ldots \ldots \ldots \ldots \ldots \ldots \ldots \ldots \ldots \ldots \ldots \ldots \ldots .22$

4.8.1 Limitations in $\mathrm{F}_{\mathrm{sa}}$ and $\mathrm{F}_{\mathrm{bs}} \ldots \ldots \ldots \ldots \ldots \ldots \ldots \ldots \ldots \ldots$

4.8.2 Limitations in $\mathrm{F}_{\mathrm{a}}$ and $\mathrm{F}_{\text {cel }} \ldots \ldots \ldots \ldots \ldots \ldots \ldots \ldots \ldots \ldots \ldots \ldots \ldots$

4.8.3 Limitations in $G_{p}$ and $F_{d} \ldots \ldots \ldots \ldots \ldots \ldots \ldots \ldots .24$

4.8.4 Limitation in $\mathrm{E}_{\mathrm{c}} \ldots \ldots \ldots \ldots \ldots \ldots \ldots \ldots \ldots . \ldots \ldots .24$

$5.0 \quad D_{\mathrm{e}}:$ Decay Correction Factor $\ldots \ldots \ldots \ldots \ldots \ldots \ldots \ldots \ldots \ldots \ldots \ldots$

$6.0 \quad \mathrm{I}_{\mathrm{cf}}:$ Iodine-131 Assumption Correction Factor $\ldots \ldots \ldots \ldots \ldots . \ldots \ldots$

6.1 Other Radionuclides $\ldots \ldots \ldots \ldots \ldots \ldots \ldots \ldots \ldots \ldots \ldots \ldots . \ldots \ldots$

6.1.1 Natural Background Radioactive Materials . . . . . . . . . 6.3

6.1 .2 Longer-Lived Fission Products . . . . . . . . . . . . . . 6.3

6.1.3 Radioactive Particulates from Corroded Ductwork . . . . . . . . 6.4

6.2 Historical Data . . . . . . . . . . . . . . . . . . . . . . . 6.5

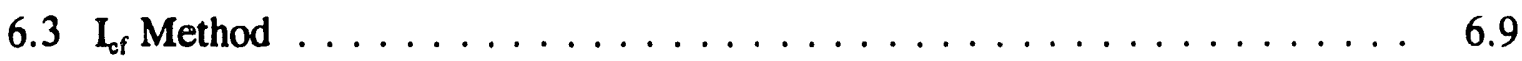

0.3.1 Approach $\ldots \ldots \ldots \ldots \ldots \ldots \ldots \ldots \ldots \ldots \ldots \ldots . \ldots \ldots$

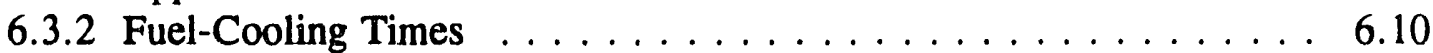

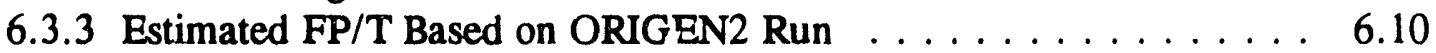

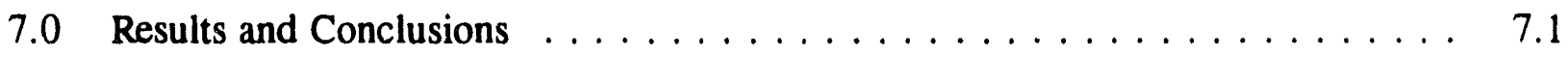

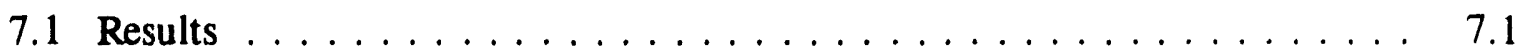

xviii 
7.1.1 Measurement Conversion Factor, $\mathbf{M} \ldots \ldots \ldots \ldots \ldots \ldots$

7.1 .2 Decay Correction Factor, $D_{c} \ldots \ldots \ldots \ldots \ldots \ldots \ldots . \ldots \ldots$

7.1.3 Iodine-131 Assumption Correction Factor, $\mathrm{I}_{\mathrm{cf}} \ldots \ldots \ldots \ldots \ldots .2$

7.2 Conclusions $\ldots \ldots \ldots \ldots \ldots \ldots \ldots \ldots \ldots \ldots \ldots \ldots \ldots$

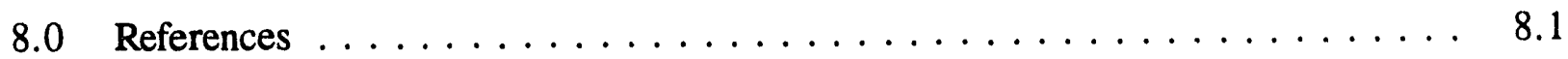

Appendix A - Historical Techniques of Determining Parameters in $\mathbf{M} \ldots \ldots$ A.1

A.1 Historical Techniques of Determining $\mathrm{F}_{\mathrm{sa}} \ldots \ldots \ldots \ldots \ldots \ldots \ldots$

A.1.1 Technique Used from February 1946 through

November $1948 \ldots \ldots \ldots \ldots \ldots \ldots \ldots$. . . . . . . . . . . . A

A.1.2 Technique Used in the $1950 \mathrm{~s} \ldots \ldots \ldots \ldots \ldots \ldots \ldots$ A.2

A.2 Historical Techniques of Determining $\mathrm{F}_{\mathrm{bs}} \ldots \ldots \ldots \ldots \ldots \ldots$ A.3

A.3 Historical Technique of Determining $\mathrm{F}_{\mathrm{a}} \ldots \ldots \ldots \ldots \ldots \ldots \ldots$ A.3

A.4 Historical Technique of Determining $\mathrm{F}_{\mathrm{cel}} \ldots \ldots \ldots \ldots \ldots \ldots \ldots$

A.5 Historical Technique of Determining $\mathrm{G}_{\mathrm{p}} \ldots \ldots \ldots \ldots \ldots \ldots \ldots$ A.4

A.6 Historical Technique of Determining $F_{d} \ldots \ldots \ldots \ldots \ldots \ldots \ldots$

Appendix B - Reconstructed Pellet Data and Results for $\mathbf{M} \ldots \ldots \ldots \ldots$ B. 1

\section{Figures}

2.1 Mica-Window Geiger-Mueller Detector and Shelf Assembly Used

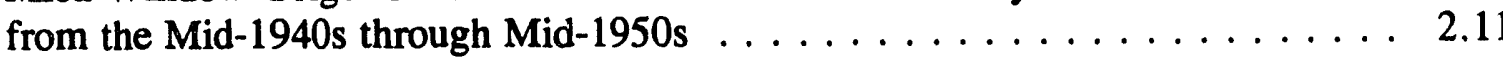

4.1 Self-Absorption, $\mathrm{F}_{\mathrm{sa}}$ (Calculated from Equation 4.2) versus Mass Thickness 


\section{Tables}

2.1 Detailed Summary of Beta-Measurement Techniques $(1945-1947) \ldots \ldots \ldots$

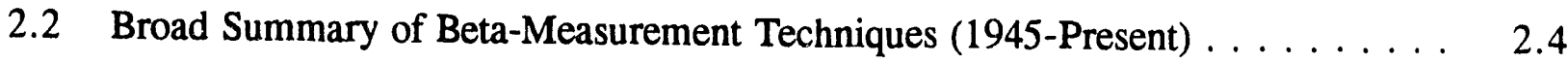

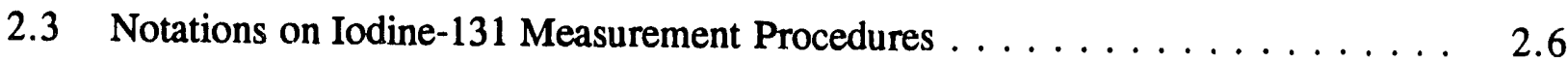

2.4 RaDEF and Iodine-131 Decay and Beta Energy Characteristics $\ldots \ldots \ldots \ldots$

2.5 Examples of 1945-1946 Measurement Data and Corresponding Reported Activity Values . . . . . . . . . . . . . . . . . . . 2.16

4.1 Comparison of Activities Determined for Iodine-131 on Different Shelves ............................. 4.4

4.2 Backscatter Parameters for Iodine-131 with Various Types of Backing . . . . . . 4.11

4.3 Mass Thickness of Thirteen Geiger-Mueller Detector Mica Windows

4.4 Historical Values of the Point-Source Geometry Parameter, $G_{p}$, Empirically Determined for Each Shelf Distance . . . . . . . . . . . . . 4.15

4.5 Historical Values of the Sample-Diameter Parameter, $F_{d} \ldots \ldots \ldots \ldots . \ldots$

4.6 Ratio of Observed Counts per Minute to True Counts per Minute as a Function of Count Rate . . . . . . . . . . . . . . . . . . 4.20

5.1 Decay Correction Factors for Iodine $-131 \ldots \ldots \ldots \ldots \ldots \ldots \ldots$

6.1 Decay Data for Two Samples, July $1945 \ldots \ldots \ldots \ldots \ldots$

6.2 Iodine-131 and Other Fission Product Activity Levels and Computed Fission Products to Total Activity $(\mathrm{FP} / \mathrm{T}) \ldots \ldots \ldots \ldots . \ldots \ldots$

6.3 Estimated Fraction of Fission Products to Total Activity (FP/T) on Vegetation $\ldots \ldots \ldots \ldots \ldots \ldots . \ldots \ldots \ldots$

6.4 Average Number of Days Fuel Cooled before Dissolving $\ldots \ldots \ldots \ldots .11$

6.5 Iodine-131, Fission Product (FP), and Total Activity (Curies) at Stack Discharge Computed from ORIGEN2 Data . . . . . . . . . . . . . . 6.13 
6.6 Average Fuel-Cooling Times and Correlation of Fission Product to Total Activity (FP/T) from ORIGEN2 and Historical Measurements $\ldots \ldots .6 .13$

6.7 Best Estimate of $I_{c f}$ Based on the Average of Historical Vegetation Data and Fission Products to Total Activity (FP/T) Generated from ORIGEN2 Data . . . . . . . . . . . . . . . . . . . . . . . . . 6.15

7.1 Historical and Reconstructed Measurement Conversion Factors and Adjustment Factors for Measurements of Iodine-131 in Vegetation Pellets . . . 7.2

A.1 Historical Averages for Self-Absorption in Vegetation $\ldots \ldots \ldots \ldots \ldots$. . . . .

B.1 Dimensions for $1-$ Gram Hand-Formed Pellets $\ldots \ldots \ldots \ldots \ldots \ldots \ldots \ldots$. . . . . .

B.2 Dimensions for $1-$ Gram Press-Formed Pellets $\ldots \ldots \ldots \ldots \ldots \ldots$

B.3 Parameters in $\mathbf{M}$ for 1-Gram Reconstructed Hand-Formed Pellets . . . . . . . . . B.15

B.4 Parameters in $\mathbf{M}$ for 1 -Gram Reconstructed Press-Formed Pellets . . . . . . . . . B. 17 


\subsection{Introduction}

During the early years of plant operations at the Hanford Site, the iodine-131 released to the atmosphere from: fuel dissolution was the major contributor of radiation dose to the public (Napier 1991). Iodine-131 is, therefore, one of the key elements being studied in the Hanford Environmental Dose Reconstruction (HEDR) Project. The period 1945-1947 was when the largest quantity of iodine-131 emissions occurred and, thus, the period of most interest to the HEDR Project. A major pathway by which persons may have received doses of radiation from Hanford emissions was drinking milk from corss that grazed on vegetation contaminated with iodine-131. Consequently, one of the purposes of the Environmental Monitoring Data Task staff is to evaluate the concentrations of iodine-131 in vegetation as indicated by historical measurements taken from 1945 through 1947.

Because beta particles are emitted when iodine-131 decays, the detection of beta particles gives an indication (although only relative) of the presence of iodine-131. Thin mica-window Geiger-Mueller (GM) detectors were available in the 1940s to count beta particles and thereby provide counting data. Although the state-of-the art was on the cutting edge at the time, calibration $^{(a)}$ techniques were not advanced enough to accurately convert the counting data to iodine-131 radioactivity (activity) levels. ${ }^{(b)}$ This was because iodine-131 standards were not available, and the understanding of all the parameters that affected detection of beta particles was inadequate.

Research to thoroughly investigate all the parameters needed to accurately convert beta ccunts to activity levels started in the late 1940s. In 1950 Hanford published a document (Healy et al. 1950) which detailed these parameters and provided adequate calibration techniques for iodine-131. Because this research is based on the same GM detector systems that were used in the 1940s to assess iodine-131 activity levels in vegetation, the reconstructed conversion factors presented in this report are mainly based on the 1950s and follow-on calibration research. No attempt was made to address the detector systems themselves: their electronics, voltage, or design. As a result, any potential biases resulting from inadequacies in the 1945-1947 detector systems are not considered.

(a) Calibration refers to the development of parameters in the messurement conversion factor $(M)$ which is discussed in detail in Chapter 4.0.

(b) Not all the radiation emitted by iodine-131 reached the detector. Thus, conversion factors were needed to determine the amount of radioactivity on the sample. However, accurate conversion factors for iodine-131 for Hanford detectors were not available until the 1950s. The conversion factors used from 1945-1947 provided biased activity values, typically recorded in units of microcuries per kilogram. Some aspects that affected what fraction of radiation emitted by iodine-131 were recorded by the detectors included distance from the detector, sample spread, and thickness of the vegetation being counted. 
Original beta counting data can be found in such laboratory notebooks as those by Bulow (1945) and Dickinson (1946). Original beta counting data are more reliable than the historical reported iodine-131 levels because: 1) the reported activities were typically given as averages and we do not know how the averages were obtained; 2) the reported iodine-131 activities were biased, and determining the conversion factors used adds another element of uncertainty; and 3) supplementary information for original counting data, such as dates of sample collection and counting, type of vegetation, pellet size, and background, is typically found in the original laboratory notebooks.

Original beta countinc data and reported iodine-131 activity levels for vegetation collected from August 1945 through early August 1946 have been found in historical literature.

However, from August 1946 through December 1947 only reported iodine-131 activity levels have been found. When original beta counting data are available, they can be directly converted to our best estimate of iodine-131 activity levels. However, when only iodine-131 activity levels are reported, adjustment factors can be applied. The adjustment factors are a ratio of the reconstructed measurement conversion factor $(M)$ to the inverse historical detector efficiency.

This report includes factors that can be used to provide best estimates of iodine-131 concentrations in vegetation, either by 1) application of reconstructed factors to directly convert the original beta counting data when beta counting data were available, or 2) factoring out historical conversion factors and applying reconstructed ones by using adjustment factors.

The limitations of each parameter are included in this report. The biases in the historical conversion factors and the methods of measuring concentrations in vegetation were identified by a review of historic literature and interviews with veteran Hanford employees. To provide context for the reader, we have included information on how the historical measurements were taken and on the 1950s absolute beta-counting research techniques (see Appendix A).

Because the size and density of the vegetation pellet affects the calibration parameters, the reconstructed conversion factors in this report are applicable only to 1-gram sagebrush pellets collected and measured according to the techniques used from September 1945 through December 1947. The factors do not apply to any other type of vegetation or any other pellet weight.

The reconstructed conversion factors reported here do not take into account any variability that may have resulted from sampling, handling, and transporting the samples. These processes are assumed to have caused no losses of iodine and thus to have caused no bias. This assumption is supported by veteran Hanford employees who, based on both the difficulty of extracting iodine from vegetation even by chemical means and the fact that they did not 
recall incidences of glove or car contamination, believed that only negligible iodine losses would have occurred (Denham et al. 1988). We also do not take into account any variability in the initial deposition of iodine that may have occurred. This potential lack of representativeness was pointed out by Norton et al. (1956). It was also discussed by Paas (1949) at various times in a series of monthiy reports. Paas points out that iodine-131 deposition patterns can have large variances in a given area. Although the deposition variability is a consideration for the interpretation of results, it is not a concern in the establishment of measurement biases or conversion factors.

Other potenial sources of variability that have not been taken into account are the differences that $\boldsymbol{m}$. ay have resulted from sampling different parts of the sagebrush. An example of that variability is reflected in one limited empirical study done in 1949 on a single medium-sized (8.1-kg/18-lb) sagebrush (Paas 1949). In that study, both iodine-131 and radioactive non-volatile (radionuclides remaining after an ashing process) components were measured. The results of that study suggest that iodine- 131 concentrations may have been greater on the top of the plant.

Gilbert et al. (1992) conducted parameter uncertainty and sensitivity analyses to evaluate the uncertainty of reconstructed iodine-131 measurements obtained using the conversion factors discussed in this report. 


\subsection{Historical Techniques and Background}

From 1945 through 1947, beta-counting technology had not yet progressed to a point where accurate conversion factors specific to the analysis of iodine-131 activities in vegetation could be determined (Healy et al. 1950). The conversion factors in use at that time did not account for all of the parameters that affected overall efficiency of the beta-counting system. Some parameters were ignored or miscalculated, and accurate iodine-131 standards were not available. As a result, the iodine-131 activities in vegetation reported historically were biased. Indeed, the measurements were recognized as being relative at the time (Healy et al. 1950).

The primary intent of the initial routine environmental monitoring program at Hanford was to evaluate trends. ${ }^{(a)}$ Thus, initially the monitoring program was less concerned with absolute levels in a given sample than with the pattern exhibited in an area. Results were used more to compare results from location to location and over time than to document the absolute concentrations at given locations.

With time, more factors were accounted for, and the accuracy of the reported iodine-131 concentration values improved. Understandably, monitoring staff were slow to adopt these improved factors because they would have affected any analyses of trends. By 1951, highly accurate conversion factors had been established so that near-absolute (rather than relative) beta counting was possible at Hanford (Healy et al. 1950). In addition, the method for analyzing iodine-131 activity in vegetation was improved by a chemical extraction method that was put into routine use in December 1948. The direct method of counting 1-gram pellets was entirely replaced by the chemical extraction method (Paas 1949). The approximate half-year overlap (August 1948 through November 1948) in methods enabled researchers to have continuity and a point of reference while testing the chemical extraction procedure (Singlevich 1948a; Singlevich 1948b).

\subsection{Measurement Techniques and Instruments from 1945 through 1947}

Late in 1944, a Site-Survey Group was organized to measure radiation exposures caused by Hanford emissions. One of the group's tasks was to develop measurement methods (Healy 1950). In 1945, measurement methods were in a state of flux because no precedent existed for environmental monitoring of the type required by irradiated fuel dissolution. In addition,

(a) Memorandum (HEDR Project Documusnt No. 03930008), "Notes on the March 27, 1989 Meeting on Biases and Uncertainties in 1945-1957 Measurements of "'II Lovels on Vegetation," from E. I. Mart, BNW consultant, to R. K. Woodruff, BNW, September 27 , 1989. 
staffing for environmental monitoring was low, resulting in few vegetation measurements in early 1945 (Denham et al. 1988). New techniques were devel ped as the need for additional environmental monitoring became apparent. Experience and trial and error quickly led to changes, and, by the end of 1945 , a program for routine vegetation sampling and monitoring was in place. The measurement method that had beer established by then remained basically the same until it was replaced by the chemical extraction method in December 1948.

Table 2.1 summarizes our understanding of measurement methods from 1945 through 1947. Table 2.2 provides a broader historical overview. These summaries are based on information found in various reports and notebooks (referenced in detail in this report) and on discussions with veteran Hanford employees as reported in Denham et al. (1988) and two memoranda. ${ }^{(*)}$ Little documentation of precise procedures used before mid-1946 when the hand-operated press was put into operation has been found. Very little information is available on the procedures used prior to September 1945. At that time, more data become available. Healy et al. (1951) describe in detail the procedure for forming pellets using a hand-operated press, a method implemented around mid-1946.

In the original routine program, the predominant vegetation was sampled weekly at designated locations (Denham et al. 1988). Samples were placed in paper bags, labeled, and delivered to a counting laboratory (Patterson 1946). The vegetation was not artificially dried. It was counted in its natural condition upon arrival from the field (Denham et al. i988).

In a historical 1957 overview report, Dozer ${ }^{(b)}$ discusses the types of vegetation sampled. Dozer states that many experiments and tests had been made on various types of vegetation. Based on these experiments, the consensus was that native, sagebrush was the best absorbent of the effluent gases, and so, wherever possible, samples of native sagebrush were collected. However, it is not certain when this decision had been reached. Veteran employees recall simply that the predominant vegetation at a given location was sampled (Denham et al. 1988).

(a) Memorandum (HEDR Project Document No. 03930003), "Notes from February 6, 1989 Moeting on Chemical Separation and Early Gamma Spectrometry Methods of Analyzing lodine-131 Lovels on Vegetation," from E. I. Mart, BNW, to Veteran Hanford Employees - P. O. Jackson, K. R. Price, J. K. Soldat, C. W. Thomas and to R. K. Woodruff, BNW, February 21, 1989. Memorandum (HEDR Project Documont No. 03930008), "Notes un Merch 27, 1989 Meeting on Biases and Uncertainties in 1945-1957 Meacurements of "'II Levels on Vegotation, " from E. I. Mart, BNW Consultunt, to R. K. Woodruff, BNW, Septomber $27,1989$.

(b) Report (HEDR Project Document No. 03930002) on carly vegetation experiments and tests from R. C. Dozer (General Electric Company) to B. V. Andersen (Ueneral Electric Company), Auguat 13, 1957, Richland, Washington. 
Table 2.1. Detailed Summary of Beta-Measurement Techniques (1945-1947)

\begin{tabular}{|c|c|}
\hline $\begin{array}{l}\text { Estimated Date of } \\
\text { Implementation }\end{array}$ & Probable Technique \\
\hline Before $7 / 20 / 45$ & $\begin{array}{l}\text { Sagebrush was piled around a thin, glass-walled GM detector } \\
\text { and the counting rate (in counts per minute) was recorded. } \\
\text { Apparently no effort was made to determine activity level from } \\
\text { the measured counts per minute. Equal sample sizes were } \\
\text { visually regulated. Measurement results were only relative. }\end{array}$ \\
\hline $7 / 21 / 45$ & $\begin{array}{l}\text { About } 1.5 \mathrm{~g} \text { of vegetation was spread over a } 5 \text {-cm- }(2 \text {-in.-) } \\
\text { diameter hole in a mounting card. The hole was plugged by a } \\
\text { watch glass. The sample was counted by a mica-window GM } \\
\text { detector. }{ }^{\left({ }^{(}\right)}\end{array}$ \\
\hline $8 / 45$ & $\begin{array}{l}\text { About } 1.5 \mathrm{~g} \text { of vegetation was secured }{ }^{(b)} \text { over a } 5-\mathrm{cm}-\left(2-\text { in. }^{-}\right) \\
\text {diameter hole in a cardboard mounting card. A holder for the } \\
\text { sample was developed to ensure consistent (vertical) geometry. } \\
\text { The sample was counted on the second shelf of a mica-window } \\
\text { GM detector. }\end{array}$ \\
\hline $9 / 45-10 / 16 / 45$ & $\begin{array}{l}\text { Hand-formed } \sim 1.5-\mathrm{g} \text { pellets of vegetation were secured on a } \\
\text { cardboard mounting card and counted on the second shelf of a } \\
\text { mica-window GM detector. }\end{array}$ \\
\hline $10 / 17 / 45-6 / 46$ & $\begin{array}{l}\text { Hand-formed } 1-\mathrm{g} \text { pellets of vegetation were secured on a card- } \\
\text { board mounting card and counted on the second shelf of a mica- } \\
\text { window GM detector. }\end{array}$ \\
\hline $7 / 46-12 / 47$ & $\begin{array}{l}\text { A 1-g pellet of vegetation was formed using a hand-operated } \\
\text { press. The pellet was secured to a cardboard mounting card and } \\
\text { counted using a mica-window GM detector. }\end{array}$ \\
\hline
\end{tabular}


Table 2.2. Broad Summary of Beta-Measurement Techniques (1945-Present)

\begin{tabular}{|l|l|}
\hline \multicolumn{1}{|c|}{$\begin{array}{c}\text { Period of } \\
\text { Implementation }\end{array}$} & \multicolumn{1}{c|}{ Technique } \\
\hline $9 / 45-11 / 48$ & $\begin{array}{l}\text { Gross beta counts of vegetation pellets } \\
\text { Chemical separation of iodine-131 from vegetation and other } \\
\text { radionuclides, and gross beta counts of the resultant silver- } \\
\text { iodide precipitate. The gross non-volatile component, which } \\
\text { was also chemically separated, was beta-counted separately } \\
\text { from the iodine-131 } \\
\text { Gamma spectrometry }\end{array}$ \\
$7 / 57-6 / 57^{\text {(a) }}$ & Present
\end{tabular}

\subsubsection{Initial 1945 Technique of Analyzing Vegetation}

When operations at Hanford started, the major hazards from the emissions were expected to be direct radiation from the passing cloud or inhalation of iodine (Healy 1950). However, soon after the first fuel dissolving, contamination of the vegetation close to the stacks was noticed. Consequently, measurements of radioactivity in vegetation began in January 1945 (Parker and Gamertsfelder 1945). The first measurements were field surveys using portable GM detectors. These instruments were inadequate because the cold weather caused the amyl acetate quench gas added to the filler gas to precipitate (Denham et al. 1988). To overcome this problem, some vegetation samples were collected and analyzed in a laboratory. Although field surveys continued through 1947, laboratory analyses were conducted as well.

The first description of the laboratory analysis technique in the historical literature is by Cantril and Healy (1945) for beta counts taken in June and July 1945. The technique is described as placing vegetation (usually sagebrush) around a thin-walled glass GM detector in the lab and measuring the counting rate. Chamberlin ${ }^{(a)}$ described the GM detector as a thinwalled glass counter tube hooked up to a scaler which was useful in detecting small amounts of beta and gamma activity. The first use of this technique is not indicated in the literature surveyed. That this particular technique was the routine method in early 1945 is inferred by correlating information in Parker and Gamertsfelder (1945) and Cantril and Healy (1945).

(a) Memorandum (HEDR Project Document No. 03930001), "A Brief History of the Health Instrument Survey Group in the 300 Area," from R. W. Chamberlin (E. I. Du Pont de Nemours and Company) to W. H. Durum (E. I. Du Pont de Nemours and Company), July 14, 1945, Richland, Washington. 
Parker and Gamertsfelder (1945) provide information on the maximum counts on sagebrush collected on the site for the week ending June 1, 1945. These samples are noted as standard samples. The mid- and late-July 1945 activities reported by Parker and Gamertsfelder (1945) agree exactly in both quantity and location with results reprorted by Cantril and Healy (1945) for the glass-walled detectors.

Because piling vegetation around a detector lacks standardization, no corrections for geometry, self-absorption, or weight can be applied for samples analyzed by this means. Therefore, the limited vegetation data available for the first half of 1945 should be considered only qualitative because actual concentrations cannot be determined reliably.

\subsubsection{Hand-Formed Pellets}

A table in a report by Cantril and Healy (1045) indicates a change in the counting technique between July 20 and 25,1945 . This change is inferred from a brief statement in a table footnote. The footnote indicates that samples collected from July 20 to August 10, 1945, were not corrected for self-absorption and were from 1.5-g samples of sagebrush spread over a circle $5 \mathrm{~cm}$ ( 2 in.) in diameter. The footnote also indicates these measurements were made with an "MW counter" (probably mica-window). 'That differs from the treatment of previous samples which was to use a GM tube that was glass walled. A corresponding change in laboratory analytical technique can be inferred rrom Parker and Gamertsfelder (1945) during the same period, the weeks ending July 20,1945, and July 27, 1945. Farker and Gamertsfelder report use of a particular technique for the first and only time. This technique was described as spreading $1.5 \mathrm{~g}$ of vegetation on a watch glass below a mica-window GM counter with an assumed 8 percent (i.e., 0.08 ) detector efficiency. Healy believes that watch glasses were used for only a short time to plug the hole in mounting cards and were soon replaced by tape as he does not recall ever using watch glasses in vegetation analysis. The use of tape is consistent with the procedure mentioned by Healy et al. (1951), and the only mention of a watch glass in the literature we surveyed is that by Parker and Gamertsfelder (1945). It, therefore, appears that watch glasses were probabiy not used in the routine vegetation monitoring program begun around September 1945.

The first beta count data (using a mica-window GM detector) found in a laboratory notebock are for samples collected July 13, 1945 (Bulow 1945). The notebook includes notations regarding sample size, geometry correction, and counting shelf, and all samples are noted as being sagebrush. Table 2.3 provides information aboui aialytical methods gleaned from notations in this notebook. 
Table 2.3. Notations on Iodine-131 Measurement Procedures (Bulow 1945)

\begin{tabular}{|c|c|}
\hline Count Date & Measurement Procedure Notations \\
\hline $7 / 17 / 45$ & $\begin{array}{l}\text { Samples were counted on the second shelf. The disintegration rate is given } \\
\text { in addition to the counting rate. Two samples were counted over four } \\
\text { consecutive days. (This provides decay information useful in identifying the } \\
\text { constituents, see Chapter } 6.0 \text { ). The detector efficiency assumed in the } \\
\text { conversion for the sample collected on Route } 4 S \text {, Mile Post } \# 7 \text { is } \sim 8.2 \\
\text { percent. The detector efficiency assumed in the conversion of the sample } \\
\text { collected from Route } 4 S \text { Mile Post } \# 6 \text { is } \sim 9.1 \text { percent. Why different } \\
\text { detector efficiencies were assumed is not known. }\end{array}$ \\
\hline $7 / 28 / 45$ & $\begin{array}{l}\text { Sample weights ranged from } 1.46 \text { to } 1.6 \mathrm{~g} \text {. An 8-percent detector efficiency } \\
\text { was assumed. }\end{array}$ \\
\hline $8 / 17 / 45$ & $\begin{array}{l}\text { Sample weights ranged from } 1.4 \text { to } 1.7 \mathrm{~g} \text {. An } 8 \text {-percent detector efficiency } \\
\text { was assumed. }\end{array}$ \\
\hline $8 / 22 / 45$ & $\begin{array}{l}\text { Approximately } 1.5 \text {-g samples. An } 8 \text {-percent detector efficiency was } \\
\text { assumed. }\end{array}$ \\
\hline $9 / 12 / 45$ & $\begin{array}{l}\text { Sample weights ranged from } 0.436 \text { to } 1.555 \mathrm{~g} \text {. The reason three significant } \\
\text { figures were given is unclear. Samples were counted on second shelf. }\end{array}$ \\
\hline $9 / 20 / 45$ & $\begin{array}{l}\text { Activity per gram computed from counts per minute is given for one sample. } \\
\text { The conversion factor indicates an 8-percent detector efficiency was } \\
\text { assumed, and no correction was made for one day of iodine-131 decay } \\
\text { between sample collection and counting. }\end{array}$ \\
\hline $10 / 4 / 45$ & Samples were counted on second shelf. \\
\hline $10 / 17 / 45$ & $\begin{array}{l}\text { On the form line that requests "accuracy required," "1-g samples" was } \\
\text { written. This may indicate a requirement to only count } 1-g \text { samples. This } \\
\text { may have become standard from that time on because after this date Bulow } \\
\text { makes no other reference to sample weight. Activities are listed next to the } \\
\text { count data and indicate that an } 8 \text {-percent detector efficiency was assumed } \\
\text { and that no correction was made for decay between sample collection and } \\
\text { counting. }\end{array}$ \\
\hline $\begin{array}{l}11 / 16 / 45 \\
12 / 21 / 45\end{array}$ & $\begin{array}{l}\text { Activities are listed next to the count data and again indicate an 8-percent } \\
\text { detector efficiency was assumed, and no correction was made for the decay } \\
\text { between sample collection and counting. }\end{array}$ \\
\hline
\end{tabular}


Our understanding of the iodine-131 measurement procedure, once the routine vegetation monitoring program started around September 1945, is that it began with collecting the predominiant vegetation at a given location. From the sample, a 1-gram pellet measured by a pan balance (a pan-and-weight scale) was made by hand and secured to a mounting card by taping the hole and covering it with cellophane. The mounting cards were $8.26 \mathrm{~cm}(3.25 \mathrm{in}$.) by $6.35 \mathrm{~cm}(2.5 \mathrm{in}$.) with holes $2.54 \mathrm{~cm}(1 \mathrm{in}$.) in diameter in the center (Healy and Pahnke 1946; Healy et al. 1951). The mounting card was slipped into the second slot of a card holder to ensure consistent vertical geometry and then was counted by a mica-window GM counter (Healy and Eisenacher 1946; Denham et al. 1988; Healy et al. 1951; Bulow 1945). The mounting cards tended to bow or wrinkle so that the distance was not necessarily exact from sample to sample. $^{(a)}$ In addition, the pellets were not flat on the surface, and their thickness was not uniform.

Nonetheless, unlike the earlier method of placing vegetation around a glass-walled GM detector, this new technique was quantitative because the physical geometry could be reproduced and estimated and because a specified sample weight was counted.

Because pellet weight affects pellet dimensions, the conversion and adjustment factors provided in this report are valid oniy' for 1-gram vegetation samples. The fact that it became routine to count only 1-gram pellets has been inferred from the historical literature and from discussions with veteran Hanford employees. In this report we assume that after October 17, 1945 (see Table 2.3) only 1-gram samples were counted. We draw this inference because Bulow (1945) gives no specific information on sample weights after October 17, 1945, other than the statement "1-g samples required for accuracy." In addition, the conversion of counts per minute to microcuries per gram indicates no correction for sample weights. All historical periodic reports that mention the procedure, however briefly, list the weight as 1 gram (e.g., Healy 1945).

\subsubsection{Press-Formed Pellets}

Use of the basic procedure described i. Subsection 2.1.2 continued through 1947, except that a hand-operated press was developed to enhance uniformity of pellets starting in about mid-1946, according to Healy. ${ }^{(b)}$ The routine monitoring procedure can, therefore, be divided into phases: 1) use of hand-formed pellets before July 1946 (an estimated implementation date) and 2) use of press-formed pellets from July 1946 through 1947. Without any direct statements found in the historical documents on the exact timing of implementation, the date Healy recommended (July 1946) is the assumed transition date. The following information supports this assumption:

\footnotetext{
(a) Memorandum (HEDR Project Document No. 03930007) "Discussions with Former or Present Employees Who Worked at Henford in the 1940s and 1950s," from E. I. Mart, BNW, to R. K. Woodruff, BNW, April 3, 1989.

(b) Letter (HEDR Project Document No. 03930004) from J. W. Healy, BNW Consultant, to D. H. Denham, BNW, February 23, 1989, Los Alamos, New Mexico.
} 
1. Healy stated (Denham et al. 1988, p. 11) that

They made pellets by hand before they developed the hand-operated press. The press was developed to ensure uniformity of pellets, and to compress the material.

This comment indicates that use of the press was implemented sometime after the routine collection of vegetation had begun.

2. Healy interpreted a statement in a document he found in his personal files to indicate that the press was implemented around mid-1946. Healy $(1950$, p. 7$)$ states

Early in 1946 an estimate of the degree of contamination was made by measuring directly the activity of one gram of the vegetation, and the possible hazard to animals noted. This series of measurements indicated possible overexposure to animals even outside of the plant reservation and steps were immediately taken to reduce the amount of $\mathrm{I}^{131}$ emitted. A press for mounting one gram of vegetation in a reproducible manner was made and surveys of the area at distances up to 100 miles from the stack instituted.

3. Healy (1948b, p. 2) states

A routine program for measuring the activity deposited on vegetation was started late in 1945. The vegetation most prevalent in the particular region was sampled and one gram aliquots mounted in the form of a small pellet about $1-1 / 2$ inches in diameter by using a hand operated press.

In this paragraph, Healy is summarizing the vegetation monitoring program, not giving a detailed description, again in retrospect from 1948. Although he mentions use of a press and instigation of the routine program in the same paragraph, the press may have been put into operation somewhat later than the routine program. Because veteran Hanford employees recall that pellets were first formed by hand and then a press was put into operation later (Denham et al. 1988), July 1946 is assumed to be the transition date.

The procedure for making press-formed pellets directly onto a sample card is described by Healy et al. (1951) who state the procedure was outdated by later analyses that were specific to iodine-131; i.e., chemical separation of iodine-131 and precipitation as silver iodide. However, the pellet procedure was noted as still being useful when large numbers of samples were measured for considerable amounts of activity. From their statement that "this procedure has been outdated" and the fact that the new procedure was put into place in 1948, the method described in 1951 is inferred to be the same method used for forming pellets by press prior to 1948. Healy et al. (1951, pp. 2.11.1-2.11.2) describe the procedure as follows: 
1. Change stainless steel compression sleeve in vegetation press before starting to mount samples. The sleeve that has been used should be placed in the cleaning solution crock for one-half hour or longer.

2. Prepare mounting cards. Use mounting cards with 1 " diameter hole. Place a short piece of scotch tape over the hole on the back side.

3. Check pan balance to be sure it is balancing.

4. Place one piece of $4 \times 8$ scratch paper on each pan and place gram rider at one (1) gram.

5. Copy all identifying data from vegetation sack onto the mounting card. Carefully note sample numbers, date, sample type and time. All data should be copies on the back of the card (the side with the cellulose tape).

A. Mark all cards consecutively, e.g., the first sample mounted \#1, the second $\# 2$, etc.

6. Cut enough vegetation from the sample to weigh $1 \mathrm{gram}$.

A. When preparing vegetation wear a leather glove on the left hand to keep from being stuck by thistle thorns.

7. Mount sample by the following steps:

A. Place mounting card in the press with the cellulose tape next to the iron base of the press.

B. Lower stainless steel sleeve.

C. Pour in vegetation sample

D. Place small cellophane square on top of sleeve.

E. Lower plunger.

F. Raise sleeve enough to allow cellophane to be flattened onto the card.

G. Fasten sample to the mounting card with 4 pieces of cellulose tape-one on each edge of the cellophane sheet.

H. Remove sample and repeat. 
8. Mount off-area samples before using the stainless steel sleeve for any area samples.

9. Mark procedure, weight of analysis and analysts' initials on request sheets for all samples and send to the counting room for beta measurement.

\subsection{Beta Counters}

Beta counters were thin mica-window GM detectors made at Hanford by the Instrument Division in the 700 Area Tube Shop (717-A Building). Construction of the shop was completed in October 1944. The Tube Shop contained all of the equipment needed for evacuating, assembling, filling, and sealing mica-window GM detectors.

The methods for making mica-window GM detectors were developed at the University of California, used at the British Metallurgical Laboratory and Clinton Laboratory, and modified mechanically for use at Hanford (Du Pont 1946). Most of the information describing micawindow GM detectors comes from a compilation of semi-annual histories of instrument development by Du Pont (1946).

The mica-window GM detectors (Figure 2.1) (Healy et al. 1950) were made from 2.8-cm copper tubing machined in the 300 Area Instrument Shop in the 3717 Building. The tube case was $6.35 \mathrm{~cm}$ long and has a $3.18 \mathrm{~cm}$ outside diameter which corresponds to a $2.86-\mathrm{cm}$-micawindow diameter. The tubes were filled to a pressure of $10 \mathrm{~cm}$ of mercury with a $90: 10$ mixture of argon and ethyl alcohol (Du Pont 1946).

A mica window was cemented to a flange at the lower end of the tubes, and a center wire was supported at the top of the tubes by a suitable insulator. Mica was chosen because it had sufficient elasticity and could conveniently be prepared in sheets of nearly perfectly uniform thickness. In addition, the mass thicknesses of mica sheets were small enough for beta counting. That is, the thickness absorbed few beta (energy-dependent) but most alpha particles. In 1950, the mass thicknesses ranged from 2.0 to $4.5 \mathrm{mg} / \mathrm{cm}^{2}$. For 13 counters, the average thickness was $3.7 \mathrm{mg} / \mathrm{cm}^{2}$ (Healy et al. 1950). The range of mass thicknesses in 1950 may not reflect the range of mass thicknesses used in the period from 1945 to 1947, given that methods may have improved. However, because no other information is available, the 1950 values are assumed to represent the values for the 1940s in this analysis. Once attached, the mica windows bowed upwards in a slightly concave curve because of a pressure differential between the inside and outside of the tube (Schwendiman 1954). 


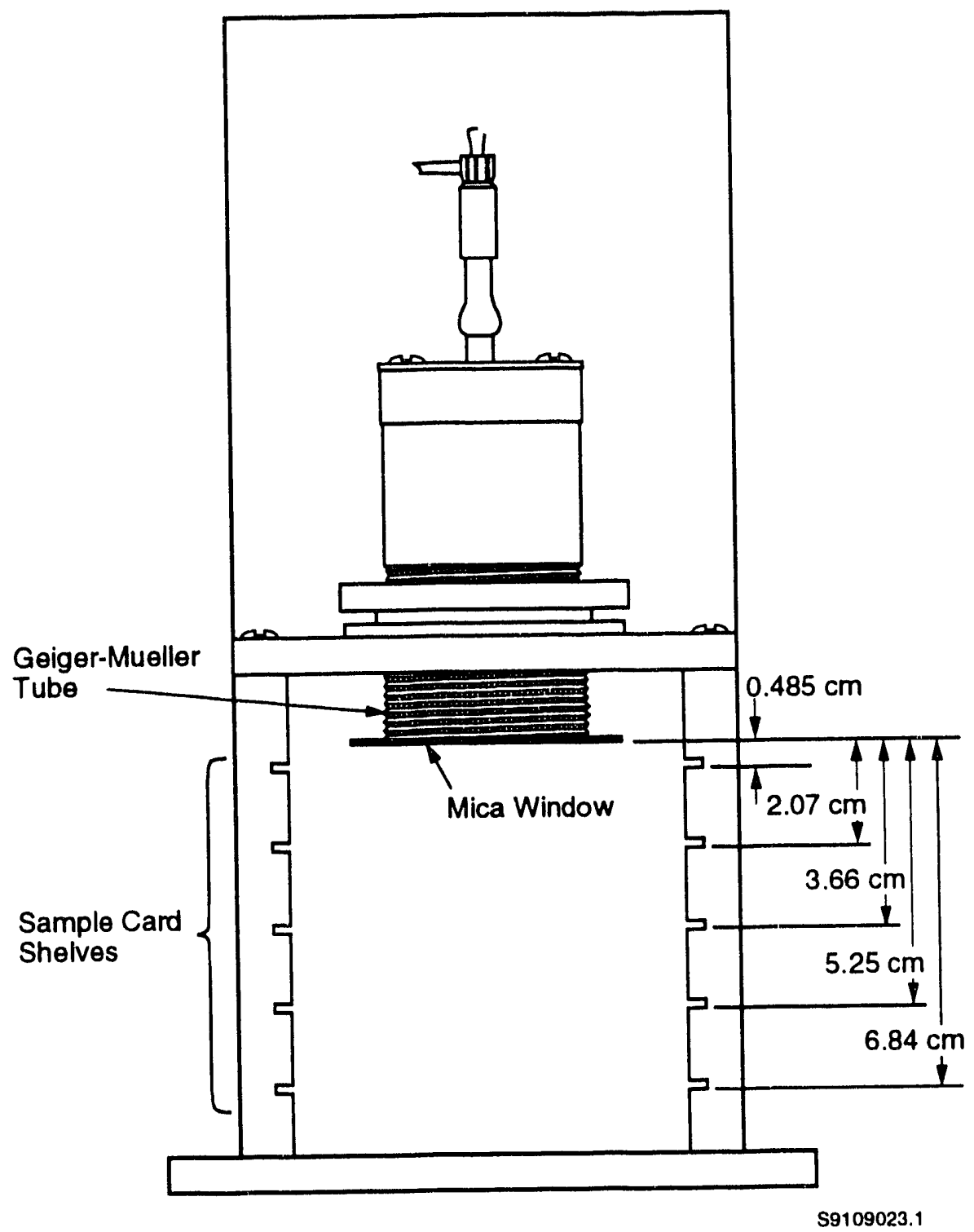

Figure 2.1. Mica-Window Geiger-Mueller Detector and Shelf Assembly Used from the Mid-1940s through Mid-1950s (Healy et al. 1950). 
The tubes were mounted at the top of a set of aluminum shelves designed to hold sample mounting cards at a set of five known distances from the counter face. The distance from the flange holding the mica window to the first shelf was $0.485 \mathrm{~cm}(0.191 \mathrm{in}$.). The distances from the other shelves to the windows were as follows: second shelf $-2.07 \mathrm{~cm}(0.85 \mathrm{in}$.), third shelf $-3.66 \mathrm{~cm}(1.44 \mathrm{in}$.), fourth shelf $-5.25 \mathrm{~cm}(2.07 \mathrm{in}$.), fifth shelf $-6.84 \mathrm{~cm}$ (2.59 in.) (Healy et al. 1950). However, the distance from the shelf to the window may not have been the same as the distance of the mounted sample from the window. For example, the cardboard mounting cards and the window may at times have been bowed or warped. In this analysis, the assumed distance from the second shelf upon which the vegetation pellet was placed to the detector does not account for any potential concavity in the window, bowing of the pellet mounting card, or non-uniformity of the pellet thickness.

The entire assembly was contained in a lead shield with walls $5.08-\mathrm{cm}(2$-in.) thick to minimize background radiation from the room and environment. The detector was operated as a self-quenched unit feeding into a scale of 64 . Coincidence losses were assumed to be around 0.2 percent per $1000 \mathrm{cpm}$ (Healy et al. 1950).

The service life of the tubes increased with time as the technicians' skills and experience increased (Du Pont 1946). Initially, a problem occurred with tube failure, especially at temperatures above $75^{\circ} \mathrm{F}$. The failure was primarily due to leakage caused by the failure of the deKhotinsky cement seal used to attach the mica window. The service life of the seal depended on the skill with which the seal was made and the temperature to which it was exposed. During the first half of 1945 , it was found that the mounting position of the quenching tube under the mica-window tube affected the temperature the seal could withstand. To prevent the temperature from rising too high, counting-room tubes were changed to selfquenched units instead of units operating with an external Neher-Harper quenching circuit (Du Pont 1946).

During the second half of 1945, performance of the mica-window GM tubes improved. The average service life increased from 18 to 119 days. This improvement came mainly from a better seal between the shell and mica windows, reflecting an increase in the skill and experience of the technicians who assembled the tubes. From January to August 1946, the average service life increased to 155 days.

Another reason some tubes were returned to the instrument shop in early 1945 was nonstatistical (unpredictable) fluctuations in the counting rate (Du Pont 1946). All tubes had a tendency to count low for a short time after they had been operated at a very high rate. This fatigue factor varied from tube to tube. Some tubes recovered immediately, but others required an overnight rest after operating at even a relatively low counting rate. In the first half of 1945 , no satisfactory test had been devised to pre-screen tubes. The tubes were simply 
replaced after this kind of weakness was discovered (Du Pont 1946). Nothing more was found in the literature reviewed regarding this problem until instrument development for the second half of 1946 was documented. At that time, a study was conducted in which counting rate and fatigue tests were carried out on thirty mica-window GM detectors to determine the effects of operating a tube above $5000 \mathrm{cpm}$. Each tube was operated with a 2000-cpm standard to determine its normal counting rate. The tubes were then operated at a high counting rate for a short period and then immediately rechecked with the standard. The observed drop in efficiency varied from 0 to 10 percent for the various tubes (Du Pont 1946).

The only other mention of the fatigue factor is a brief comment in a 1944 memo (Overbeck 1944, p. 3). This memo states that

Mica window tubes have a memory effect which makes it difficult to reproduce counts after increasing and then decreasing the voltage or counting a very hot sample. The normal recovery time is 10 or 15 minutes. The warm up time varies from tube to tube and it is good practice to run the final plateau 24 hours after the high voltage is put on the tube.

Plateaus should be run at 2000 counts per minute with at least 10,000 total counts. The tube should not be run at higher than 10,000 counts per minute under normal conditions.

The mention of $10,000 \mathrm{cpm}$ as the limiting counting rate indicates the fatigue factor was not a concern when counting the relatively low-activity environmental vegetation samples.

During the last quarter of 1949 , all of the counting laboratory beta detectors were fitted with test Radium D, E, and F (RaDEF) sources whose activity had been determined by the alpha counters. These subsidiary standards were compared with sources from the U.S. Bureau of Standards (USBS, now National Institute for Standards and Testing). The average beta count was 0.7 percent off the expected standard which was considered adequate (Parker 1950). In this analysis, the beta counters referred to are assumed to be identical to the mica-window GM detectors used for analysis of vegetation pellets, from 1945-1947, although this is not explicitly stated.

\subsection{Iodine-131 and RaDEF Standards}

Because both iodine-131 standards and RaDEF standards were used in the 1950s to develop some of the parameters for absolute beta-counting and because the reconstructed conversion factors are largely based on this 1950 s research, a discussion of these standards is 
warranted. No information was found in the historical research on the iodine-131 standards used in the 1950s. However, Jackson recalls that the iodine-131 standards either came from the Oak Ridge Laboratory or the Hanford technical group (Denham et al. 1988). This discussion of iodine-131 standards is, therefore, limited to decay characteristics.

Accurate iodine-131 standards were needed to adequately calibrate the GM detectors for iodine-131 measurements because each beta emitter exhibits a unique beta spectrum. These beta spectra are unique because of their differing maximum and average beta energies, spectral distributions, coincident gamma activities, and probabilities of decay by various means.

The RaDEF standards were lead-210 ( $R a D)$, bismuth-210 (RaE), and polonium-210 (RaF). The RaDEF standards apparently came from two sources. They were either made at Hanford or obtained from the USBS. No mention of other sources has been found.

The exact date when Hanford started to obtain USBS RaDEF sources is unknown. However, Schwendiman (1954) lists the USBS RaDEF standards that were available in the Radiological Sciences Department at that time. His list gives USBS numbers, certificate disintegration rates, and calibration dates. The list includes two standards that were calibrated (presumably at USBS) on June 3, 1948. Thus, 1948 may have been the earliest date that Hanford received USBS RaDEF sources. These sources were plated on palladium-coated silver discs that were approximately $1.27 \mathrm{~cm}(0.5 \mathrm{in}$.) in diameter (Schwendiman 1954). It is assumed that USBS sources were used in the 1950s research on absolute beta-counting methods, given that Schwendiman (1954) compiled research methods and results for absolute beta counting of various isotopes.

Characteristics of the RaDEF standard and iodine-131 are provided in Table 2.4. Average beta energies were obtained from the International Commission on Rediological Protection (ICRF 1983). The other information was obtained from Shleien and Terpilak (1984).

\subsection{Historical Conversion Factors}

From September 1945 to February 1946, apparently only a single conversion factor was used to obtain disintegration rates in $\mathrm{dpm} / \mathrm{g}$ for 1 -gram vegetation pellets. The resultant conversion factor was 12.5 to account for an assumed geometry of 8 percent (Parker and Gamertsfelder 1945; Bulow 1945; Dickinson 1946; Lindvig 1946a). Although an 8-percent geometry was probably assumed most of the time, it was not used exclusively (Lindvig 1946b; Bulow 1946). 
Table 2.4. RaDEF and Iodine-131 Decay and Beta Energy Characteristics

\begin{tabular}{|c|c|c|c|c|c|}
\hline Radionuclide & Half-Life & $\begin{array}{l}\text { Decay } \\
\text { Mode }\end{array}$ & $\begin{array}{l}\text { Max. } \\
\text { Energy } \\
(\mathrm{MeV})\end{array}$ & $\begin{array}{l}\text { Avg. } \\
\text { Energy } \\
(\mathrm{MeV})\end{array}$ & $\begin{array}{c}\text { Maximum } \\
\text { Beta Range } \\
\left(\mathrm{mg} / \mathrm{cm}^{2}\right)\end{array}$ \\
\hline iodine-131 & 8 days & beta & $0.606^{(a)}$ & 0.192 & 220 \\
\hline lead-210 & 22.3 years & beta & 0.061 & 0.038 & 5.5 \\
\hline bismuth-210 & 5 days & beta & 1.161 & 0.389 & 450 \\
\hline polonium-210 & 138 days & alpha & 5.305 & -- & -- \\
\hline
\end{tabular}

Starting in February 1946, another parameter was included in the historical detector geometry to compensate for the absorption of beta activity by the vegetation pellets themselves. This self-absorption parameter may also have compensated for sample spread, depending on the experimental method used in deriving the value. No information has been found regarding the experimental method used. Self-absorption was historically evaluated to be 3 (Healy and Eisenacher 1946). Therefore, to compensate for both geometry and selfabsorption, the counting data were multiplied by a total factor of 37.5 to arrive at the historically reported activity levels.

Table 2.5 provides examples of how to determine the historically assumed detector efficiency from documents containing original beta counting data. The periods over which the conversion factors were applied were estimated by comparing the reported iodine-131 activities $(\mu \mathrm{Ci} / \mathrm{g})$ with the corresponding background corrected counting rates $(\mathrm{cpm} / \mathrm{g})$. That is, to determine the historical conversion factors used, the reported activity levels $(\mu \mathrm{Ci} / \mathrm{g})$ were divided by the applicable factors to obtain the corresponding originally reported counting rates $(\mathrm{cpm} / \mathrm{g})$. Even though inclusion in the original notebooks of both the beta-counting rate and the corresponding assumed iodine-131 activity is rare, enough data were found to establish the historical conversion factors used and to subsequently develop adjustment factors (Bulow 1945; Lindvig 1946a; Dickinson 1946).

The historically assumed overall adjustment factors can be determined by using the following equations, each representing a different time period:

$$
\mu \mathrm{Ci} / \mathrm{g}=\frac{\mathrm{cpm} / \mathrm{g}}{\mathrm{G}_{\mathrm{h}} \mathrm{x}(\mathrm{dpm} / \mu \mathrm{Ci})} \text { for } 10 / 45 \text { through } 1 / 46
$$


Table 2.5. Examples of 1945-1946 Measurement Data and Corresponding Reported Activity Values

\begin{tabular}{|c|c|c|c|c|c|}
\hline Date & $\mathrm{cpm}^{(a, b)}$ & $\begin{array}{c}\text { Geometry } \\
\text { Factor }^{(c)}\end{array}$ & $\begin{array}{c}\text { Self-Abs. } \\
\text { Factor }\end{array}$ & $\mu \mathrm{Ci} / \mathbf{g}^{(\mathbf{a}, \mathrm{d})}$ & Reference \\
\hline $9 / 19 / 45$ & 39 & 12.5 & $N A^{(e)}$ & $2.2 \times 10^{-4}$ & Bulow (1945) \\
\hline $10 / 18 / 45$ & 1170 & 12.5 & NA & $6.7 \times 10^{-3}$ & Bulow (1945) \\
\hline $11 / 6 / 45$ & 277 & 12.5 & NA & $1.6 \times 10^{-3}$ & Bulow (1945) \\
\hline $12 / 21 / 45$ & 761 & 12.5 & NA & $4.5 \times 10^{-3}$ & Bulow (1945) \\
\hline $1 / 1 / 46$ & 155 & 12.5 & NA & $9.0 \times 10^{-4}$ & Lindvig (1946) \\
\hline $1 / 16 / 46$ & 44 & 12.5 & NA & $2.6 \times 10^{-4}$ & Dickinson (1946) \\
\hline $1 / 25 / 46$ & 616 & 12.5 & NA & $3.4 \times 10^{-3}$ & Dickinson (1946) \\
\hline $1 / 31 / 46$ & 332 & 12.5 & 3 & $5.6 \times 10^{-3}$ & Dickinson (1946) \\
\hline $2 / 12 / 46$ & 35 & 12.5 & 3 & $5.9 \times 10^{-4}$ & Dickinson (1946) \\
\hline \multicolumn{6}{|c|}{$\begin{array}{l}\text { (a) During this time period, apparently no decay corrections were made; the } \mathrm{cpm} \text { and } \mu \mathrm{Ci} / \mathrm{g} \text { values are exactly as they } \\
\text { recorded in the original notebooks. } \\
\text { (b) The counting rate in the historical record had been corrected for instrument plus room background. } \\
\text { (c) The geometry factor times the self-absorption factor equals the inverse of the assumod historical detector efficiency. } \\
\text { (d) The conversion of dpm to microcuries is via the atandard relationahip: } 2.22 \times 10^{\circ} \mathrm{dpm} / \mu \mathrm{Ci} \text {. } \\
\text { (o) NA = not applicable; no self-abeorption factor was used at this time. }\end{array}$} \\
\hline
\end{tabular}

$$
\begin{gathered}
\mu \mathrm{Ci} / g=\frac{\mathrm{cpm} / g \times \mathrm{SA}_{\mathrm{b}}}{\mathrm{G}_{\mathrm{b}} \times(\mathrm{dpm} / \mu \mathrm{Ci})} \text { for } 2 / 46 \text { through } 6 / 46 \\
\mu \mathrm{Ci} / \mathrm{g}=\frac{\mathrm{cpm} / \mathrm{g} \times \mathrm{SA} \mathrm{a} \mathrm{D}_{\mathrm{b}}}{\mathrm{G}_{\mathrm{b}} \times(\mathrm{dpm} / \mu \mathrm{Ci})} \text { for } 7 / 46 \text { through } 12 / 47
\end{gathered}
$$

where $\mathrm{cpm}=$ net counting rate registered by the GM detector after correcting for the background counting rate; i.e., cpm with no source beneath the detector.

$G_{b}=$ historical detector efficiency factor which was assumed to be 0.08 (i.e., a multiplier of 12.5) from 1945-1947 


$$
\begin{aligned}
& \mathrm{SA}_{\mathrm{h}}=\text { historical self-absorption factor which was assumed to be } 3 \text { when applied } \\
& D_{\mathrm{h}}=\text { decay factor used historically to account for decay occurring in the interval }
\end{aligned}
$$

No count data, as opposed to activity data, have been discovered for the period from mid August 1946 through November 1947. It was, therefore, necessary to estimate the historical detector efficiency assumed from information other than that in laboratory notebooks. However, one data sheet with counting rate information was found for December 1947. The detector efficiency assumed at that time corresponds to Equation (2.3). From this, we infer that Equation (2.3) applies to the period from July 1946 through December 1947. In all cases, the mass is assumed to be 1 gram.

\subsection{Pellet Dimensions}

The historical Hanford documents reviewed contained only limited information about the actual dimensions of the vegetation pellets that were constructed from 1945 through 1947. Veteran Hanford employees recall that pellet diameters were about $3.81 \mathrm{~cm}(1.5 \mathrm{in}$.) (Denham et al. 1988). Unfortunately, the original pellets no longer exist.

However, the thickness and average diameter of a pellet are parameters in the expression that defines the reconstructed measurement conversion factor $(M)$. (See Section 4.0.) Therefore, to estimate dimensions of the historic pellets, HEDR Project staff constructed several prototype 1-gram green sagebrush and dried cheatgrass pellets in 1989-1990. These prototypes were evaluated by several veteran Hanford employees who worked in the environmental sampling program in the 1940s. ${ }^{(a)}$ Some disagreement arose on the cheatgrass pellets, but the consensus on the sagebrush pellets was that they generally resembled those made in the 1940s, only were too perfectly shaped. One person thought the historical pellets contained more leaves, but another person thought that stems would have been included because removing the leaves from the stems entailed too much handling. Apparently, the historical pellets were more crudely formed because personnel tried to minimize the handling of the samples.

(a) Communication Log (HEDR Project Document No. 03930006), "Evaluation of Our Hand-Formed Sagebrush and Cheatgrass Counting Pellets ( 1 g)," telephone conversation between R. W. Hanf, BNW, and R. C. Thorburn. BNW Consultant, August 9, 1989. 
Based on these comments, HEDR Project staff collected green sagebrush samples monthly for about a year (1989-1990) and constructed hand-formed and press-formed pellets using the procedures outlined in the historic documents. The majority of these pellets contained both leaves and small stems. Some pellets also contained flowers or parts of flowers. A total of 55 hand-formed and 55 press-formed 1 -gram sagebrush pellets were constructed between September 1989 and July 1990--10 pellets of each type in September and usually 5 pellets of each type in other months.

Calipers were used to measure the thickness and diameter of each pellet. Thickness was taken as a single measurement for each pellet. Diameter was measured at four evenly spaced points ( $-45^{\circ}$ apart around the pellet surface). The average (arithmetic mean) diameter was computed from these four measurements. Surface area was computed by the equation

$$
S=\pi r_{a}^{2}
$$

where $S=$ estimated surface area $\left(\right.$ in $\left.\mathrm{cm}^{2}\right)$

$r_{1}=$ average radius in $\mathrm{cm}$, calculated from the four evenly spaced diameter measurements by the equation $r_{4}=\left[D_{1}+D_{2}+D_{3}+D_{4}\right] / 8$, where $D_{i}$ represents the diameter measurements made at each of the evenly spaced $\left(\sim 45^{\circ}\right)$ points.

In Appendix B, Table B. 1 for hand-formed pellets and Table B. 2 for press-formed pellets list dimensions of the reconstructed pellets (thickness, four measured diameters, computed average diameter, and computed surface area). 


\subsection{Biases Overview}

Two types of historical int mmation on vegetation measurements for iodine-131 have been found. One type consists of original counting rate data sheets and laboratory notebooks (e.g., Herde 1946; Dickinson 1946; Bulow 1945). The other type consists of reported iodine-131 activities (typically as averages or sometimes maximums) found in monthly and quarterly reports (e.g., Singlevich 1948a; Healy and Tumer 1946). The reported activities were determined in the 1940s by applying the historical detector efficiency values to the beta counting rates (i.e., background corrected $\mathrm{cpm} / \mathrm{g}$ ) to obtain disintegration rates (i.e., dpm/g), and then further converted to $\mu \mathrm{Ci} / \mathrm{kg}$ by the standard relationships between activity and disintegration rate and between grams and kilngrams. Beta counting rate data have been found for the period from Iuly 1945 to August 1946. However, from August 1946 through November 1947 , only reported iodine-131 activity values have been found.

This section provides an overview of the equations used to convert the October 1945 through December 1947 data to our best estimates of actual iodine-131 activity levels in vegetation. October 1945 is used as the starting date because, as discussed in Section 2.0, that is the time when 1-gram sagebrusin pellets are assumed to have been measured in the routine environmental monitoring program, and the reconstructed conversion factors only apply to 1-gram samples.

Three values are necessary for either converting original beta counting-rate data in $\mathrm{cpm} / \mathrm{g}$ or adjusting reported iodine-131 activities in $\mu \mathrm{Ci} / \mathrm{kg}$ to a best estimate of true activity in $\mu \mathrm{Ci} / \mathrm{kg}$. These three values are $\mathrm{M}$, the reconstructed measurement conversion factor; $D_{c}$, the decay correction factor; and $I_{f f}$, the iodine-131 assumption correction factor. Each value is discissed in detail: $M$ in Section 4.0, $D_{c}$ in Section 5.0, and $I_{c f}$ in Section 6.0).

These reconstructed values are needed because the detector efficiency assumed historically to convert count data to activity did not account for all of the parameters that would have affected the percentage of ernitted betas registered as counts. Furthermore, the historical detector efficiency was not dirived using an iodine-131 standard of known activity.

Historically, the following equation was used to convert total counts collected by the GM detector to background-corrected counts per mi.ute per gram (cpm/g): 


$$
\mathbf{U}=(\mathbf{G}-\mathbf{B}) / \mathrm{W}
$$

where $U=$ background-corrected $\mathrm{cpm} / \mathrm{g}$ measurement made by a GM detector on a historical vegetation pellet

$$
\begin{aligned}
& \mathrm{G}=\text { gross beta counts per rninute in cpm } \\
& \mathrm{B}=\text { background counts per minute } \\
& \mathrm{W}=\text { weight in grams of the vegetation pellet. }
\end{aligned}
$$

The historical background-corrected counts per minute per gram are converted to a best estimate of activity by the equation

$$
\mathbf{V}=\mathbf{U} \mathbf{C}
$$

where $\quad \mathrm{V}=$ estimated iodine-131 activity in $\mu \mathrm{Ci} / \mathrm{kg}$

$$
\mathrm{C}=\text { total reconstructed conversion factor in units of }(\mu \mathrm{Ci} / \mathrm{kg}) /(\mathrm{cpm} / \mathrm{g}) \text {. }
$$

The value of $\mathrm{C}$ is determined in turn by the equation

$$
\begin{aligned}
C & =D_{c} I_{c f} M \frac{1000 g}{k g} \frac{\mu C i}{2.22 \times 10^{6} \mathrm{dpm}} \\
& =0.00045 \mathrm{M} \mathrm{D} \mathbb{I}_{c f}(\mu \mathrm{Ci} / \mathrm{kg}) /(\mathrm{cpm} / \mathrm{g})
\end{aligned}
$$

where $D_{c}=$ radiological decay correction factor (unitless) which accounts for iodine-131 losses in vegetation due to decay during the interval between sample collection and counting (discussed in Section 5.0)

$I_{c f}=$ iodine-131 assumption correction factor (unitless) which corrects for the fact that all of the counts registered by the GM detector did not result from iodine131 disintegrations in the sample (discussed in Section 6.0)
$\mathbf{M}=$ reconstructed measurement conversion factor $(\mathrm{dpm} / \mathrm{cpm})$ (discussed in Section 4.0)

The factors $2.22 \times 10^{6} \mathrm{dpm} / \mu \mathrm{Ci}$ and $1000 \mathrm{~g} / \mathrm{kg}$ are standard conversion constants. By substitution, the value of $\mathrm{V}$ for a given pellet is determined by 


$$
\mathrm{V}(\mu \mathrm{Ci} / \mathrm{kg})=0.00045 \mathrm{M} \mathrm{D}_{\mathrm{c}} \mathrm{I}_{\mathrm{cf}} \mathrm{U}
$$

To convert the historical count data to a best estimate of activity, a value for $U$ is needed as well as the conversion factors discussed in Sections 4,5 , and 6 . The ratio of $M$ to the inverse of the historical detector efficiency converts reported activities. This unitless ratio is referred to as an adjustment factor (A) in this report. Reported activity levels can be multiplied by A to obtain an estimation of activity in the pellet. See Table 7.1 for estimates of A. 


\subsection{M: Reconstructed Measurement Conversion Factor}

This section discusses the method and basis for approximating the reconstructed measurement conversion factor (M). The value of $M$ is estimated by first evaluating all of the parameters that would have affected the overall efficiency of the counting system. The second step is to derive values for those parameters that are commensurate with the counting techniques used to evaluate vegetation pellets from 1945 through 1948. The appendices provide a discussion of the historical methods of determining parameters in $\mathbf{M}$ (Appendix A) and a discussion of the reconstructed pellet data and results for M (Appendix B).

For the counting systems in use at Hanford during the period from 1945 to 1947, most of the parameters in $M$ are determined as described by Healy et al. (1950) and by Schwendiman (1954). Their research on absolute beta-counting began in 1948 with an extensive program to fully calibrate the Hanford beta detectors for specific radionuclides (Healy 1950). This calibration program continued and the original work published in 1950 was updated by Schwendiman (1954) and again by Thomas et al. (1956). Thomas et al. $(1956$, p. 1) state that

This report serves the two-fold purpose of presenting a tabulation of the correction factors used in determining the absolute activity of various isotopes and serving as a guide for all groups within the Radiological Chemical Analysis Operation. The results reported were selected as the most valid after careful scrutinization of all available data and are specific to the measuring methods and equipment employed with the Operation.

Thus, the 1956 results were at that time considered to be the best available parameters for computing M. This was reconfirmed by Thomas in 1992.(a) However, Thomas et al. (1956) did not discuss the methods used in developing these parameters. Thomas indicated that the methods they had used to develop the parameters in $\mathbf{M}$ were consistent with those described by Schwendiman (1954). Other research on absolute beta-counting techniques was also carried out in the late 1940s and 1950s at areas other than Hanford (see Aten 1950; Baker and Katz 1953; Bayhurst and Prestwood 1959; Burtt 1949; Gleason, Taylor, and Tabern 1951; Nervik and Stevenson 1952; Seliger and Schwebel 1954; and Yankwich, Norris, and Huston 1947). Just as the early Hanford researchers had done, BNW staff also used the non-Hanford research

(a) Communication Log (HEDR. Project Document No. 03930009), "Parameters Developed in 1956 in Thomas, Polinsky and Schwendiman Report," telephone conversation between E. I. Mart, BNW Consultant, and C. W. Thomas, BNW consultant, December 29, 1992. 
to corroborate the Hanford research. In this particular case, the non-Hanford research has been considered in deriving the parameters in $\mathbf{M}$.

Although the point is not explicitly stated in the early Hanford documentation, in the September 1988 workshop Healy stated, "The same counters used in 1945 were used in 1950" (Denham et al. 1988, p. 13). Hence, the absolute beta-counting research done in the $1950 \mathrm{~s}$ is assumed to have involved the same mica-window GM detectors used from 1945 through 1947. This assumption is further supported by the fact that the research that culminated in the 1950s began in 1948, and brief descriptions of the GM detectors in use from 1945 through 1947 are consistent with the description of the counting system given by Healy et al. (1950) (see Subsection 2.2). Also, the results reported by Healy et al. (1950), Schwendiman (1954), and Thomas et al. (1956) are sufticiently similar to infer that the same counting systems were used.

The research done in the 1950s resulted in radionuclide-specific conversion factors that accounted for all of the parameters affecting overall counting system efficiency. By 1954, $4 \pi$ counting techniques had been developed with which the activity in standards could be determined with a high degree of accuracy (Schwendiman 1954; Mickelson 1954). One potential source of bias in the absolute beta counting program is that the lead-210 component of the RaDEF sources emits a low-energy gamma ray ( $47 \mathrm{kev}) 4$ percent of the time. This low-energy gamma ray would probably have been counted with high efficiency. ${ }^{(a)}$ The result may have been a bias in the conversion factors developed using RaDEF sources. This potential bias in the development of calibration factors done in the 1950s, however, is not taken into account in this report. Otherwise, veteran Hanford employees consider the research documented in those 1950 records highly reliable.

Documented historical accounts also demonstrate the reliability of this 1950 s research upon which much of the reconstructed conversions factors are based. Some historical accounts include the following:

1. Hanford staff independently evaluated the activity of standards received from the United States Bureau of Standards (USBS). Schwendiman (1954) reported some results from a comparison of activities determined at Hanford using the absolute beta-counting calibration factors with the quoted USBS values. The activities compared well, within

(a) Communication Log (HEDR Project Document No. 03930005), "Gamma Ray Contributions to Beta Counts, "telephone conversation between E. I. Mart, BNW, and C. W. Thomas, BNW, March 9, 1989. 
5 percent on 16 beta counters in 1950, within 3 percent in 1952, and within 1 percent in 1953 when using $4 \pi$ counting techniques. (Denham et al. 1988; Healy et al. 1950; Mickelson 1954).

2. Healy et al. (1950) gave an account of close agreement with Argonne National Laboratory in determinations of carbon-14 activity. One carbon-14 standard was obtained from Argonne. This standard had been calibrated carefully because it was to be used in a half-life determination. The Argonne value was $1.15( \pm 0.014) \times 10^{5}$ $\mathrm{dpm}$; the value obtained at Hanford was $1.22( \pm 0.029) \times 10^{5} \mathrm{dpm}$. This was about a 6-percent difference. Although the methods used at Argonne are not known, this agreement at least indicates that two separate determinations were quite close, especially considering the GM detector systems were particularly hard to calibrate to carbon- 14 because of its very low beta energy $(0.16 \mathrm{MeV}$ maximum; $0.05 \mathrm{MeV}$ average).

3. In 1950, Hanford assessed the activity of a USBS carbon-14 standard. They found approximately a 5-percent variance from the USBS-determined activity. The USBS was notified about the bias and later confirmed that the Hanford determination was accurate (i.e., that the quoted USBS value was in error by about 5 percent) (Denham et al. 1988). Again, this accuracy was remarkable given the low beta energy of carbon-14.

4. Schwendiman (1954, Section 2.10) discussed a means of assessing the accuracy of disintegration rate determinations in the narrative that follows.

An index to the reliability of any interpretation of counting rates is the agreement among disintegration rates determined using different combinations of source mountings and zeometrical arrangements for which counting factors have been determined. Ideally, when the same aliquot of a radioactive material is prepared for counting as a point source, as spread source, etc., and counted on any shelf, an identical disintegration rate should be obtained in each case if factors are exact. Only after satisfactory precision has been shown for sources counted in various configurations should estimates be made of overall accuracy.

The activity density of several solutions of isotopes was determined by preparing (a) point sources mounted by evaporation on flat discs,

(b) point sources mounted by evaporation on standard one-inch discs,

(c) sources spread with one cc of water and evaporated on one-inch dishes, and (d) sources spread with one $\mathrm{cc}$ of water and evaporated on 
standard 1-1/2 inch dishes. The sources were counted on the first four shelves and disintegration rates calculated using the factors presented. In most cases a multiple of the aliquot used for the first and second sheif counts was used for the third and fourth shelf sources because of the much lower efficiency of counting. Four samples of each configuration were prepared to increase the reliability of the measurement. The percentage sample standard deviation for the samples measured indicates the reproducibility of the measurement including errors from all sources. Results presented in the following table [Table 4.1 for iodine-131]:

Table 4.1. Comparison of Activities Determined for Iodine-131 on Different Shelves (Schwendiman 1954, Section 2.10)

\begin{tabular}{|c|c|c|c|c|}
\hline \multirow[b]{2}{*}{ Mounting } & \multicolumn{4}{|c|}{ DPM/25 Microliters } \\
\hline & $\begin{array}{c}\text { Shelf } 1 \\
\mathrm{dpm} / 25 \mu \mathrm{L}\end{array} \quad \pm \sigma \mathscr{\%}^{(a)}$ & $\begin{array}{cc}\text { Shelf } 2 & \pm \sigma \\
\mathrm{dpm} / 25 \mu \mathrm{L} & \%\end{array}$ & $\begin{array}{cc}\text { Shelf 3 } & \pm \sigma \\
\text { dpm } / 25 \mu \mathrm{L} & \%\end{array}$ & $\begin{array}{c}\text { Shelf } 4 \\
\mathrm{dpm} / 25 \mu \mathrm{L}\end{array} \quad \pm \sigma \%$ \\
\hline $\begin{array}{l}\text { Point source } \\
\text { on flat disc }\end{array}$ & $13,700 \pm 2$ & $13,600 \pm 2$ & $13,600 \pm 1$ & $13,600 \pm 1$ \\
\hline $\begin{array}{l}\text { Point source } \\
\text { on 1-in. } \\
(2.54-\mathrm{cm}) \text { dish }\end{array}$ & $13,700 \pm 1$ & $13,700 \pm 3$ & $13,500 \pm 1$ & $13,400 \pm 1$ \\
\hline $\begin{array}{l}\text { Spread source } \\
\text { on 1-in. } \\
(2.54-\mathrm{cm}) \text { dish }\end{array}$ & $13,500 \pm 1$ & $13,600 \pm 3$ & $13,800 \pm 1$ & $13,800 \pm 1$ \\
\hline $\begin{array}{l}\text { Spread source } \\
\text { on } 1.5 \text {-in. } \\
\text { (3.81-cm) dish }\end{array}$ & $13,500 \pm 4$ & $13,600 \pm 2$ & $13,900 \pm 1$ & $13,300 \pm 1$ \\
\hline
\end{tabular}

In his document, Schwendiman also provided similar tables for sulfur-35, cobalt-60, and phosphorus-32 solutions. The data in these tables indicate a high degree of accuracy as well.

Schwendiman (1954, Section 2.10$)$ also assessed the reliability of the activity determinations using his conversion factors: 
The accuracy with which disintegration rates can be determined is largely a function of the number of factors required to correct the counting rates, the uncertainty in each factor contributing to the net error in the quoted rate. Greatest accuracy (and precision) is attained with sources mounted in very simple configurations, preferably as point sources with no residue, and counted at high geometries to minimize errors in the air-window extrapolation. For $I^{131}$ and $\mathrm{P}^{32}$ mounted in these configurations agreement with U.S.B.S. $\mathrm{I}^{131}$ and $\mathrm{P}^{32}$ calibrated solutions has been within $5 \%$ using factors presented. It is recommended that all calibrations requiring accuracy be made with point sources on flat discs whenever possible.

For samples containing residues spread on large areas the absolute disintegration rate can seldom be quoted with an error as low as $5 \%$ and when soft emitters are counted an error of $10 \%$ can easily be introduced through inability to duplicate conditions under which the factors were determined and as a result of the uncertainties in the values of the factors.

From Schwendiman's (1954) narrative, it is inferred that, although the reliability of the conversion factors was probably quite high for the counting conditions they represented, the uncertainty of the reconstructed conversion factors for vegetation pellets is also quite high. The counting conditions for the vegetation pellets have not been reproduced, the pellets were far from being point sources, and the spread of the vegetation certainly was not evenly distributed. In addition, the pellets were thick, introducing the inherent variability in distance (geometry) from the source and size (sample-diameter) of every pellet, as well as self absorption. Gilbert et al. (1992) discuss in detail the uncertainty surrounding the reconstructed conversion factors for vegetation pellets.

\subsection{Equation for Measurement Conversion Factor, $M$}

Because much information was available, the method chosen for approximating $\mathbf{M}$ involves the evaluation of 1950 s historical research concerning the parameicrs that affect $M$ for the counting systems used in the 1940s. The parameter values and resulting values for $M$ are given in Appendix B.

The measurement conversion factor, $\mathbf{M}$, as partially derived by Healy et al. (1950), Schwendiman (1954), and Thomas et al. (1956) is modeled by the equation

$$
M=\left(F_{s a} F_{a} F_{b s} F_{c e l} G_{p} F_{d} E_{c}\right)^{-1}
$$

$$
\text { where } \begin{aligned}
F_{\mathrm{sa}} & =\text { self-absorption parameter } \\
\mathrm{F}_{\mathrm{a}} & =\text { absorption parameter } \\
\mathrm{F}_{\mathrm{bs}} & =\text { backscatter parameter } \\
\mathrm{F}_{\mathrm{cel}} & =\text { cellophane-scatter parameter }
\end{aligned}
$$




$$
\begin{aligned}
& \mathrm{G}_{\mathrm{p}}=\text { point-source geometry parameter } \\
& \mathrm{F}_{\mathrm{d}}=\text { sample-diameter parameter } \\
& \mathrm{E}_{\mathrm{c}}=\mathrm{GM} \text { tube detection parameter. }
\end{aligned}
$$

The self-absorption parameter $\left(\mathrm{F}_{2}\right)$ corrects for self-absorption of beta particles by the vegetation in which the iodine-131 was dispersed. This corrects for those beta particles that are absorbed by the vegetation when they strike vegetation particles. This correction is dependent on both energy and the mass thickness of the vegetation and is discussed in detail in Subsection 4.2.

The absorption parameter $\left(F_{2}\right)$ corrects for absorption of beta particles after they leave the vegetation pellet and pass through cellophane, air, and the mica window. This correction depends on beta particle energy, the combined mass thicknesses of cellophane, air, and the mica window, and the iodine-131 beta absorption coefficient. The F, parameter is discussed in detail in Subsection 4.4.

The backscatter parameter $\left(\mathrm{F}_{\mathrm{b}_{2}}\right)$ compensates for an increase in the counting rate from betas being reflected back towards the GM detector. The backscattering medium is typically the material upon which the source is mounted (e.g., the stainless steel planchet). The ratio of the measured activity of a source without backing material to that of the same source with backing material is the backscatter parameter $\left(\mathrm{F}_{\mathrm{b}_{\mathrm{a}}}\right)$. The amount of reflection depends on both the atomic mass of the backing material and the beta energy. For the 1945-1947 vegetation pellets, the backscattering medium is the vegetation itself because the mass of the vegetation is large. The $F_{b a}$ is discussed in detail in Subsection 4.3.

The cellophane-scatter parameter $\left(F_{c e}\right)$ accounts for an increase in the counting rate from the cellophane that was placed directly on top of the vegetation pellets and deflected additional betas into the GM detector. The $F_{\text {cel }}$ is discussed in detail in Subsection 4.5.

The point-source geometry parameter $\left(G_{p}\right)$ corrects for count losses that occurred because some of the beta particles emitted did not reach the GM detector's sensitive volume. The greater the distance from the detector's window, the more correction is required. This parameter is independent of beta energy. The $G_{p}$ is discussed in detail in Subsection 4.6.1.

The sample-diameter parameter $\left(\mathrm{F}_{\mathrm{\alpha}}\right)$ corrects for the change in geometry caused by the spreading out of activity, such that the source (vegetation pellet) does not approximate a point source. That is, it corrects for horizontal displacement. The $F_{d}$ is discussed in detail in Subsection 4.6.2.

The GM tube detection parameter $\left(E_{c}\right)$ accounts for the fraction of betas and gammas counted once inside the GM tube, and for the coincidence/dead-time losses. $E_{c}$ is discussed in detail in Subsection 4.7.2. 


\subsection{Self-Absorption Parameter, $F_{s a}$}

The self-absorption parameter $\left(\mathrm{F}_{\mathrm{s}}\right)$ accounts for absorption of the beta particles in the vegetation pellet itself. It can be approximated by the equation of Schwendiman (1954)

$$
F_{s a}=\left(1-e^{-m x}\right) / m x
$$

where $\mathrm{F}_{\mathrm{sa}}=$ fraction of iodine-131 betas not absorbed by passing through the vegetation pellet.

$\mathrm{m}$ = beta absorption coefficient, $0.0365 \mathrm{~cm}^{2} / \mathrm{mg}$ (Baltakmens 1977)

$\mathrm{x}=$ mass thickness of vegetation which is determined individually for each reconstructed pellet by dividing the weight $(1000 \mathrm{mg})$ by the surface area (S) as computed by Equation (2.4). Note that the surface area also equals density times thickness.

In the vegetation pellet, self-absorption would have occurred along with self-scatter and backscatter (see Section 4.3). Both self-scatter and backscatter processes are highly complex in thick vegetation pellets. Equation (4.2) only accounts for self-absorption. This approximation is acceptable in this analysis because the pellets had large mass thicknesses of approximately $70 \mathrm{mg} / \mathrm{cm}^{2}$ based on the reconstructed pellets made in 1989 and 1990 , and the organic vegetation matter was of a low atomic number. Self-scatter tends to increase the counting rate by deflecting betas into the solid angle. The amount of increase in counting rate is related to mass thickness, beta particle energy, and atomic mass of the material (Nervik and Stevenson 1952; Schwendiman 1954). The lower the mass thickness and the higher the beta energy and the material's atomic number, the greater the increase in counting rate that can be expected. The effect of self-scatter and self-absorption are illustrated for a silver-iodide precipitate in Figure 4.1 (Schwendiman 1954). Starting in 1948, iodine-131 was chemically extracted from vegetation and precipitated as silver iodide. This technique replaced the routine method of counting beta activity in a vegetation pellet and assuming all counts originated from iodine-131 decay. In Figure 4.1, the dashed curve is the self-absorption parameter, $F_{s a}$, calculated from Equation (4.2). The dashed curve matches empirical results after the initial rise which occurs from self-scatter. The dark line shows the empirical results.

The silver-iodide precipitate had a much lower mass thickness than vegetation pellets and a greater atomic mass. Because of these differences, the values for self-absorption and selfscatter determined empirically at Hanford in the 1950s did not necessarily represent the values for vegetation pellets. This is true even though $\mathrm{F}_{\mathrm{sa}}$ was presented as a function of mass thickness and the curve of $F_{m}$ versus mass thickness does approximate reasonably well the equation used in this analysis for estimating $F_{\mathrm{sa}}$ in vegetation pellets. Because the 


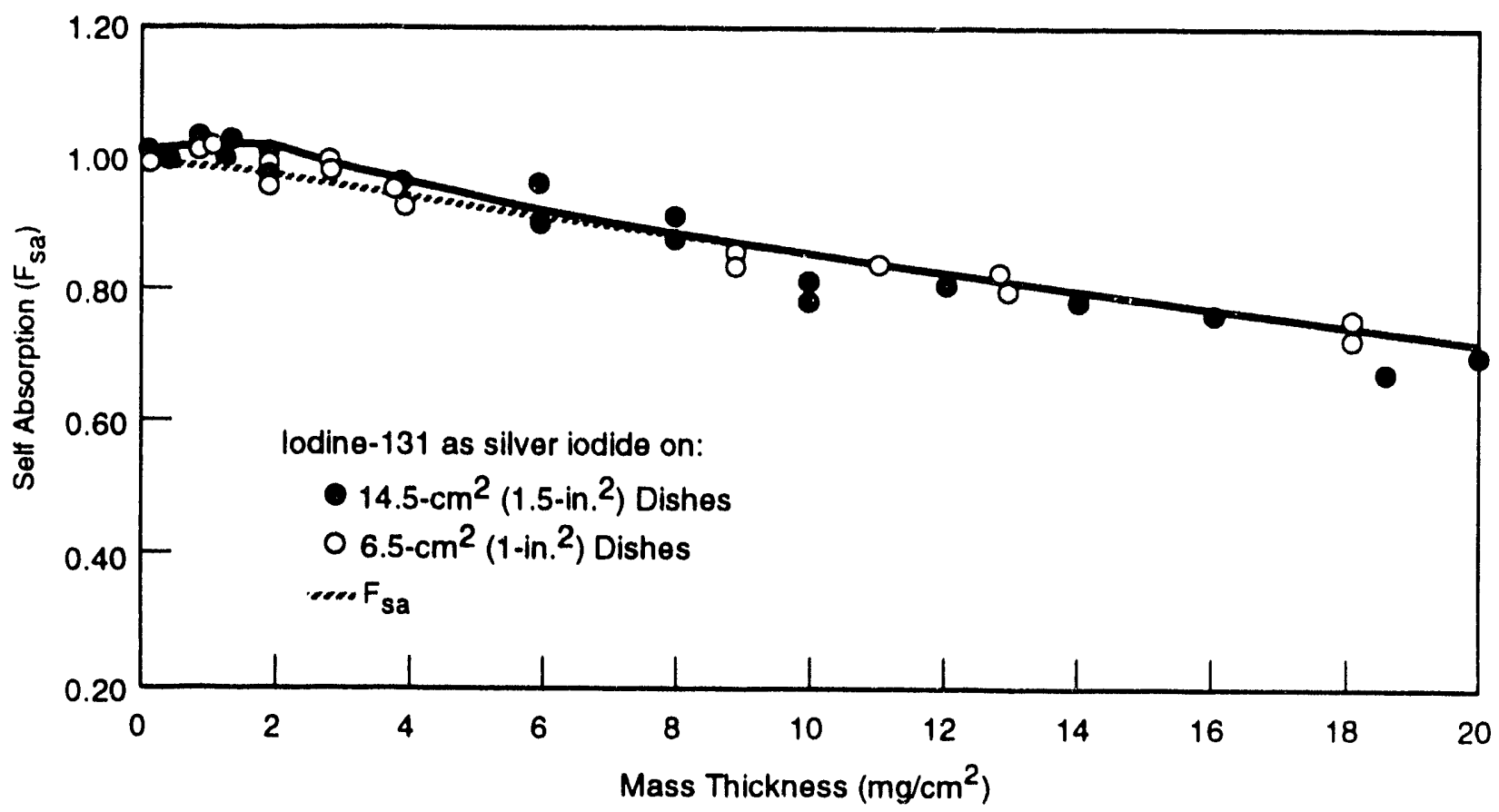

S9109001.2

Figure 4.1. Self-Absorption, $F_{2 u}$ (Calculated from Equation 4.2) versus Mass Thickness (Schwendiman 1954).

empirically derived curve is only drawn to a mass thickness end point of $20 \mathrm{mg} / \mathrm{cm}^{2}$, selfabsorption for greater mass thicknesses can be extrapolated by extending the curve by using Equation (4.2) but may not be accurate.

Schwendiman (1954) determined empirically that the value of $F_{u}$ was approximately 0.72 for a mass thickness for AgI of $20 \mathrm{mg} / \mathrm{cm}^{2}$. This value is supported by Thomas et al. (1956) who indicate an $F_{\mathrm{at}}$ at $20 \mathrm{mg} / \mathrm{cm}^{2}$ of around 0.73 . These two reports also indicate only a slight increase in counting rate for an $F_{\mu s}$ value greater than 1.0 because of self-scatter. From Equation (4.2) a value of 0.71 at $20 \mathrm{mg} / \mathrm{cm}^{2}$ using Baltakmen's (1977) coefficient can be calculated. Therefore, it appears that, at least from 8 to $20 \mathrm{mg} / \mathrm{cm}^{2}$, a rather close agreement exists between the empirical values for silver-iodide precipitates and calculated values.

The $F_{\mathrm{u}}$ results for the reconstructed pellets are given in Appendix B (Tables B.3 and B.4). The average $F_{\mu}$ value for the 55 reconstructed hand-formed pellets is 0.35 with a minimum value of 0.28 and a maximum of 0.46 . The average for the 55 reconstructed press-formed pellets is 0.31 with a minimum value of 0.24 and a maximum of 0.38 . Interestingly, these values are very close to the historical self-absorption parameter of 3 or $1 / 0.33$ empirically 
determined from minimal data in 1946. The exact method for this empirical evaluation is not known (see Appendix A for more information).

\subsection{Backscatter Parameter, $F_{b s}$}

The backscatter parameter $\left(F_{b s}\right)$ compensates for an increase in the counting rate from betas being reflected back towards the GM detector. The backscattering medium is typically the material upon which the source is mounted (e.g., the stainless steel planchet). The ratio of the measured activity of a source without backing material to that of the same source with backing material is the backscatter parameter $\left(\mathrm{F}_{\mathrm{bs}}\right)$. The amount of reflection depends on both the atomic mass of the backing material and the beta energy. For the 1945-1947 vegetation pellets, the backscattering medium is the vegetation itself because the vegetation mass is large.

The amount of backscatter also depends to some extent on the counting geometry because scatter is not likely to be symmetrical and the probability of small-angle scatter is greater than that of large-angle scatter (Healy et al. 1950). At about one-third of the maximum beta range, a backscattering saturation thickness of the mount is obtained (Friedlander et al. 1981). That is, a further increase in the thickness of the backing material does not result in a corresponding increase in the measured counting rate. The maximum range for iodine-131 (considering only the $0.6-\mathrm{MeV}$ beta activity) is about $220 \mathrm{mg} / \mathrm{cm}^{2}$. One-third of this range is about $73 \mathrm{mg} / \mathrm{cm}^{2}$ which is within the range of the mass thicknesses of reconstructed 1-gram sagebrush pellets. Therefore, it is assumed that saturation thickness is obtained within the pellet.

Backscatter in a radioactive vegetation pellet is a complex process that in reality should not be considered separately from other scatter components and self-absorption. Among the several kinds of scattering that would have occurred in addition to backscattering are selfscattering, scattering from the shield and shelf assembly, scattering from the cellophane covering, and even scattering out of the solid angle by the mica window. Although most of these forms of scatter are neglected, cellophane scattering is discussed in Subsection 4.5. Studies by Burtt (1949) indicate that for iodine-131 the number of beta particles backscattered into the solid angle by air and the aluminum holder walls would be negligible. Therefore, this parameter will be ignored in the present analysis. Backscattering of incident betas off the mica window is likewise assumed to be negligible and is also ignored. In this approximation, the backscatter parameter is considered independently of these other processes.

The simplest backscatter parameter to define is that of the reflection of beta particles from a thin radioactive precipitate on an inert metal plate. However, no historical measurements of backscatter from a radioactive vegetation pellet were found. 
If the thickness of the radioactive pellet is conceptualized as being divided into $\mathrm{N}$ increments, each increment serves as an absorber of the beta particles being emitted from the increment below, and that increment acts as a backscattering material for the beta particles being emitted from above. With each interaction, some attenuation of beta energy occurs with resultant changes in the probabilities of both absorption and scatter.

Although no historical empirical measurements were found that relate to the amount of backscattering from a thick vegetation pellet, backscatter parameters were evaluated for iodine-131 on filter paper which, like vegetation, has a low atomic mass. The empirical measurements made on filter paper are, therefore, used in this analysis to approximate the increase in activity expected as a result of backscattering of beta particles. It should be noted that the filter paper would not have approached the saturation mass thickness for iodine-131 for $0.608-\mathrm{MeV}$ beta which is approximately $70 \mathrm{mg} / \mathrm{cm}^{2}$.

Table 4.2 lists backscatter parameters for iodine-131 with various types of backing, including filter paper. These parameters were reported by Burtt (1949); Healy et al. (1950); Schwendiman (1954); and Thomas et al. (1956). Most of the backscatter parameters were determined for the first shelf of the GM detector. Only a few measurements were made on other shelves. Schwendiman (1954, Section 2.03) noted that the "results show a trend toward slightly lower factors with decreased geometry;" i.e., on lower shelves. However, a comparison of parameters indicates that this trend is minimal for shelves 1,2 , and 3. Burtt (1949) found that iodine-131 tended to have backscatter parameters very close to or just slightly smaller than those for RaDEF standards. To aid in the evaluation, $F_{b a}$ values for RaDEF are also provided in Table 4.2.

For this approximation, a backscatter parameter of 1.1 is assumed for every pellet, based on the measurements given in Table 4.2 and the low atomic mass of vegetation. That is, the backscatter parameter empirically determined for filter paper for iodine-131 is assumed to represent the backscatter expected from a thick vegetation pellet.

\subsection{Cellophane, Air, and Mica-Window Absorption Parameter, Fa}

The absorption parameter $\left(F_{2}\right)$ corrects for the absorption of beta particles after they leave the vegetation pellet and pass through the cellophane, air, and mica window. This correction depends on beta particle energy, the combined mass thicknesses of cellophane, air, and the mica window, and the iodine-131 beta-absorption coefficient. As beta particles traverse any material, some will be absorbed or scattered by the material being traversed. The probability of absorption increases with mass thickness $\left(\mathrm{mg} / \mathrm{cm}^{2}\right)$. In this analysis, the effects of additional scattering by the aluminum source holder, air, or the mica window are ignored. Also, the path length is assumed to be normal (i.e., perpendicular) to the detector. However, those betas emitted at angles other than normal would experience longer path lengths and, therefore, greater probabilities of absorption. 
Table 4.2. Backscatter Parameters for Iodine-131 with Various Types of Backing

\begin{tabular}{|c|c|c|c|c|c|}
\hline $\begin{array}{l}\text { Radio- } \\
\text { nuclides }\end{array}$ & Backing Material & $\begin{array}{l}\text { Backing } \\
\text { Depth } \\
\text { (cm) }\end{array}$ & $\begin{array}{l}\text { Distance }^{(a)} \\
\quad(\mathrm{cm})\end{array}$ & $F_{b}$ & Reference \\
\hline Iodine-131 & Cardboard & $\max$ & 1.66 & 1.14 & Burtt 1949 \\
\hline Iodine-131 & $\begin{array}{l}\text { Whatman } \# 40 \text { filter } \\
\text { paper }\end{array}$ & $N G^{(b)}$ & 0.49 & 1.09 & Schwendiman 1954 \\
\hline Iodine-131 & $\begin{array}{l}\text { Whatman \#40 filter } \\
\text { paper }\end{array}$ & NG & 2.07 & 1.09 & Schwendiman 1954 \\
\hline Iodine-131 & H-70 filter paper & 0.046 & 0.49 & 1.11 & Schwendiman 1954 \\
\hline Iodine-131 & H-70 filter paper & 0.046 & 2.07 & 1.10 & Schwendiman 1954 \\
\hline Iodine-131 & H-70 filter paper & NG & 0.49 & 1.11 & Thomas et al. 1956 \\
\hline Iodine-131 & H-70 filter paper & NG & 2.07 & 1.07 & Thomas et al. 1956 \\
\hline Iodine-131 & Aluminum & $\max$. & 1.66 & 1.26 & Burtt 1949 \\
\hline Iodine-131 & Aluminum & $\max$ & 0.49 & 1.19 & Healy et al. 1950 \\
\hline Iodine-131 & Aluminum & $\max$ & 0.49 & 1.24 & Schwendiman 1954 \\
\hline Iodine-131 & Aluminum & $\max$. & 2.07 & 1.26 & Schwendiman 1954 \\
\hline $\operatorname{RaDEF}^{(0)}$ & Filter paper & NG. & 1.66 & 1.10 & Burtt 1949 \\
\hline RaDEF & Cardboard & 0.099 & 1.66 & 1.19 & Burtt 1949 \\
\hline RaDEF & Aluminum & 0.079 & 1.66 & 1.29 & Burtt 1949 \\
\hline RaDEF & $\begin{array}{l}\text { Whatman } \# 40 \text { filter } \\
\text { paper }\end{array}$ & NG & 0.49 & 1.08 & Schwendiman 1954 \\
\hline RaDEF & H-70 filter paper & NG & 0.49 & 1.09 & Schwendiman 1954 \\
\hline RaDEF & H-70 filter paper & NG & 0.49 & 1.18 & Thomas et al. 1956 \\
\hline RaDEF & H-70 filter paper & NG & 1.66 & 1.12 & Thomas et al. 1956 \\
\hline \multicolumn{6}{|c|}{$\begin{array}{l}\text { (a) Distance is from the source to the counter window. } \\
\text { (b) NG = not given. } \\
\text { (c) RaDEF rofors tu bismuth-210 (RaE) because lond-210 (RaD) emitted a beth that was too weak to penetrate the cellophane } \\
\text { coveriug, and polonium-210 (RaF) emitted only an alpha particlo. }\end{array}$} \\
\hline
\end{tabular}


Cellophane, air, and the mica window are barriers that would absort beta particles from the vegetation pellet. The total mass thickness of these barriers is the sum of their individual mass thichnesses. So the absorption parameter, $\mathrm{F}_{\mathrm{a}}$, is determined by the equation

$$
F_{2}=e^{(-m x)}
$$

where $\mathrm{m}=$ iodine-131 beta absorption coefficient, $0.0365 \mathrm{~cm}^{2} / \mathrm{mg}$ (Baltakmens 1977 )

$x=$ mass thickness $\left(\mathrm{mg} / \mathrm{cm}^{2}\right)$.

For the 1940 s GM detector system, this equation can be represented by

$$
F_{a}=e^{\left[-m\left(M_{c}+M_{a}+M_{w}\right]\right.}
$$

where $M_{c}=$ mass thickness of cellophane, $-3.1 \mathrm{mg} / \mathrm{cm}^{2}$ (Healy et al. 1950;

Schwendiman 1954). The Health Instrument's group did have a goal of developing thinner windows, indicating the earlier mica windows may have been thicker.

$M_{1}$ = mass thickness of the air; i.e., the distance from the top of the pellet to the detector window multiplied by the density of air $\left(\sim 1.2 \mathrm{mg} / \mathrm{cm}^{3}\right.$ is representative of Hanford air density).

$\mathrm{M}_{\mathrm{w}}=$ average mass thickness of mica window, $-3.7 \mathrm{mg} / \mathrm{cm}^{2}$ in this analysis. This is based on the average mass thickness of the 1950s GM detector's mica windows. See Table 4.3.

Table 4.3 indicates the thickness of the mica windows varied among counters from about 2.4 to $4.6 \mathrm{mg} / \mathrm{cm}^{2}$ with an average mass thickness of $3.7 \mathrm{mg} / \mathrm{cm}^{2}$. The assumption is made in this analysis that the mica-window mass thicknesses for these 1950 detectors represent the mica-window mass thicknesses of detectors used from 1945 through 1947.

Thus, Equation (4.3) can further be represented by

$$
F_{1}=e^{\{-0.0365\{6.78+1.21(2.073-T)\}}
$$

where $\quad T=$ thickness of the pellet in $\mathrm{cm}$

$2.07-T=$ distance from the top of the pellet to the detector window in $\mathrm{cm}$

Results for $F_{a}$ for the 55 reconstructed hanc-formed and 55 reconstructed press-formed pellets are given in Appendix B (Tables B.3 and B.4). The average $F_{a}$ for both 
Table 4.3. Mass Thickness of Thirteen Geiger-Mueller Detector Mica Windows (Healy et al. 1950)

\begin{tabular}{|c|c|c|}
\hline Set. No. & Tube No. & $\begin{array}{c}\text { Window Mass } \\
\text { Thickness } \\
\left(\mathrm{mg} / \mathrm{cm}^{2}\right)^{(\mathrm{a})}\end{array}$ \\
\hline 1 & 158 & 4.5 \\
2 & 164 & 4.6 \\
3 & 139 & 2.9 \\
4 & 119 & 2.9 \\
5 & 136 & 3.4 \\
6 & 185 & 3.0 \\
7 & 128 & 4.1 \\
8 & 112 & 4.6 \\
9 & 103 & 3.2 \\
10 & 168 & 4.5 \\
11 & 155 & 4.3 \\
12 & 161 & 3.4 \\
13 & $5 \mathrm{~A}-60$ & 2.4 \\
\hline (a) Average $=3.7 \mathrm{mg} / \mathrm{cm}^{2}$. & \\
\hline
\end{tabular}

hand-formed pellets (with a minimum of 0.72 and a maximum of 0.74 ) and for press-formed pellets (with a minimum of 0.73 and a maximum of 0.74 ) is 0.73 .

\subsection{Cellophane-Scatter Parameter, $F_{\text {cel }}$}

Historically, cellophane was placed directly on top of both hand- and press-formed pellets when counting. This physical arrangement would have increased the counting rate of iodine131 because the cellophane would have scattered some beta particles that were initially moving at angles far outside the geometry cone between the source and the detector and deflected them toward the detector (Parker 1952; Schwendiman 1954). Schwendiman (1954) found that the increase in counting rate, resulting when cellophane was placed directly on a RaDEF source 
on the first shelf rather than close to the window, was a factor of 1.06. With the RaDEF source on the second shelf, he found the factor to be about 1.07.

Nervik and Stevenson (1952) found that generally the greater the beta energy, the greater the self-scattering component. Based on their data, for a cellophane mass thickness of $3.1 \mathrm{mg} / \mathrm{cm}^{2}$ and the maximum beta energy for iodine-131 $(\sim 0.6 \mathrm{MeV})$, the increase from self-scattering is estimated to be a factor of 1.05 . Because the bismuth-210 self-scatter component indicated by Nervik and Stevenson is slightly higher than the increases measured by Schwendiman (1954) for cellophane scattering, the iodine-131 self-scatter component measured by Nervik and Stevenson is presumed to be also higher than the cellophane scattering that would have occurred for iodine-131 beta particles emerging from a vegetation pellet. Therefore, an $\mathrm{F}_{\mathrm{cel}}$ factor of 1.04 is approximated for iodine-131.

The beta spectrum emerging from the top of a pellet would be attenuated by scattering and other processes occurring within the pellet. Thus, even if the $F_{\text {cel }}$ for iodine-131 had been meajured directly by Schwendiman, it might not represent the value for iodine-131 beta particles emerging from the top of a thick pellet.

\subsection{Point-Source Geometry Parameter, $G_{p}$, and Sample-Diameter Parameter, $\mathbf{F}_{\mathrm{d}}$}

Both the point-source geometry parameter $\left(G_{p}\right)$ and sample-diameter parameter $\left(F_{d}\right)$ relate to the physical geometry of the vegetation pellet and to the GM detector system. Therefore, both of these parameters are considered in this section. In addition, the calculation of $G_{p}$ and $F_{d}$ both require an additional parameter called the mean effective distance (MED) discussed in Section 4.6.3.

The point-source geometry parameter, $G_{p}$, accounts for the fraction of beta particles that would reach the sensitive volume of the GM detector, assuming a point source at a given distance, with no self-scatter; no self-absorption; no absorption in air, cellophane, or window; and no backscattering from the sample or mount (Schwendiman 1954). The $G_{p}$ can be defined as the ratio of the solid angle that is subtended by the aperture of the sensitive volume of the GM detector tube to the total (4x) solid angle (Healy et al. 1950).

The sample-diameter parameter $\left(F_{d}\right)$ accounts for the difference between the counting rate of a spread source and that of a point source of the same activity with both centered directly under the detector. A spread source will always produce a lower count rate than a point source of equal activity. Schwendiman (1954) defined $F_{d}$ as the ratio of the counting rate of a 
uniform circular source of a given diameter to the counting rate of the same quantity of radioactive material mounted as a point source.

Historically, values for the $G_{p}$ and $F_{d}$ parameters were determined empirically for thin sources. However, because the pellets were considerably thicker than those thin sources, a problem arises in using the empirically determined values for $G_{p}$ and $F_{d}$. The values for these geometry parameters depend on distance. Even a small change in distance can greatly affect the values. With a thick pellet, individual $G_{p}$ and $F_{d}$ parameters are needed for a range of distances. Ideally, a complex integration should be performed over the thickness of the pellet. However, to simplify the calculations and uncertainty analysis, a mean effective distance (MED) is calculated and used as the distance parameter in the equations for $G_{p}$ and $F_{d}$ (Equations 4.4 and 4.5 ) to compensate for the pellet thickness.

\subsubsection{Determination of $\mathbf{G}_{p}$}

Historically, $G_{p}$ was determined for each shelf distance, as reproduced in Table 4.4. These historical determinations are used to derive the reconstructed point source geometry parameter.

Table 4.4. Historical Values of the Point-Source Geometry Parameter, $G_{p}$, Empirically Determined for Each Shelf Distance ${ }^{(2)}$

\begin{tabular}{|c|c|c|}
\hline Shelf & $\begin{array}{c}\text { Distance } \\
(\mathrm{cm})\end{array}$ & $\mathrm{G}^{p}$ \\
\hline 1 & 0.49 & 0.22 \\
2 & 2.07 & 0.07 \\
3 & 3.66 & 0.03 \\
4 & 5.25 & 0.02 \\
5 & 6.84 & 0.01 \\
\hline (a) Schwendiman (1954) and Norton et al. (1956)-both documents contuin identical G values. \\
\hline
\end{tabular}


To approximate the values in Table 4.4 so $\mathrm{G}_{\mathrm{p}}$ could be rapidly calculated, Gilbert et al. (1992, p.3.1) developed the equation

$$
\left.\left.G_{p}=10^{[0.647 \times \log (1 / M E D} \cdot 0.185\right)-0.8381\right]
$$

where MED $=2.07-\mathrm{fT}$

$f=0.70$ for hand-formed pellets

$=0.72$ for press-formed pellets

$\mathrm{T}=$ pellet thickness

The fractions 0.70 and 0.72 were determined using the method in Section 4.6.3.

Gilbert et al. (1992) discuss the basis for Equation (4.4) and the uncertainties in the approximation of $G_{p}$ and $F_{d}$.

Because $G_{p}$ was determined empirically, it actually accounts for the sensitive volume of the detector. The physical dimensions of the detector do not necessarily correspond to the sensitive volume because of dead space behind the mica window.

\subsubsection{Determination of $F_{d}$}

The value of $F_{d}$ depends on the distance from the sample source to the detector, the source (pellet) diameter, and the detector diameter.

Historically, $F_{d}$ was determined for diameters of $2.54 \mathrm{~cm}(1 \mathrm{in}),. 3.81 \mathrm{~cm}(1.5 \mathrm{in}$.$) , and$ $5.08 \mathrm{~cm} \mathrm{(2} \mathrm{in.)} \mathrm{and} \mathrm{for} \mathrm{the} \mathrm{distances} \mathrm{between} \mathrm{each} \mathrm{of} \mathrm{the} \mathrm{five} \mathrm{shelves} \mathrm{and} \mathrm{the} \mathrm{mica} \mathrm{window.}$ The historical values are reproduced in Table 4.5. These $F_{d}$ values were determined empirically for sources with maximum beta energies greater than $0.3 \mathrm{MeV}$ and for the GM detector described in Subsection 2.2.

A curve-fit equation was developed by Gilbert et al. (1992) to fit the empirically determined data given in Table 4.5 for distances less than $2.07 \mathrm{~cm}(0.81$ in.):

$$
F_{d}=1-\left(-0.4136+1.565 \log \text { DIAM) } 10^{-0.1311 \times \text { MED }}\right.
$$

which is appropriate

where DIAM $=$ average diameter of the vegetation pellets

MED = (see definition following Equation 4.4) 
Table 4.5. Historical Values of the Sample-Diameter Parameter, $F_{d}$

\begin{tabular}{|c|c|c|c|c|c|}
\hline \multirow[b]{2}{*}{ Shelf } & \multirow[b]{2}{*}{$\begin{array}{c}\text { Distance }^{(a)} \\
(\mathrm{cm})\end{array}$} & \multicolumn{3}{|c|}{ Pellet Diameter } & \multirow[b]{2}{*}{ Reference $^{(b)}$} \\
\hline & & $\begin{array}{l}2.54 \mathrm{~cm} \\
(1.0 \mathrm{in} .)\end{array}$ & $\begin{array}{l}3.81 \mathrm{~cm} \\
(1.5 \mathrm{in} .)\end{array}$ & $\begin{array}{l}5.08 \mathrm{~cm} \\
(2.0 \text { in.) }\end{array}$ & \\
\hline 1 & 0.485 & 0.83 & 0.60 & 0.39 & Healy et al. 1950 \\
\hline 1 & 0.485 & 0.84 & 0.60 & 0.39 & Schwendiman 1954 \\
\hline 1 & 0.485 & 0.81 & 0.56 & - & Thomas et al. 1956 \\
\hline 2 & 2.073 & 0.87 & 0.82 & 0.67 & Healy et al. 1950 \\
\hline 2 & 2.073 & 0.87 & 0.75 & 0.62 & Schwendiman 1954 \\
\hline 2 & 2.073 & 0.88 & 0.73 & -- & Thomas et al. 1956 \\
\hline 3 & 3.660 & 0.91 & 0.85 & 0.77 & Healy et al. 1950 \\
\hline 3 & 3.660 & 0.94 & 0.86 & 0.76 & Schwendiman 1954 \\
\hline 3 & 3.660 & 0.93 & 0.83 & -- & Thomas et al. 1956 \\
\hline 4 & 5.248 & 0.95 & 0.91 & 0.86 & Schwendiman 1954 \\
\hline 4 & 5.248 & -- & -- & -- & Thomas et al. 1956 \\
\hline 5 & 6.835 & 0.96 & 0.92 & 0.89 & Healy et al. 1950 \\
\hline 5 & 6.835 & 0.96 & 0.94 & 0.90 & Schwendiman 1954 \\
\hline 5 & 6.835 & -- & -- & -- & Thomas et al. 1956 \\
\hline \multicolumn{6}{|c|}{$\begin{array}{l}\text { (a) Distance refors to the distance from the ahelf to the mica window. } \\
\text { (b) The } 1950 \text { values were apecifically dotermined for iodine-131 sources. The } 1954 \text { and } 1956 \text { values are listed for beta-emitters with } \\
\text { maximum beta energies greater than } 0.3 \mathrm{MeV} \text {. The values in Thomas et al. (1956) are considered the least reliable because they are } \\
\text { for the application of a gilver-iodide precipitate distributod on a backing of the diameter listed in the table. Undoubtedly, the silver- } \\
\text { iodide precipitate would have \& smaller diameter than that of its mount. }\end{array}$} \\
\hline
\end{tabular}

\subsubsection{Determination of Mean Effective Distance, MED}

The geometry parameters $\left(G_{p}\right.$ and $\left.F_{d}\right)$ generated in the 1950s were for thin precipitates rather than thick pellets. Because the geometry parameters depend on distance from the detector, the values for these parameters actually vary throughout the thickness of the pellets. To compensate for the effect of pellet thickness, a mean effective distance (MED) from the detector is calculated, taking into account the thickness of the pellet as well as the distance from the top of the pellet to the detector window. 
The MED should be calculated such that the $G_{p}$ and $F_{d}$ values are representative of the entire vegetation pellet, taking into consideration the decreasing proportion of iodine-131 beta particles being emitted from each pellet layer because of varying amounts of absorption within the pellet. Otherwise, the midpoint of the pellet would be the best estimate of MED, whereas the MED is at some point between the midpoint of the pellet and the top. The changing proportion of absorption that occurs with increasing pellet thickness weights the distance from which $G_{p}$ and $F_{d}$ are interpolated.

The value of MED was determined using a three-step procedure. First, the measurement conversion factor $(M)$ was approximated by dividing each pellet into 10 layers, calculating $M$ for each of the 10 incremental pellet thicknesses, and taking the average of the 10 values of M:

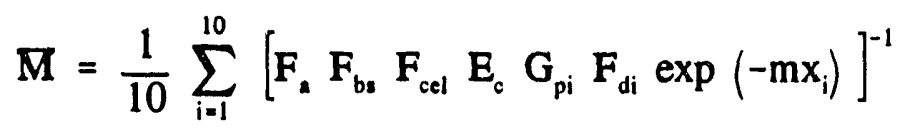

All of the parameters, except the exponential, are as defined immediately following Equation (4.1). The parameters $\mathrm{G}_{\mathrm{pi}}, \mathrm{F}_{\mathrm{di}}$, and $\exp \left(-\mathrm{mx}_{\mathrm{i}}\right)$ are the values of $\mathrm{G}_{\mathrm{p}}, \mathrm{F}_{\mathrm{d}}$, and $\mathrm{F}_{\mathrm{sa}}$, respectively, determined for the ith incremental pellet thickness. The factor $\exp \left(-\mathrm{mx}_{\mathrm{i}}\right)$ is the weight that is applied to $G_{p i}$ and $F_{d i}$ for the ith incremental mass thickness $x_{i}$, where

$$
\begin{aligned}
& m=\text { beta-absorption coefficient, } 0.0365 \mathrm{~cm}^{2} / \mathrm{mg} \text { (Baltakmens 1977) } \\
& x_{i}=\text { mass thickness of the } i^{\text {th }} \text { incremental thickness of the vegetation pellet. }
\end{aligned}
$$

The factor $\exp \left(-\mathrm{mx}_{\mathrm{i}}\right)$ is calculated at the center of the ith incremental pellet thickness to approximate the mean absorption for that thickness.

The second step in determining MED is to calculate $M$ using Equation (4.1) for different values of MED in Equations (4.4) and (4.5). The third and last step is to compare $\bar{M}$ computed using the above equation with the values of $M$ computed in Step 2. The best estimate of MED is that value of MED in Step 2 that gave a value of $M$ closest to $\bar{M}$.

Using the model MED $=2.07-\mathrm{fT}$, where $\mathrm{T}$ is known (see Tables B. 1 and B. 2 in Appendix B) and MED is the best estimate of MED, the value of $f$ was determined to be 0.70 for hand-formed pellets and 0.72 for press-formed pellets.

The approximation of $\mathbf{M}$ could be improved by dividing the pellet into a greater number of layers and by considering self-scatter and variation in path length with changing solid angles. 


\subsection{4 $G_{p}$ and $F_{d}$ Results}

The $G_{p}$ and $F_{d}$ values for the 55 hand-formed and 55 press-formed pellets computed by the method in Subsection 4.6.3 are found in Appendix B (Tables B.3 and B.4). The average $G_{p}$ value for the 55 reconstructed hand-formed pellets is 0.082 and the $F_{d}$ is 0.66 ; the average $G_{p}$ value for the 55 reconstructed press-formed pellets is 0.081 and the $F_{d}$ is 0.70 .

\subsection{Parameters with Negligible or No Impact}

This subsection discusses two potential areas of bias that were evaluated and found to have negligible or no impact. Consequently, these parameters do not affect the value for the reconstructed $M$. The two areas of bias are 1) handling/processing losses, and 2) the GM tube detection parameter, $\mathbf{E}_{c}$.

\subsubsection{Handling/Processing Losses}

This potential source of bias represents iodine-131 losses that might have occurred as a result of the collection, transportation, and handling of the vegetation samples. It could also include losses from compressing vegetation into a pellet.

Veteran Hanford employees believe that any losses from this source were probably minimal (Denham et al. 1988) because of the difficulty personnel had in finding a successful method to even chemically extract iodine- 131 from vegetation. Several attempts were made to remove iodine from vegetation by harsh chemical-extraction procedures before a successful method was discovered in 1948 . The early, harsh attempts produced only low yields. One reason for this may have been that iodine-131 entered the stomata of leaves, precluding easy chemical separation. ${ }^{(a)}$ Also, even after severe rainfalls, the iodine-131 was found still tightly bound to the vegetation.

The veteran Hanford employees also felt that the lack of contamination on leather gloves used for collecting data and the lack of incidence of contamination on vehicles and in the laboratory provided more evidence that the iodine-131 had sorbed tenaciously to vegetation (Denham et al. 1988). In addition, Wolff (1951) assigns a value of 1.0 for "vegetation collection efficiency" which supports the above conclusion. Presumably, if removal of iodine131 had been found from handling losses, the value would have been less than 1.0 to compensate for such losses.

(a) Memorandum (HEDR Project Document No. 03930003), "Notes from February 6, 1989 Meeting on Chemical Separation and Early Gamma Spectrometry Methods of Analyzing Iodine-131 Lovels on Vegetation," from E. I. Mart, BNW, to Veteran Hanford Employees - P. O. Jackson, K. R. Price, J. K. Soldat, C. W. Thomas and to R. K. Woodruff, BNW, February 21, 1989. 
Because of the evidence cited above, no loss of iodine-131 from handling or processing is assumed.

\subsubsection{GM Tube Detection Parameter, $\mathbf{E}_{\mathbf{c}}$}

The GM tube detection parameter $\left(\mathrm{E}_{\mathrm{c}}\right)$ accounts for the fraction of betas and gammas counted once inside the GM tube, and for coincidence/dead-time losses. This parameter and other instrument effects are assumed not to impact the value for the reconstructed measurement conversion factor, $\mathbf{M}$.

The GM tube detection parameter, $\mathrm{E}_{\mathrm{r}}$, is defined by the equation

$$
E_{c}=C_{d}\left(E_{\beta}+E_{\gamma}\right)
$$

where $C_{d}=$ coincidence and dead-time parameter

$$
\begin{aligned}
& \mathbf{E}_{\beta}=\text { beta-detection parameter } \\
& \mathbf{E}_{\gamma}=\text { gamma-detection parameter }
\end{aligned}
$$

\subsubsection{Coincidence and Dead-Time Parameter, $C_{d}$}

This parameter considers counts that were lost because a beta particle entered the GM tube's sensitive volume while it was recovering from a previous pulse (dead-time) or coincidentally with another beta.

Because nothing has been found in the literature surveyed that suggests corrections were made for coincidence/dead-time losses, it is assumed that prior to 1950 such corrections were not made. However, at least by 1950 , any sample with a count rate of $5000 \mathrm{cpm}(50,000$ $\mathrm{dpm}$, or $0.02 \mu \mathrm{Ci} / \mathrm{g}$, assuming 10 percent efficiency) was moved to a lower shelf of the $\mathrm{GM}$ counter to reduce the count rate. By 1950, no specific determination for coincidence losses had been made for the mica-window GM detectors used at Hanford, although in general a 0.2 percent loss per thousand cpm was assumed (Healy et al. 1950). In 1951, coincidence losses in five systems were studied and found to vary from 0.5 percent per $1000 \mathrm{cpm}$ to 1.5 percent per $1000 \mathrm{cpm}$ with an average of 1.0 percent per $1000 \mathrm{cpm}$ (Parker 1951). Schwendiman (1954) supplied an equation that approximates the effect:

$$
\text { True cpm }=\frac{\text { cpm observed }}{1-(\pi \times \text { cpm observed })}
$$

where $\pi=$ counter-resolving time. 
Schwendiman (1954) also supplied a table that listed the ratio of observed counts per minute to true counts per minute as a function of counting rate. The table is reproduced in Table 4.6 with corresponding coincidence/dead-time losses.

Few environmental samples would be expected to have activities high enough to result in significant coincidence losses. The bias from neglecting coincidence/dead-time losses is, therefore, assumed to have been minimal, and no count rate losses from this phenomena are assumed. $C_{d}$ is assigned a value of 1 for inclusion in Equation (4.6).

\subsubsection{Beta-Detection Parameter, $\mathrm{E}_{\beta}$}

This parameter considers those betas that entered the sensitive volume of a GM tube but did not generate counts. For any charged particle that enters the sensitive volume of a GM tube, the counting effectiveness is essentially 100 percent (Knoll 1979). However, a small, dead space often occurs just behind the entrance to the mica window in which the local electric field may be too small to prevent recombination or electron loss. In addition, a small amount of beta activity is not counted because the particles interact too far into the walls of the GM counter to liberate any electrons in the GM tube's sensitive volume.

In this analysis, the inference is made that the dead space behind the mica window was compensated for by empirical determinations of $G_{p}$. Because the beta-counting effectiveness once inside the sensitive volume is essentially 100 percent, this parameter is assigned a value of 1 for inclusion in Equation (4.6).

Table 4.6. Ratio of Observed Counts per Minute to True Counts per Minute as a Function of Count Rate (Schwendiman 1954)

\begin{tabular}{|c|c|c|}
\hline $\begin{array}{c}\text { Observed Count } \\
\text { Rate (cpm) }\end{array}$ & $\begin{array}{c}\text { Ratio of Observed } \\
\text { to True Activity }\end{array}$ & $\begin{array}{c}\text { Coincidence/ } \\
\text { Dead-Time Losses }\end{array}$ \\
\hline $0-1000$ & 1.00 & 0.00 \\
$1000-2000$ & 0.99 & 0.01 \\
$2000-3000$ & 0.98 & 0.02 \\
$3000-4000$ & 0.97 & 0.03 \\
$4000-5000$ & 0.96 & 0.04 \\
$5000-6000$ & 0.95 & 0.05 \\
\hline
\end{tabular}




\subsubsection{Gamma-Detection Parameter, $\mathbf{E}_{\boldsymbol{\gamma}}$}

Iodine-131 emits betas and gammas simultaneously, both of which can be detected (i.e., result in counts) by the GM detector. Because the source of counts (whether from betas or gammas) collected by a GM detector cannot be identified, counts originating from gammas would erroneously be interpreted as beta counts. While gamma detection by the GM detectors cannot be ruled out, Healy et al. $(1950$, p. 36$)$ indicate that, in general, gamma contributions in the small mica-window GM detectors were minimal. They state that

For most of the routine work no correction is made for the contribution to the counting rate caused by gamma radiation, because of the low efficiency of the particular type of counters used. This in general means that the rate for the routine samples will be higher than the true rate and will therefore serve as a safety factor in health measurements. For accurate work however, it is necessary to obtain a value for the beta radiation only. This is generally accomplished by the use of an aluminum absorber of such thickness as to allow complete absorption of the beta particles but minimum absorption of the gamma photons.

Therefore, because no quantitative indications of the gamma contributions from the decay of iodine-131 to the beta analyses of vegetation pellets using GM detectors have been found in the historical literature surveyed, $\mathrm{E}_{\gamma}$ is assigned a value of zero in Equation (4.6).

\subsection{Limitations}

The parameters in the equation for $\mathbf{M}$ must be considered only approximations and interpreted with an understanding of the limitations of the methods by which they were determined. (See Appendix A for a discussion of the historical methods used to derive the parameters in M.)

One broad method of refining the estimates of $M$ would be to build a mathematical model in which all of the processes of beta interactions would be incorporated along with the pellet and detector geometries. Such a model would require a complex series of equations and would also have limitations. Some items that would have to be considered in building the model include:

1. probable dimensions of the GM detector's sensitive volume 
2. probability of backscatter, self-scatter, and absorption based on beta energy (considering the beta spectrum, incident angle, and location of emission with the pellet)

3. effects occurring in each pellet layer or increment and corresponding effects in adjoining layers

4. solid-angle relationships in each pellet layer.

In addition, not all of the notebooks or historical documents have been comprehensively reviewed with respect to parameters that affect $\mathbf{M}$. A comprehensive review of all available historical documents could yield more information to be used in refining $M$.

\subsubsection{Limitations in $F_{\text {a }}$ and $F_{\text {bo }}$}

Ideally, self-absorption $\left(F_{s,}\right)$ and scatter within the pellet (such as $F_{b s}$ ) would not be considered independently because the interrelationship between these processes is very complicated, particularly in a thick vegetation pellet (Aten 1950). Scattering in air or from the aluminum source holder was not evaluated.

\subsubsection{Limitations in $F_{\text {a }}$ and $F_{\text {col }}$}

The beta absorption coefficient used in computing $\mathrm{F}_{\mathrm{a}}$ assumes an unattenuated iodine-131 beta spectrum. However, the actual iodine-131 beta spectrum that emerges from a pellet would be of lower energy overall because of interactions with the vegetation pellet. Therefore, a consideration of the lower-energy iodine-131 spectrum in the computation of $F_{a}$ could help refine this estimate.

Because path lengths differ depending on the angle of the particle incident to the detector window, the actual mass thickness is slightly greater than the mass thickness for a beta particle traveling perpendicular to the GM counter. However, given the low density of both the air and the mica window, this difference would be negligible and is ignored in this analysis.

The cellophane-scattering parameter $\left(F_{c e}\right)$ for iodine-131 was never directly measured for the detector systems used in the 1940s. However, the measurements of $F_{\text {cel }}$ made with a USBS RaDEF standard by Schwendiman (1954) and other information provided by Nervik and Stevenson (1952) indicate the expected upper limit. An iodine-131 beta spectrum that had already traversed the pellet would be more attenuated than an iodine-131 spectrum from a sample with low mass thickness. Consequently, the actual energy of the beta particles subject to cellophane scattering would be lower. 


\subsubsection{Limitations in $G_{p}$ and $F_{d}$}

Ideally, $\mathbf{M}$ would be computed by dividing the pellet into a very large number of incrernents for the determination of $G_{p}, F_{d}$, and $F_{\mu \mu}$. In addition, variations in path length that would occur as the solid angle changed with distance were not considered.

\subsubsection{Limitation in $\mathbf{E}_{\mathrm{c}}$}

The assumption that the $\mathrm{E}_{\gamma}$ component of $\mathrm{E}_{\mathrm{o}}$ equals 0 is only an approximation. Some gammas, albeit few, would have been detected. 


\section{0 $D_{\mathrm{e}}$ : Decay Correction Factor}

Iodine-131 has a half-life of 8.05 days. As a result, iodine-131 activity in vegetation samples would decrease steadily in the interval between sampling and counting. After about 8 days, the activity would be half the original. This section discusses the need to correct data for losses in activity caused by iodine-131 decay that would have occurred during the time interval $(t)$ between sample collection and counting.

All original counting rate data (cpm/g) for which the specific time interval $(\mathrm{t})$ is known should be corrected individually. From July 1946 on, all reported activities $(\mu \mathrm{Ci} / \mathrm{kg})$ are assumed to have been decay-corrected. However, if reported activity data for the period before July 1946 is used, it should be corrected for decay assuming an average decay time. It should be noted that the uncertainty in the decay correction factor for reported activities prior to July 1946 will be greater than for the following period.

Herde (1946) indicates that the method for correcting counts for decay was known in 1945. However, the conversions of counts per minute (cpm) to microcuries per gram $(\mu \mathrm{Ci} / \mathrm{g})$ shown on 1945 and 1946 count sheets indicate that decay corrections were not made for measurements before February 1946. After February 1946, the data sheets found do not contain both $\mathrm{cpm} / \mathrm{g}$ and corresponding $\mu \mathrm{Ci} / \mathrm{kg}$. The first mention of the use of iodine-131 decay corrections in the historical literature is by Turner (1946) in reference to vegetation measurements for July 2 through August 31, 1946. Subsequent periodic reports clearly indicate that decay corrections were conducted routinely after that time. The average activities $(\mu \mathrm{Ci} / \mathrm{kg})$ reported after June 1946 are, therefore, assumed to have already been corrected for decay.

The decay correction factor $D_{e}$ can be estimated by the equation

$$
D_{c}=e^{\lambda \ell}
$$

where $D_{e}=$ ratio of the amount of activity in the sample when collected to the activity in the sample when counted

$\lambda=$ decay constant; for iodine- $131, \lambda=(\ln 2) / 8.05$ days or $0.086 /$ day

$\mathrm{t}=$ time interval in days between sample collection and counting. 
In addition to iodine-131, the vegetation pellets also contained longer-lived radionuclides, both from naturally occurring sources and from other fission products. With longer intervals between collection and counting, the percentage of these other, longer-lived radionuclides would increase. The escimated iodine-131 correction factor (see Section 6.0) compensate for other radionuclides and eliminate the bias (i.e., the overestimation of the amoint of activity) caused by decay-correcting the total activity by the iodine-131 half-life. Such a bias would occur because the decay constant for longer-lived fission products is much smaller than that of iodine-131.

If the decay interval for a given sample is not known, a best estimate of the interval can be calculated by evaluating the interval for other measurements made the same day or the day before or after. In some cases, the average decay interval for th: given week may be the most appropriate estimate. For specific cases, the method of obtaining a best estimate of the decay interval must be determined individually based on the information available.

Decay correction factors are given in one-day increments in Table 5.1. These are factors by which the observed data must be multiplied to obtain the activity level at the time of sampling.

Table 5.1. Decay Correction Factors for Iodine-131

\begin{tabular}{|c|c|}
\hline $\begin{array}{c}\text { Decay Interval }(t) \\
\text { (days) }\end{array}$ & $\begin{array}{c}\text { Decay Correction } \\
\text { Factor }\left(\mathrm{D}_{\mathrm{c}}\right)\end{array}$ \\
\hline 1.0 & 1.09 \\
2.0 & 1.19 \\
3.0 & 1.29 \\
4.0 & 1.41 \\
5.0 & 1.54 \\
6.0 & 1.68 \\
7.0 & 1.83 \\
\hline
\end{tabular}




\section{0 $I_{c f}$ : Iodine-131 Assumption Correction Factor}

This section provides estimates of the $I_{c f}$ correction factors that compensate for the bias that occurred by assuming the total beta count; on vegetation reflected the presence of iodine131 only. The goal is to approximate $I_{c f}$ as a function of fuel-cooling time. BNW staff approached evaluating $I_{c f}$ as a function of fuel-cooling time by reviewing empirical monitoring data and computer-generated fuel-inventory data. Both of these data sets contain information on the fraction of iodine-131 activity to total activity on a sample of vegetation. Both modeled and empirical data are then correlated with fuel-cooling times. The parameter $I_{c f}$ is defined to be:

$$
\mathrm{I}_{\mathrm{of}}=1-(\mathrm{FP} / \mathrm{T})
$$

where $\quad I_{c f}=$ Fraction of activity resulting from iodine-131 decay

FP = activity of fission products other than iodine-131

$\mathrm{T}=$ total activity (iodine-131 + FP).

The quantity FP/T is approximated on the basis of a comparison of historical counting data and computer-modeled fuel-inventory data correlated with fuel-cooling time.

From 1945 through 1947, the observed gross beta activity on vegetation pellets was assumed to reflect the presence of iodine-131 only (Healy 1948a), even though beta radiation from other fission products and from naturally occurring radionuclides could alsn have contributed to the observed activity levels. This assumption was acceptable initially for samples where the observed counting rates were at least two standard deviations above the naturally occurring background counting rate, given that iodine-131 was by far the most predominant radionuclide deposited on vegetation. This is indicated by decay measurements of onsite samples (see Subsection 6.1.1 for details). Later, when iodine-131 was first chemically separated from vegetation before beta counting, the bias caused by the assumption that all beta counts represented iodine-131 was nearly eliminated. This separation technique became the sole routine analytical method beginning in December 1948.

Although the levels of naturally oscurring radionuclides in vegetation varied only slightly (seasonally and with plant species), $\mathrm{I}_{\mathrm{cf}}$ as defined by Equation (6.1) is believed to have varied widely according to where the depositions occurred and the time interval between deposition and collection as well as fuel-cooling time prior to processing. The contribution from iodine131 to the total activity on vegetation could have changed with a number of variables such as 
fuel-cooling time before dissolution, fuel-specific power history, ${ }^{(a)}$ dissolution process, meteorology, and time elapsed after deposition. In addition, the activity measured in a given sample may have resulted from deposition from multiple dissolution campaigns. The number of these variables makes it difficult to estimate a generic correction factor for the iodine-131 assumption for a specified time period or location. Because of weather variations, weathering (i.e., removal of iodine-131 from vegetation by natural weathering processes such as wind or rain), and the short half-life of iodine-131, the true fraction of iodine-131 on vegetation on any given date and location could approach zero and, correspondingly, $\mathrm{I}_{\mathrm{cf}}$ could approach zero as well. In addition to the large number of variables affecting $I_{c f}$, there are few historical vegetation-monitoring data, particularly for samples collected offsite, from which $\mathrm{I}_{\mathrm{cf}}$ can be estimated. For this reason, computer-modeled data were also used to estimate $I_{c f}$ (see Subsection 6.3 for a description of the computer-modeled data).

The application of $I_{c f}$ to a given vegetation sample requires knowledge of the probable fuelcooling times for the multiple production campaigns that would have resulted in deposition on a given vegetation sample. This requires a correlation of dissolution with meteorology and knowledge of decay times since deposition. Thus, accurate application is not straightforward. The uncertainty analyses conducted by Gilbert et al. (1992) investigate the effect of this uncertainty in $\mathrm{I}_{\mathrm{cf}}$ on the uncertainty of the total reconstructed conversion factor (C).

Subsection 6.1 discusses radionuclides other than iodine-131 that may have contributed to the observed gross beta activity on vegetation. These other radionuclides include naturally occurring potassium-40 and uranium decay-chain emitters, and longer-lived fission products, including the particulates that were released because of a stack ductwork corrosion problem that occurred in 1947. Subsection 6.2 covers the historical data from which contributions from other fission products can be estimated. Subsection 6.3 describes the method used to approximate the correction factors for the iodine-131 assumption.

\subsection{Other Radionuclides}

The vegetation present in the Hanford area from 1945 through 1947 contained naturally occurring radionuclides as well as any iodine-131 and other longer-lived fission products that resulted from fuel dissolution at Hanford. Some of these fission products were radioactive particulates that came from corroded stack ductwork that flaked off in 1947. This singular occurrence was corrected shortly after discovery. In the 1950s, above-ground testing of nuclear weapons at times also contributed to the activity detected on vegetation.

(a) Fuel burnup in units of megawatt days per short ton (MWD/ST). 


\subsubsection{Natural Background Radioactive Materials}

The only important radionuclide occurring naturally in vegetation in this analysis is potassium -40 . The potassium- 40 content of vegetation was analyzed extensively in the late 1940s (South 1949). In one document, a value as high as $50 \mathrm{pCi} / \mathrm{g}$ was given (Singlevich 1948b). The concentration levels were found to vary with plant moisture and the season, peaking in late April and May (Paas and Singlevich 1951). More recent data on potassium-40 levels are found in the 1973 and 1974 Hanford Environmental Monitoring Reports (Nees and Corley 1974; Fix 1975). These reports indicate that $10 \mathrm{pCi} / \mathrm{g}$ is a good estimate of average potassium-40 levels in vegetation native to the Hanford area. Singlevich (1948b) summarized research on potassium- 40 content in sagebrush. The average concentration of potassium-40 was about $3.5 \mathrm{cpm} / \mathrm{g}$.

In their report for the week ending December 13, 1945, Parker and Gamertsfelder (1945) indicate that noncontaminated vegetation obtained from Portland, Oregon, and from Berkeley, California, also produced counting rates above instrument background. Therefore, even noncontaminated Hanford vegetation would have produced a certain count rate (although an insignificant one) with the counting systems in use in the 1940s, and this count rate presumably would have come from potassium -40 . The count rate from naturally occurring potassium-40 is not high enough to warrant a special correction factor. The error resulting from failure to compensate for potassium- 40 is minimal and causes a bias in the conservative direction; i.e, an overestimate of true activity, albeit a minimal one.

Other radionuclides occurring naturally in vegetation include radium-224 $(<0.04 \mathrm{pCi} / \mathrm{g})$, radium-226 $(<0.11 \mathrm{pCi} / \mathrm{g})$, and total uranium $(<0.55 \mathrm{pCi} / \mathrm{g})$ (Fix 1975). The average activities from these components are even lower than those from potassium- 40 . Therefore, they do not warrant special correction factors.

\subsubsection{Longer-Lived Fission Products}

From the start of operations, in addition to iodine-131, longer-lived fission products were also emitted from the exhaust stacks of the Hanford fuel-dissolution plants, mostly as aerosols. Trace amounts of fission products other than iodine-131 were detected on desert vegetation at an early date (Parker 1948). Although each element would have a unique dispersion pattern based on chemical interactions in the environment, in this analysis the longer-lived fission products (both droplets and aerosols) are assumed to have dispersed similarly to iodine-131. The dispersion and deposition of these droplets and aerosols were casually tracked by analyses of vegetation and air (Parker 1948). Parker observed that the percentage of longer-lived activity to iodine-131 found in the samples was increasing steadily with time. 
The historical record contains few measurements from which levels of other fission products can be compared with iodine-131 levels on vegetation in the period from 1945 through 1947. Parker (1948) remarks on the meagerness of this type of data in a review of longer-lived fission product activity. As a result, only limited historical information is available to estimate $\mathrm{FP} / \mathrm{T}$.

The fission products that would have been released from the stacks were somewhat dependent on the actual dissolution chemistry. The principal longer-lived fission products that would have been counted in the measurement of pellets include isotopes of ruthenium, cerium, yttrium, cobalt, strontium, and cesium (Napier 1991). Most of the other fission products were generated in minimal quantities or were of limited volatility which precluded significant release through the stacks. Noble gases are highly volatile and were released, but because of their inert chemical characteristics, they would not have been deposited or retained on vegetation.

\subsubsection{Radioactive Particulates from Corroded Ductwork}

In 1947, a unique problem occurred with fission products that had adhered to corroded stack ductwork and subsequently flaked off (Parker 1948). Replacement of the corroded ductwork in 1948 eliminated contamination by the larger particulates but had little influence on the emission of smaller particulates (droplets), confirming that the primary source of small particulates was directly from fuel dissolution.

The radioactive particulate problem resulting from corroded iron ductwork was discnvered in September 1947 because of recurrent contamination, presumably of personnel (Parker 1948). It was estimated that the problem started around April 1947 about six months prior to detection. However, a review of contamination data indicated the problem had rapidly increased in magnitude just prior to its discovery (Mickelson 1947; Parker 1948). By midOctober 1947, the general distribution pattern around T and B Plant stacks had been defined sufficiently to indicate these stacks were the source. By late November 1947, the particulates were found to have come from effluent fission products that had adhered to black iron in the stack fan ductwork and then started to flake off.

The visible particulates derived from the corroded ductwork ranged from about 0.02 to 1.5 $\mathrm{mm}$ (linear dimensions), and their activities ranged from about 0.1 to $3 \mu \mathrm{Ci}$. The actual sizes ranged all the way down to ultra-fine particulates that were effectively aerosols. The particulates from the ductwork contained only long-lived emitters. The effective half-life was about 300 days. The activity was identified as representing cerium-144, yttrium-90, strontium-90, and some alpha activity from plutonium (Burger 1991). 
Deposition velocities would have varied, depending on particulate size and shape, with larger particles being deposited closer to the stacks. The corroded duct particulates were mainly deposited close to the 200 Areas in which they were produced, trailing off in an ellipsoid pointing toward the southeast (Rees 1947; Zuerner 1947). Once deposited, some particulates may have been re-suspended and transported farther by wind. Analyses of variations in the samples, taken at 1 -mile intervals about 2 to 5 miles from the stacks as well as within the 200 Areas, indicated that the deposition of long-lived fission products was more like a continuous distribution than a particulate one. General Electric's Health Instruments Department concluded that the main source of this continuously distributed long-lived activity was not stack corrosion particles and that the 1947 particulate releases represented only a fraction of the total long-lived fission product emissions from the stacks (Parker 1948). This conclusion was supported by the observation that numerous smaller particulates continued to be emitted even after the replacement of fans and ductwork in January 1948, although the replacement did eliminate the emissions of large corrosion particles. The smaller particulates were identified as coming from mists produced by boiling solutions and by the transfer of liquids using steam jetting (Burger 1991).

Because the duct particulates were generally large, they are assumed to have been only deposited close to the 200 Area stacks and, therefore, did not contribute to the gross beta activity of off-site vegetation collected in 1947. This assumption is supported by Parker (1948) where he concludes the lack of wide variation in counts of 1-gram vegetation pellets (even those from the plant environs) indicates minimal contributions. For these reasons, separate correction factors for samples with potential particulate depositions from corroded ductwork are not provided in this analysis.

\subsection{Historical Data}

With time, radionuclides other than iodine-131 began to contribute increasingly to the total observed activity on vegetation. Longer fuel-cooling times, accumulation of long-lived fission products both in the fuel and on vegetation, and iodine-131 emission control devices placed in the stacks in 1948 contributed to this trend. The best historical data from which to assess $I_{c f}$ come from 1945 and early 1946 because decay data have been found in a laboratory notebook (Bulow 1945). Also, other documents discuss conclusions based on decay curves or an estimate of the ratio of iodine-131 to other fission products on vegetation (Parker 1948). The contributions from other radionuclides were rarely measured before chemical separation procedures were adopted in mid-1948, and the few activity or count data found for other radionuclides are from samples collected on the Hanford Site. 
Basing $\mathrm{I}_{\mathrm{cf}}$ on historical information has limitations. For instance, the number of dissolution campaigns that resulted in deposition on the collected samples and the time elapsed between deposition and sample counting is not known. The length of time elapsed would have affected the amount of activity resulting from iodine-131 relative to the activity of other fission products. With a long elapsed time, the overall activity would be expected to be relatively low, and with a long enough time, $I_{\mathrm{cf}}$ would approach zero. However, for samples collected from 1945 through 1947, a sample with undetectable iodine-131 levels would likewise be expected to have minimal or undetectable quantities of longer-lived fission products.

The value of FP/T indicated by historical measurements of samples collected on the Hanford Site may not correspond to the contribution at more distant off-site locations. Such a lack of correspondence could result from differences in how the components dispersed in the atmosphere, in the rates at which they were deposited on vegetation, in the rates at which the radionuclides were retained, and in the length of time elapsed from deposition to sample counting. The rate of deposition of iodine-131 relative to other species is complex. Burger (1991) discusses iodine behavior in the atmosphere and deposition; thus, this topic will not be addressed further here.

Another limitation is that BNW staff have not discovered the analytical methods used prior to 1948 to measure iodine-131 and other fission products separately. The historical record contains only limited information on these measurements: date of collection and counting and sometimes the sampling location. Consequently, the historical measurements must be interpreted in the light of these limitations.

Plotting the data obtained by periodically counting a given vegetation sample over several days or weeks can be used in conjunction with radionuclide half-life information to indicate which radionuclide predominates in a sample. Decay data on samples collected in 1945 indicate that iodine-131 was the predominant radionuclide (Bulow 1945; Parker and Gamertsfelder 1945; Healy and Turner 1946). Bulow (1945) reported counting data for two on-site samples collected approximately 4 and 5 miles southeast of the 200 East Area in July 1945 (see Table 6.1). The background-corrected counts per minute (cpm) given by Bulow (1945) for each day are compared with the cpm that would be expected if iodine-131 were the only radionuclide present. The expected $\mathrm{cpm}$ values were obtained by decay correcting the observed cpm taken on July 17, 1945 (i.e., Day 0) by the iodine-131 decay factor for each day thereafter. These results, given in Table 6.1, indicate that the observed activity from both samples was primarily from iodine- 131 . 
Table 6.1. Decay Data for Two Samples, July 1945 (Bulow 1945)

\begin{tabular}{|c|c|c|c|}
\hline Location $^{(\mathrm{a})}$ & Day & $\begin{array}{l}\text { Observed } \\
\text { cpm }\end{array}$ & $\begin{array}{c}\text { Expected } \\
\text { cpm from }{ }^{131} I^{(\mathrm{b})}\end{array}$ \\
\hline R4S-MP6 & 0 & 317 & 317 \\
\hline R4S-MP6 & 1 & 281 & 291 \\
\hline R4S-MP6 & 2 & 268 & 267 \\
\hline R4S-MP6 & 3 & 246 & 245 \\
\hline R4S-MP6 & 4 & 227 & 225 \\
\hline R4S-MP7 & 0 & 287 & 287 \\
\hline R4S-MP7 & 1 & 253 & 263 \\
\hline R4S-MP7 & 2 & 242 & 242 \\
\hline R4S-MP7 & 3 & 222 & 222 \\
\hline R4S-MP7 & 4 & 204 & 203 \\
\hline \multicolumn{4}{|c|}{$\begin{array}{l}\text { (a) Location: R4S refers to the main Hanford-Site highway diagonally southeast from } \\
\text { the } 200 \text { East Area and designated as Route } 4 \text { South. MP6 and MP7 refer to } \\
\text { Mileposts } 6 \text { and } 7 \text {, respectively, from the } 200 \text { East Area. } \\
\text { (b) The expected cpm, assuming all of the counts per minute were from iodine- } 131 \text {, } \\
\text { was computed by multiplying the observed "zero-day" cpm by e. } \\
\text { iodine-131. }\end{array}$} \\
\hline
\end{tabular}

Other reports also indicate that the activity was mainly iodine-131, again based on decay measurements. Parker and Gamertsfelder (1945) in their report for the week ending February 16,1945 , stated that activity on a sagebrush sample decayed with a half-life of 8 days. Healy and Eisenacher (1946) indicated that a sagebrush sample collected November 26, 1945, and counted in January 1946 gave a value indicative of iodine-131 with its characteristic 8-day half-life. In addition, both Richland air and fuel-dissolution stack measurements made in March 1945 indicate that iodine-131 levels in the air were two to four orders of magnitude greater than the levels of long-lived fission products (Parker 1948). These results support the assumption that off-site iodine levels on vegetation in early 1945 were significantly higher than levels of long-lived fission products. Thus, the activity on vegetation in 1945 is assumed to have been predominantly from iodine- 131 .

In the historical literature surveyed, few documents provided actual measurements on activities of both long-lived fission products and iodine-131 for the same samples. One of 
these documents (Healy 1948b) contained activity data as provided below in Table 6.2. The ratio of fission products to total activity was computed from these data as also provided in Table 6.2.

All of the data in Table 6.2 were for samples collected on the Hanford Site. The ratio of FP/T for off-site samples could have been different because of differences in the deposition patterns for iodine-131 and the other fission products. As discussed previously, no particulates from corroded ductwork are assumed in the relatively low activity for 1947, given that these particulates were so highly raclioactive the count data would have been extremely high, and the problem did not escalate until about September 1947 (Parker 1948).

Parker (1948) estimated the ratio of other fission products to total activity as given in Table 6.3. For location, he merely refers to "desert vegetation" which is presumably on site. He does not, however, describe the analytical process used.

Table 6.2. Iodine-131 and Other Fission Product Activity Levels (Healy 1948b) and Computed Fission Products in Total Activity (FP/T)

\begin{tabular}{|c|c|c|c|c|c|}
\hline Sampling Date & Location $^{(a)}$ & $\begin{array}{l}\text { Average Fuel- } \\
\text { Cooling Time } \\
\text { (Days) }\end{array}$ & $\begin{array}{l}\text { Iodine-131 } \\
(\mathrm{pCi} / \mathrm{g})\end{array}$ & Other FP $(\mathrm{pCi} / \mathrm{g})$ & $\mathrm{FP} / \mathrm{T}^{(\mathrm{c})}$ \\
\hline $11 / 04 / 46$ & R4S-MP4 & 65 & 800 & 100 & 0.11 \\
\hline $11 / 25 / 46$ & R4S-MP7 & 65 & 14000 & 700 & 0.05 \\
\hline $11 / 26 / 46$ & R4S-MP2 & 65 & 13000 & 1900 & 0.13 \\
\hline $4 / 29 / 47$ & Met & 68 & 600 & 300 & 0.33 \\
\hline $6 / 20 / 47$ & 200-E & 77 & 2600 & 2200 & 0.46 \\
\hline $7 / 22 / 47$ & $200-W$ & 78 & 1100 & 700 & 0.39 \\
\hline $7 / 14 / 47$ & $200-W$ & 78 & 3300 & 5000 & 0.60 \\
\hline \multicolumn{6}{|c|}{ 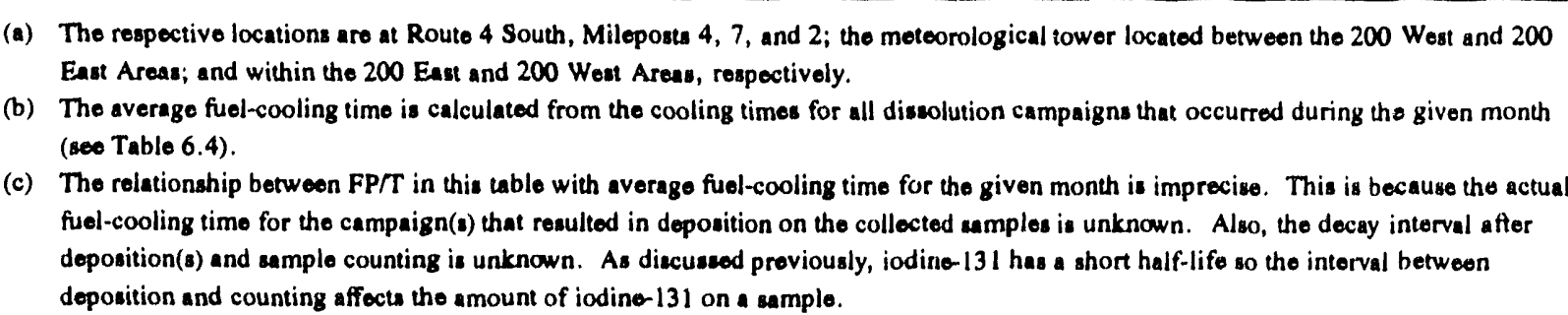 } \\
\hline
\end{tabular}


Table 6.3. Estimated Fraction of Fission Products to Total Activity (FP/T) on Vegetation (Parker 1948)

\begin{tabular}{|c|c|c|c|}
\hline & Period Stated in Parker (1948) & Assumed Date & $\mathrm{FP} / \mathrm{T}$ \\
\hline & After one year of operation & $12 / 1945^{(a)}$ & 0.00005 \\
\hline & After two years of operation & $12 / 1946^{(b)}$ & 0.10 \\
\hline & March 1948 & $3 / 1948$ & $0.50^{(\mathrm{c})}$ \\
\hline & \multicolumn{3}{|c|}{ 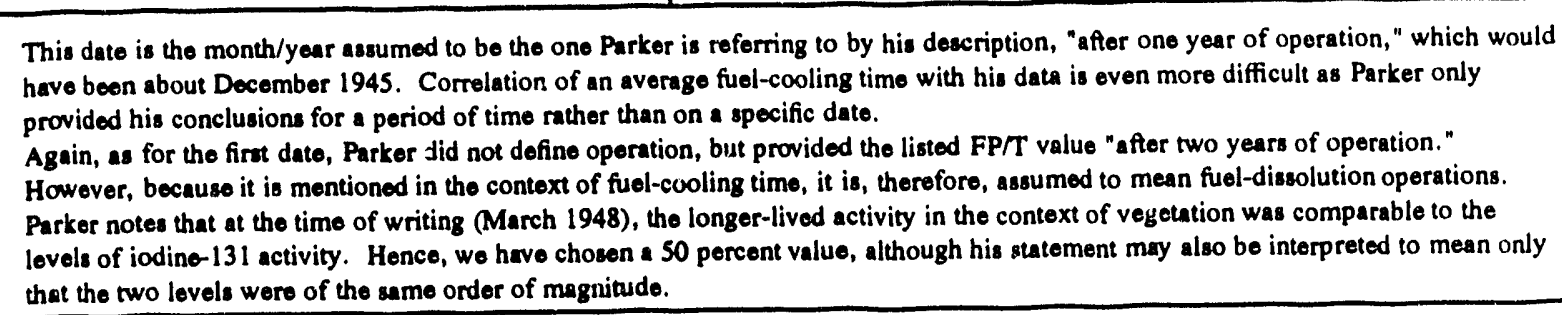 } \\
\hline
\end{tabular}

\section{3 $I_{c f}$ Method}

This section includes discussions of the approach (6.3.1), fuel-cooling times (6.3.2), and estimated FP/T values (6.3.3) based on computer-generated fuel burnup to estimate the FP/T values on vegetation in the Hanford environs as a function of fuel cooling time.

\subsubsection{Approach}

$I_{c f}$ as defined by Equation (6.1) is believed to have varied over time and area. The contribution from iodine-131 to the total activity on vegetation could have changed with a number of variables such as the fuel-cooling time before dissolution, burnup, fuel-dissolution process, multiple fuel-dissolution campaigns, meteorology, and time elapsed after deposition. These variables make it difficult to estimate specific values for a given time period. In addition to the large number of variables affecting this ratio, there are few historical data from which FP/T values can be estimated, particularly for samples collected off site. For this reason, additional information is needed to derive estimated $I_{c f}$ values.

This additional information has been provided by ORIGEN2 (Croff 1980), ${ }^{(a)}$ a computer code that calculates the fission product inventory in fuel based on bumup and length of time after removal of fuel from the reactor. This computer code provides the inventories of light activation products and fission products, and inventories of actinides at a fuel bumup of

(a) ORIGEN2 data transferred from C. M. Heeb, BNW, to E. I. Mart, BNW Consultant, January 13, 1993. 
$200 \mathrm{MWD} / \mathrm{ST}$, the target discharge burnup in the years prior to 1950. ORIGEN2 does not compute the expected fission product activity at the point of stack discharge resulting from fuel dissolution. To derive this latter value, release fractions must be applied to the inventories.

The ORIGEN2 code prints activities per short ton for three radionuclide categories: 1) light-element activation products, 2) actinides and their decay products, and 3) fission products. It also includes total activities in each category. The values generated for total activities for all light activation products and fission products, iodine-131, and the noble gases were used to derive an estimate of FP/T.

In this approximation, the approach used in estimating FP/T from ORIGEN2 and historical $\checkmark$ ata as a function of fuel cooling time is to assume that the contribution that fission products other than iodine-131 made to the total activity (determined from measurements of on-site samples and determined from the ORIGEN2 run at the point of stack discharge) represents the contribution at all sampling locations.

\subsubsection{Fuel-Cooling Times}

Table 6.4 lists average monthly fuel-cooling times from Napier (1991). Longer fuelcooling times resulted in more iodine-131 decay before emission, increasing FP/T and consequently decreasing $I_{c f}$. For example, after 30 days of cooling, fuel would contain approximately 8 percent of the original iodine-131 activity at reactor discharge. After 60 days it would contain 0.6 percent, and after 90 days it would contain only 0.04 percent. Longer-lived radionuclides would not be depleted as rapidly.

\subsubsection{Estimated FP/T Based on ORIGEN2 Run}

The data generated by the ORIGEN2 computer code include activities for total fission products as a function of fuel-cooling time and for a burnup of $200 \mathrm{MWD} / \mathrm{ST}$. The ORIGEN2 data list activities per short ton (ST) for each radionuclide after cooling times ranging from 10 to 90 days in 20-day increments, at 150 days, and also at discharge. The ORIGEN2 output also includes total activities at each cooling time for each category. The ORIGEN2 data only compute the inventory in the fuel, not at the point of discharge from the stacks. Release fractions must be applied to each element in the inventory to derive fissionproduct activities at point of stack discharge.

Release fractions resulting from fuel dissolution were obtained from Heeb (1992) for iodine-131 and from Napier (1992) for all other fission products. A release fraction of 0.91 
Table 6.4. Average Number of Days Fuel Cooled before Dissolving (Napier 1991, p. 2.2)

\begin{tabular}{|c|c|c|c|c|c|}
\hline Month/Year & $\begin{array}{c}\text { Average Fuel- } \\
\text { Cooling Time } \\
\text { (Days) }\end{array}$ & Month/Year & $\begin{array}{c}\text { Average Fuel- } \\
\text { Cooling Time } \\
\text { (Days) }\end{array}$ & Month/Year & $\begin{array}{c}\text { Average Fuel- } \\
\text { Cooling Time } \\
\text { (Days) }\end{array}$ \\
\hline $12 / 44$ & 49 & $1 / 46$ & 62 & $1 / 47$ & 62 \\
$1 / 45$ & 39 & $2 / 46$ & 67 & $2 / 47$ & 69 \\
$2 / 45$ & 53 & $3 / 46$ & 70 & $3 / 47$ & 69 \\
$3 / 45$ & 52 & $4 / 46$ & 62 & $4 / 47$ & 68 \\
$4 / 45$ & 42 & $5 / 46$ & 62 & $5 / 47$ & 68 \\
$5 / 45$ & 36 & $6 / 46$ & 73 & $6 / 47$ & 77 \\
$6 / 45$ & 35 & $7 / 46$ & 68 & $7 / 47$ & 78 \\
$7 / 45$ & 40 & $8 / 46$ & 63 & $8 / 47$ & 82 \\
$8 / 45$ & 39 & $9 / 46$ & 59 & $9 / 47$ & 84 \\
$9 / 45$ & 38 & $10 / 46$ & 65 & $10 / 47$ & 90 \\
$10 / 45$ & 44 & $11 / 46$ & 65 & $11 / 47$ & 95 \\
$11 / 45$ & 52 & $12 / 46$ & 62 & $12 / 47$ & 95 \\
$12 / 45$ & 47 & & & & \\
\hline
\end{tabular}

for iodine-131 was provided by Heeb (1992, p. 4.28). Napier (1992, p. 5.6) provides the following estimated release fractions for other fission products: 1.00 for noble gases, and 0.00001 for all other nonvolatile radionuclides and for ruthenium isotopes. ${ }^{(a)}$

The following equation is used to compute fission products other than iodine-131 at the point of stack discharge ${ }^{(b)}$ :

(a) Napier (1992) revised the release fraction for ruthenium isotopes from Phase I estimates of 0.01 (Napier 1991). The Phase I estimates were given to compensate for an initial impression that large amounts of nuthenium were emitted in periodic (particulate) events. Because continued research indicated that ruthenium and other fission products were continuously emitted as mists, and the bulk of emissions were from these mists rather than particulates (see Section 6.1.3 for a discussion on the particulate releases), Napier reduced the estimated release fraction. Napier based the release fraction for all other fission products on an analysis of historical data for the 1945 through 1947 period found in Healy (1948a, 1948b), Parker (1948), Greager and MacReady (1948), and on information in documents coveriag later years.

(b) Note that actinides are not included in the total fission products. Actinides are not fission products and.would not be expected to be released from the dissolution process except in minute quantities. Xenon and krypton isotopes are subtracted out of the total amount because they are noble (inert) gases and would not have deposited onto vegetation. They could not have contributed to the gross beta count registered by the $\mathrm{GM}$ detectors. 


$$
\mathrm{FP}=\left(\text { Total }-\mathrm{Kr}-\mathrm{Xe}-{ }^{131} \mathrm{I}\right) 0.00001
$$

where FP = fission and activation products other than actinides, iodine-131, and the noble gases at the point of stack discharge.

Total $=$ total activity for all fission products as given in the ORIGEN2 run

$\mathrm{Kr}=$ activity for significant krypton isotopes ${ }^{(a)}$ as given in the ORIGEN2 run $(\mathrm{Kr}$ 85)

$\mathrm{Xe}=$ activity for significant xenon isotopes $^{(b)}$ as given in the ORIGEN2 run (Xe$131 \mathrm{~m}, \mathrm{Xe}-133, \mathrm{Xe}-133 \mathrm{~m}$ )

${ }^{131} I$ = activity for iodine-131 as given in the ORIGEN2 run.

For simplicity, all fission products were used because ORIGEN2 output represents total activity. Decay modes and beta energies were not considered, so that even those fission products that would not have been detected by the counters used in the 1940s were included in FP. Even though some fission products may have been present on vegetation, they may not have emitted beta particles at all or at least not those with sufficient energy to have been readily detected. Conversely, other fission products may have emitted much more energetic beta particles and, consequently, may have been detected much more readily. In this analysis, the simplifying assumption is made that all fission-product activity would have been detected equally by the mica-window GM counters. The krypton and xenon radionuclides were not accounted for in the total fission-product activity because they are noble gases which do not react chemically and, thus, do not deposit onto vegetation. Actinides were excluded because insignificant quantities would have been emitted. The ORIGEN2 run provided actinide values separately from the fission products.

The estimated activities of iodine-131 and other fission products as calculated by ORIGEN2 and computed by Equation (6.2) at the stack-discharge point are listed in Table 6.5. As given in Table 6.5, FP/T approximates the fraction of activity not resulting from iodine131 decay relative to the total activity at the stack-discharge point in fuel-cooling time increments ranging from 10 to 90 days. Table 6.6 shows FP/T values computed from data in the ORIGEN2 run, those inferred from interpretation of historical vegetation data, and averages of those two data sets which BNW staff assume to be the best estimates of FP/T.

(a) Significant krypton isotopes are those present in an appreciable quantity and, thus, affect the ratio FP/T if included in the total amount. (b) Significant xenon isotopes are those present in an appreciable quantity and, thus, affect the ratio FP/T if included in the total amount. 
Table 6.5. Iodine-131, Fission Product (FP), and Total Activity (Curies) at Stack Discharge Computed from ORIGEN2 Data

\begin{tabular}{|c|c|c|c|c|}
\hline $\begin{array}{l}\text { Fuel-Cooling } \\
\text { Time (Days) }\end{array}$ & $\begin{array}{c}{ }^{131} I^{(a)} \text { at Stack } \\
\text { Discharge }\end{array}$ & $\begin{array}{c}\text { FP }^{(b)} \text { at Stack } \\
\text { Discharge }\end{array}$ & $\begin{aligned} & { }^{131} \mathrm{I}+\mathrm{FP} \\
= & \text { Total }(\mathrm{T})\end{aligned}$ & $\mathrm{FP} / \mathrm{T}^{(\mathrm{c})}$ \\
\hline 10 & 10064 & 4 & 10068 & $<0.001$ \\
\hline 30 & 1796 & 3 & 1799 & 0.001 \\
\hline 50 & 320 & 2 & 322 & 0.006 \\
\hline 70 & 57 & 2 & 59 & 0.03 \\
\hline 90 & 10 & 1 & 11 & 0.12 \\
\hline \multicolumn{5}{|c|}{$\begin{array}{l}\text { lodine-131 activity at stack discharge is estimated as the total iodine-131 activity given by the ORIOEN2 run multiplied by a release } \\
\text { fraction of } 0.91 \text {. } \\
\text { FP at stack discharge is eatimated by Equation (6.2). } \\
\text { FP/T approximates the fraction of the total activity coming from fission products other than iodine-131. Conversely, the quantity } \\
(1-\mathrm{FP} / \mathrm{T}) \text { is the fraction of the activity that came from iodine-131: FP/T }=[\mathrm{FP}(0.00001)] /(\mathrm{FP}(0.00001)+\text { iodine- } 131(0.905)]\end{array}$} \\
\hline
\end{tabular}

Table 6.6. Average Fuel-Cooling Times and Correlation of Fission Product to Total Activity (FP/T) from ORIGEN2 and Historical Measurements ${ }^{(a)}$

\begin{tabular}{|c|c|c|c|}
\hline $\begin{array}{l}\text { Fuel-Cooling } \\
\text { Time (Days) }\end{array}$ & $\begin{array}{l}\text { FP/T Computed from } \\
\text { ORIGEN2 Data } \\
\end{array}$ & $\begin{array}{c}\text { FP/T Inferred from } \\
\text { Vegetation Data }^{\left({ }^{()}\right)}\end{array}$ & $\begin{array}{l}\text { FP/T Averages of ORIGEN2 } \\
\text { and Vegetation Data }{ }^{(\mathrm{c})} \\
\end{array}$ \\
\hline 10 & $<0.001$ & $<0.001$ & $<0.001$ \\
\hline 30 & 0.001 & 0.001 & 0.001 \\
\hline 50 & 0.006 & 0.003 & 0.005 \\
\hline 70 & 0.03 & 0.23 & 0.13 \\
\hline 90 & 0.12 & 0.50 & 0.31 \\
\hline $\begin{array}{l}\text { (a) This table was cc } \\
\text { (b) The FPPT was in } \\
\text { given in Bulow ( } \\
\text { (c) Average FPTT ve }\end{array}$ & $\begin{array}{l}\text { Healy (1948b), and Park } \\
\text { re assumed to be the best }\end{array}$ & $\begin{array}{l}\text { rough } 6.5 \text {. } \\
\text { 8 he average fuel-cooling tir } \\
\text { rom which to compute } \mathrm{L}_{\text {tr }}\end{array}$ & es \\
\hline
\end{tabular}

Values of FP/T generated from ORIGEN2 data must be considered only approximations. Computer-modeled fuel inventories have inherent limitations, especially for interpreting historical conditions. For instance, the actual burnup for any campaign would have varied somewhat even though they had the target burnup of $200 \mathrm{MWD} / \mathrm{ST}$. It is difficult for any simulation to represent true reactor core conditions, given non-uniform flux and neutron 
energies, other variations and unknowns. In addition, the true release fraction from the fueldissolution process would be unique for each fission product. Nonetheless, the approximation of FP/T computed from ORIGEN2 data in liii, analysis is useful in quantifying the decrease in iodine-131 activity associated with longer fuel-cooling times because the vegetation data also have limitations (see Section 6.0).

The values of FP/T estimated from the ORIGEN2 data support the conclusions drawn from the historical record for fuei-cooling times from 10 to 50 days. However, for fuel-cooling times for 70 to 90 days, the estimates of FP/T from these two sources diverge. While the values at FP/T nbta ned using ORIGEN2 continue to increase fairly proportionally, the values obtained from the vegetation data increase sharply. This casts doubt on the reliability of the vegetation data for fuel-cooling times from 70 to 90 days, particularly for samples collected immediately after deposition. Because the time between deposition and counting is difficult to assess and because both estimation methods have limitations, it was decided to average the values of FP/T obtained using the two methods. $I_{f f}$ was estim ted using Equation (6.1) and the averages given in Table 6.6.

Table 6.7 provides best estimates of $I_{c f}$ for several cooling times. These approximate values of $I_{\mathrm{cf}}$ can be applied to historical pellet measurements by applying information on the fuel-conling time from the reactor discharge to sample counting for the particular production campaigns that resulted in deposition on the collected sample. As mentioned previously, multiple campaigns could have resulted in deposition or not on a given vegetation sample depending on wind patterns and varying lengths of decay time since deposition. Thus, the application of $I_{c f}$ is complex, and the $I_{c f}$ value itself must be understood to be only an approximation, as are any measurements calculated using $\mathrm{I}_{\mathrm{cf}}$. In addition, $\mathrm{I}_{\mathrm{cf}}$ can only be applied to measurements where detectable activity was observed; i.e., above $40 \mathrm{pCi} / \mathrm{g}$ (Leboeuf 1950). 
Table 6.7. Best Estimate of $I_{c f}$ Based on the Average of Historical Vegetation Data and Fission Products to Total Activity (FP/T) Generated from ORIGEN2 Data

\begin{tabular}{|c|c|c|}
\hline & Fuel-Cooling Time ${ }^{(a)}$ (Days) & Best Estimate of $I_{c f}^{(b)}$ \\
\hline & 10 & $>0.99$ \\
\hline & 30 & 0.99 \\
\hline & 50 & 0.99 \\
\hline & 70 & 0.87 \\
\hline & 90 & 0.69 \\
\hline \multicolumn{3}{|c|}{$\begin{array}{l}\text { See Table } 6.4 \text { for information on average fuel-cooling times from Docember } 1944 \text { through } \\
\text { December } 1947 \text {. } \\
\mathrm{L}_{f}=1-\mathrm{FP} / \mathrm{T} \text {. Application of } \mathrm{L}_{t} \text { to any given somple requires an estimate of the fuel-cooling } \\
\text { time from the reactor discharge to the sample counting and interpolation of } \mathrm{t} f \text { from the values } \\
\text { in this table. }\end{array}$} \\
\hline
\end{tabular}




\subsection{Results and Conclusions}

In the years from 1945 through 1947, beta-counting technology had not yet progressed to the point where detector efficiency specific to the analysis of iodine-131 activities in vegetation could be determined (Healy et al. 1950). Historical detector efficiency did not account for all of the parameters that affected overall efficiency of the beta-counting system. Some parameters were ignored or were miscalculated, and accurate iodine-131 standards were not available. As a result, the activities reported for vegetation were biased. However, as time went on, more factors were accounted for, so that the accuracy of the reported values improved.

Therefore, to adequately interpret the historical measurements, this analysis was conducted with the goal of providing estimated factors for converting historical count data to an estimate of actual activity.

\subsection{Results}

Three primary factors affected what percentage of the beta particles emitted by iodine-131 disintegrations in a vegetation pellet resulted in counts registered by the GM counters used in the 1940s. These factors are the measurement conversion factor $(M)$, the decay correction factor $\left(D_{e}\right)$, and the iodine-131 assumption correction factor $\left(I_{c f}\right)$.

\subsubsection{Measurement Conversion Factor, $M$}

The measurement conversion factor (M) converts original counting data into an approximation of disintegration rate from which activity in curies ran be obtained by the standard relationship of $2.22 \times 10^{6} \mathrm{dpm} /$ microcurie. The measurement conversion factor approximates the historical relationship between disintegrations in a 1-gram sagebrush pellet and the count rate registered by a GM detector.

$M$ is also used to derive an adjustment factor for reported activities. The adjustment factor (A) is obtained by dividing the reconstructed $M$ by the inverse of the historical detector efficiency used. Then, the reported activity can be multiplied by $A$ to obtain an approximation of the true activity in the pellet. 
Table 7.1 provides results for A for two time periods, October 1945 through June 1946 and July 1946 through December 1947, and results for three time periods. The time periods are divided according to when changes occurred in historical detector efficiency.

Table 7.1. Historical and Reconstructed Measurement Conversion Factors and Adjustment Factors for Measurements of Iodine-131 in Vegetation Pellets

\begin{tabular}{|c|c|c|c|c|}
\hline & Date $^{(a)}$ & $\begin{array}{l}\text { Reconstructed } \mathrm{M}^{(\mathrm{b})} \\
(\mathrm{dpm} / \mathrm{cpm})\end{array}$ & $\begin{array}{c}\text { Inverse Detector } \\
\text { Efficiency } \\
(\mathrm{dpm} / \mathrm{cpm})\end{array}$ & $\begin{array}{l}\text { Adjustment } \\
\text { Factor }(\mathrm{A})^{(\mathrm{d})}\end{array}$ \\
\hline & $10 / 45-01 / 46$ & & 12.5 & 5.06 \\
\hline & $02 / 46-06 / 46$ & 03.2 & 38.5 & 1.64 \\
\hline & $07 / 46-12 / 47$ & 68.9 & 38.5 & 1.79 \\
\hline $\begin{array}{l}\text { (a) } \\
\text { (b) } \\
\text { (c) } \\
\text { (d) }\end{array}$ & \multicolumn{4}{|c|}{$\begin{array}{l}\text { The time periods are based on historical procedure and historical conversion factors used. The pellets were formed by hand until } \\
\text { about } 7 / 46 \text {. The assumed detector efficiency changed in February } 1946 \text { because of an additional factor of } 3 \text { to compensate for } \\
\text { self-absorption within the pellet. } \\
M \text { is the factor discussed in Section } 4.0 \text {. } \\
\text { The inverse detector efficiency refers to the inverse of the historically used component as discussed in Section } 2.0 \text {. } \\
\text { These unitless values are the ratio of: } M \text { /(inverse historical detoctor efficiency). }\end{array}$} \\
\hline
\end{tabular}

\subsubsection{Decay Correction Factor, $D_{\text {. }}$}

The decay correction factor, $D_{e}$, corrects for the loss of iodine-131 in the interval between sample collection and counting. Because most raw count data in notebooks included information on the length of this time interval, a decay correction can be made. The uncertainty in this correction is based on a lack of knowledge about the time of day the sample collection and counting occurred (see Gilbert et al. 1992).

No decay correction is required for activities reported after June 1946 because this is when decay corrections started being routinely made.

The time of deposition to time of counting is not reflected in $D_{e}$. However, the interval between deposition and counting is an issue in interpreting and using the historical vegetation data. It is not an issue in the determination of $D_{c}$.

\subsubsection{Iodine-131 Assumption Correction Factor, $I_{c f}$}

The iodine-131 assumption correction factor, $I_{\mathrm{cf}}$, corrects for the bias that occurred in historical measurements from assuming that all of the registered counts reflected iodine-131 decay. $I_{\mathrm{cf}}$ is based on an estimation of the ratio of iodine-131 activity to total activity as a 
function of fuel-cooling time. The values in this report are based on limited historical information averaged together with the computer modeling data.

As discussed in Section 6.0, the application of $\mathrm{I}_{\mathrm{cf}}$ requires an analysis of a number of variables that determine which fuel campaigns resulted in deposition on the given sample and the decay time. The value of $I_{c f}$ to use for any given pellet depends on the probable fuelcooling time for the campaign(s) that resulted in the deposition at that particular sampling location and on the time interval between deposition and sample collection.

\subsection{Conclusions}

Gilbert et al. (1992) provide a corollary analysis of the uncertainty in the total conversion factors. Gilbert evaluates each parameter and develops a possible range of values and a best. estimate of the true value for a given parameter based on the range. The results given in this report should be interpreted with an understanding of the uncertainty as provided in Gilbert's corollary report.

While these results are necessarily estimates, they provide a basis for estimating the overall uncertainty in the available vegetation data for the 1945-1947 period. Because the uncertainty in the total conversion factors (Gilbert et al. 1992) relative to the uncertainty in the models and model parameters being developed to predict radiation doses is small, further refinement of these vegetation estimates is not deemed appropriate nor planned for the balance of this project. 


\subsection{References}

Aten, A. H. W., Jr. 1950. "Corrections for Beta Particle Self Absorption." Nucleonics, 6(1):68-74.

Baker, R. G., and L. Katz. 1953. "Absolute Beta Counting of Thick Planar Samples." Nucleonics, 11(2):14-19.

Baltakmens, T. 1977. "Accuracy of Absorption Methods in the Identification of Beta Emitters." Nuclear Instruments and Methods, 142(3):535-538.

Bayhurst, B. P., and R. J. Prestwood. 1959. "A Method for Estimating Beta-Counting Efficiencies." Nucleonics, 17(3):82-85.

Bulow, W. F. 1945. Vegetation (Sage) Samples and Analysis for 7/1/45 Through 12/21/45, and Water Samples and Analysis for 4/23/45 Through 12/24/45 for the Columbia-River, Hanford Site and Tri-Cities, HEW-6660-T, E. I. Du Pont de Nemours and Company, Hanford Engineer Works, Richland, Washington.

Bulow, W. F. 1946. H.I. Survey, Counter Record-Miscellaneous: Period Covering 12-12-45 thru 8-28-46. HEW-584-L, E. I. Du Pont de Nemours and Company, Hanford Engineer Works, Richland, Washington.

Burger, L. L. 1991. Fission Product Iodine During Early Hanford-Site Operations: Its Production and Behavior During Fuel Processing, Off-Gas Treatment and Release to the Atmosphere. PNL-7210 HEDR, Pacific Northwest Laboratory, Richland, Washington.

Burtt, B. P. 1949. "Absolute Beta Counting." Nucleonics, 5(2):28-43.

Cantril, S. T. , and J. W. Healy. 1945. Iodine Metabolism with Reference to $I^{13 I}$. HW-7-2604, E. I. Du Pont de Nemours and Company, Hanford Engineer Works, Richland, Washington.

Croff, A. G. 1980. ORIGEN2-A Revised and Updated Version of the Oak Ridge Isotope Generation and Depletion Code. ORNL-5621, Oak Ridge National Laboratory, Oak Ridge, Tennessee. 
Denham, D. H., E. I. Mart, and R. K. Woodruff. 1988. Notes from Key Former Hanford Employees Workshop on Vegetation Data Biases and Uncertainties 1944 to 1948, September 19-21, 1988. PNL-SA-16497, Pacific Northwest Laboratory, Richland, Washington.

Dickinson, P. 1946. Site Survey - Water, Vegetation, and Special Samples, Period Covering 1-20-46 thru 8-29-46. HEW-616-T, E. I. Du Pont de Nemours and Company, Hanford Engineer Works, Richland, Washington.

E. I. Du Pont de Nemours and Company. 1946. Operation of Hanford Engineer Works Book 7: Medical Department, Health Instrument. HAN-73214-BK7-Del, Hanford Engineer Works, Richland, Washington.

Fix, J. J. 1975. Environmental Surveillance at Hanford for CY-1974. BNWL-1910, Battelle Pacific Northwest Laboratories, Richland, Washington.

Friedlander, G., J. W. Kennedy, E. S. Macias, and J. M. Miller. 1981. Nuclear and Radiochemistry, 3rd Edition. John Wiley and Sons, New York.

Gilbert, R. O., E. I. Mart, D. L. Strenge, and T. B. Miley. 1992. Uncertainty and Sensitivity Analysis of Historical Measurements of Iodine-131 for Vegetation in 1945 - 1947. PNWD-1978 HEDR, Battelle Pacific Northwest Laboratories, Richland, Washington.

Gleason, G. E., J. D. Taylor, and D. L. Tabern. 1951. "Absolute Beta Counting at Defined Geometries." Nucleonics, 8(5):12-21.

Greager, O. H., and W. K. MacReady. 1948. Stack Gas Decontamination - Separations Plants, HW-8667, General Electric Company, Hanford Works, Richland, Washington.

Healy, J. W. 1945. "B" II - Special Samples 7-25-45 through 12-10-45. HEW-494-L, E. I. Du Pont de Nemours and Company, Hanford Engineer Works, Richland, Washington.

Healy, J. W. 1948a. H. I. Environs Report for Month of June, 1948. HW-10427, General Electric Company, Hanford Works, Richland, Washington.

Healy, J. W. 1948b. Long-Lived Fission Activities in the Stack Gases and Vegetation at the Hanford Works. HW-10758, General Electric Company, Hanford Works, Richland, Washington.

Healy, J. W. 1950. H. I. Methods Development and History. HW-89078, General Electric Company, Hanford Works, Richland, Washington. 
Healy, J. W., and P. L. Eisenacher. 1946. H. I. Section Special Studies Reports - January thru August, 1946. HW-3-33 , E. I. Du Pont de Nemours and Company, Hanford Engineer Works, Richland, Washington.

Healy, J. W., and L. D. Pahnke. 1946. Vegetation Analysis for $I^{131}$. HW-3-3598, E. I. Du Pont de Nemours and Company, Hanford Engineer Works, Richland, Washington.

Healy, J. W., L. C. Schwendiman, and R. C. Thorburn. 1950. Counter Calibrations in the Health Instrument Methods Group. HW-18258, General Electric Company, Hanford Works, Richland, Washington.

Healy, J. W., R. C. Thorburn, and Z. E. Carey. 1951. H. I. Control Laboratory Routine Chemical Procedures. HW-20136, General Electric Company, Hanford Works, Richland, Washington.

Healy, J. W., and L. D. Turner. 1946. Vegetation Contamination for the First Quarter of 1946. HW-3-3495, E. I. Du Pont de Nemours and Company, Hanford Engineer Works, Richland, Washington.

Heeb, C. M. 1992. Iodine-131 Releases from the Hanford Site, 1944 through 1947, Volume 1 - Text, Volume 2-Data. PNWD-2033 HEDR, Battelle Pacific Northwest Laboratories, Richland, Washington.

'Herde, K. E. 1946. Technical Notebook (H. I. Dept.) Period Covering 12-6-45 thru 8-29-46. HEW-594-T, E. I. Du Pont de Nemours and Company, Hanford Engineer Works, Richland, Washington.

ICRP International Commission on Radiological Protection. 1983. Radionuclide Transformations: Energy and Intensity of Emissions. ICRP Publication 38, Vols. 11-13, Pergamon Press, New York.

Kalmon, B. 1953. "Experimental Method for Determination of Counting Geometry." Nucleonics, 11(7):56-59.

Knoll, G. F. 1979. Radiation Detection and Measurement. John Wiley and Sons, New York.

Leboeuf, M. B. 1950. Analysis of Vegetation for $I^{131}$. HW-15743, General Electric Company, Hanford Works, Richland, Washington. 
Lindvig, P. E. 1946a. H. I. Survey - for period covering 10-6-45 thru 8-26-46. HEW-423L, E. I. Du Pont de Nemours and Company, Hanford Engineer Works, Richland, Washington.

Lindvig, P. E. 1946b. H.I. Site Survey Data - 200 Areas: Period Covering 4-2-44 thru 8-2246. HEW-389-L, E. I. Du Pont de Nemours and Company, Hanford Engineer Works, Richland, Washington.

Mickelson, M. L. 1947. Preliminary Report on Existing Active Particle Hazard - 100 Area. HW-7865, General Electric Company, Hanford Works, Richland, Washington.

Mickelson, M. L. 1954. Annual Report of the Radiological Sciences Department 1953. HW-30464, General Electric Company, Hanford Atomic Products Operation, Richland, Washington.

Napier, B. A. 1991. Selection of Dominant Radionuclides for Phase I of the Hanford Environmental Dose Reconstruction Project. PNL-7231, Pacific Northwest Laboratory, Richland, Washington.

Napier, B. A. 1992. Determination of Radionuclides and Pathways Contributing to Cumulative Dose. BN-SA-3673 HEDR, Battelle Pacific Northwest Laboratories, Richland, Washington.

Nees, W. L., and J. P. Corley. 1974. Environmental Surveillance at Hanford for CY-1973. BNWL-1811, Battelle Pacific Northwest Laboratories, Richland, Washington.

Nervik, W. E., and P. C. Stevenson. 1952. "Self-Scattering and Self-Absorption of Betas by Moderately Thick Samples." Nucleonics, 10(3):18-22.

Norton, H. T., P. O. Jackson, and D. L. Reid. 1956. Standard Practices Radiochemical Calculation Manual. HW-46436, General Electric Company, Hanford Atomic Products Operation, Richland, Washington.

Overbeck, W. P. 1944. Instruments in 3706 Counting Room. HW-3-962, E. I. Du Pont de Nemours and Company, Hanford Engineer Works, Richland, Washington.

Paas, H. J. 1949. Regional Survey Monthlies 1949. HW-89075, General Electric Company, Hanford Works, Richland, Washington. 
Paas, H. J., and W. Singlevich. 1951. Radioactive Contamination in the Environs of the Hanford Works for the Period July, August, September 1950. HW-20700, General Electric Company, Hanford Works, Richland, Washington.

Parker, H. M. 1948. Review of the Stack Discharge Active Particle Contamination Problem. HW-9259, General Electric Company, Hanford Works, Richland, Washington.

Parker, H. M. 1950. Quarterly Progress Report Research and Development Activities for October-December, 1949. HW-15787, General Electric Company, Hanford Works, Richland, Washington.

Parker, H. M. 1951. Quarterly Progress Report Research and Development Activities for January-March, 1951. HW-20866, General Electric Company, Hanford Works, Richland, Washington.

Parker, H. M. 1952. Radiological Sciences Department Quarterly Progress Report Research and Development Activities for October-December 1951. HW-23332, General Electric Company, Hanford Works, Richland, Washington.

Parker, H. M., and C. C. Gamertsfelder. 1945. Weekly H. I. Reports on 200 Area and Environs for 1-5-45 thru 2-13-46. HW-7-1115, E. I. Du Pont de Nemours and Company, Hanford Engineer Works, Richland, Washington.

Patterson, C. M. 1946. Medical Department Health Instrument Section, Manual of Standard Procedures, Site Survey (Special Studies). HW-7-4279, E. I. Du Pont de Nemours and Company, Hanford Engineer Works, Richland, Washington.

Rees, L. C. 1947. Particle Distribution 200-East. HW-8430, General Electric Company, Hanford Works, Richland, Washington.

Schwendiman, L. C. 1954. Standard Practices Counting Manual. HW-30492, General Electric Company, Hanford Atomic Products Operation, Richland, Washington.

Seliger, H. H., and A. Schwebel. 1954. "Standardization of Beta-Emitting Nuclides." Nucleonics, 12(7):54-63.

Shipler, D.B. 1992. Integrated Task Plans for the Hanford Environmental Dose Reconstruction Project, FY 1992 through May 1994. PNWD-2020 HEDR, Battelle, Pacific Northwest Laboratories, Richland, Washington. 
Shleien, B., and M. S. Terpilak. 1984. The Health Physics and Radiological Health Handbook. Nucleon Lectern Associates, Olney, Maryland.

Singlevich, W. 1948a. H. I. "Environs" Report for Month of August 1948. HW-10998, General Electric Company, Hanford Works, Richland, Washington.

Singlevich, W. 1948b. H. I. "Environs" Report for Month of November, 1948. HW-11833, General Electric Company, Hanford Works, Richland, Washington.

South, D. I. 1949. H. I. Technical Notebook 2-7-49 thru 3-5-51. HEW-2867-T, General Electric Company, Hanford Works, Richland, Washington.

Thomas, C. W., D. M. Polinsky, and L. C. Schwendiman. 1956. A Tabulation of the Isotopic Counting Correction Factors and Decay Schemes. HW-18258-APP, General Electric Company, Hanford Atomic Products Operation, Richland, Washington.

Turner, L. D. 1946. Vegetation Contamination for Period July 2, 1946 to August 31, 1946. HW-3-5055, General Electric Company, Hanford Works, Richland, Washington.

Wolff, J. H. 1951. Calcuiation Constants Used by Regional Survey. HW-22682, General Electric Company, Hanford Works, Richland, Washington.

Yankwich, P. E., T. H. Norris, and J. Huston. 1947. "Correcting for the Absorption of Weak Beta-Particles in Thick Samples." Analytical Chemistry, 19(7):439-441.

Zuerner, L. V. 1947. Particle Distribution 200-West. HW-8429, General Electric Company, Hanford Works, Richland, Washington. 
Appendix A

Historical Techniques of Determining Parameters in $\mathbf{M}$ 


\section{Appendix A}

\section{Historical Techniques of Determining Parameters in M}

This appendix describes the methods used in the 1940s and 1950s to derive parameters to calibrate mica-window GM counters to enable absolute beta counting.

\section{A.1 Historical Techniques of Determining $\mathbf{F}_{\mathrm{sa}}$}

\section{A.1.1 Technique Used from February 1946 through November 1948}

In 1945, the Health Instruments Group recognized the limitations of their method of counting iodine-131 activity on vegetation. They realized that the measurements were not a determination of absolute beta levels in vegetation but were relative. They attributed the relative nature of counting mainly to absorption of beta particles in the vegetation that had not been accounted for. Nevertheless, they felt that the relative values were good (Healy and Pahnke 1946). To reduce the amount of self-absorption, attempts were made in 1945 and early 1946 to develop chemical methods for extracting iodine-131 from vegetation (Healy and Eisenacher 1946; Healy and Pahnke 1946; Lindvig 1946a; Parker and Gamertsfelder 1945). These initial efforts failed, and no viable method of separating iodine-131 was achieved until 1948 (Singlevich 1948a). In the absence of such a method, it was decided that the most appropriate procedure would be to continue counting 1-gram pellets but to determine an additional parameter that would compensate for self-absorption. A factor of 3 (corresponding to an $F_{s}$ parameter of 0.33 ) was determined early in 1946 and applied to all results starting in February 1946 (Parker and Gamertsfelder 1945).

Although the literature surveyed does not provide an experimental method, Healy has surmised that the 1946 self-absorption parameter was probably determined by first counting an aliquot of iodine-131 solution on a planchet, then dropping an equivalent aliquot evenly onto the standard vegetation sample and counting again (Denham et al. 1988). The ratio between the two measurements was the self-absorption parameter. Self-absorption measurements were done five times each for four types of vegetation (sagebrush, seeds, twigs, and straw grass). Of these four types of vegetation, only sagebrush and straw grass were routinely collected (Bulow 1945; Dickinson 1946). Seeds and twigs were not typically counted. For sagebrush the average self-absorption parameter was 3 (Healy and Eisenacher 1946). Table A.1 lists the averages for the five determinations on the four vegetation types. 
Table A.1. Historical Averages for Self-Absorption in Vegetation (Healy and Eisenacher 1946)

\begin{tabular}{|l|c|c|}
\hline $\begin{array}{c}\text { Vegetation } \\
\text { Type }\end{array}$ & $\begin{array}{c}\text { Average Empirical } \\
\text { Parameter }\end{array}$ & $\begin{array}{c}\text { Inverse Parameter } \\
\left(\mathrm{F}_{\mathrm{s}}\right)\end{array}$ \\
\hline Sagebrush & 3.0 & 0.33 \\
Seeds & 2.5 & 0.40 \\
Twigs & 3.4 & 0.29 \\
Straw Grass & 2.4 & 0.42 \\
\hline
\end{tabular}

Interpretation of the results is limited because the exact experimental method is not known. Thus, these values cannot be used to reconstruct $F_{a \mathrm{a}}$ as described in Section 4.2. For example, if the initial iodine-131 aliquot dropped onto the pellet approximated a point source, the empirical determination could also have compensaied for sample spread. If the initial aliquot spread to approximate a pellet diameter, the result would not have compensated for that effect. In addition, the empirical determination could have accounted for any self-scatter and backscatter in the vegetation depending on how the aliquot was distributed. Another consideration is that if the initial aliquot was placed on stainless steel, the initial count would have been elevated because of the high level of backscatter expected from stainless steel.

\section{A.1.2 Technique Used in the 1950s}

In the 1950s, precise determinations were made of the self-absorption parameter for the types of analyses being done. At that time, counts of vegetation pellets had been replaced by counts of a chemical extraction of iodine- 131 from the vegetation. The self-absorption measurements were, therefore, made for the type of carrier/residue obtained from the extraction process. The values for the self-absorption parameters, $F_{s a}$, generated from the $1950 \mathrm{~s}$ studies are approximated by Equation (4.2) for silver iodide.

Schwendiman (1954) has detailed how the self-absorption parameter was determined for silver-iodide precipitates. A known volume of iodine-131 was associated with set quantities of silver-iodide precipitates. The silver iodide was precipitated according to the standard procedure and transferred in varying quantities to a standard mount. After drying, the plates were re-weighed and counted. Knowing the weight of precipitate made it possible to calculate the apparent specific activity $(\mathrm{cpm} / \mathrm{mg})$. This value was then divided by the actual specific activity to obtain the self-aosorption/self-scatter parameter. From these data, curves of $F_{s a}$ versus mass thickness $\left(\mathrm{mg} / \mathrm{cm}^{2}\right)$ were generated. 


\section{A.2 Historical Techniques of Determining $\mathbf{F}_{\mathrm{bs}}$}

In 1950, backscatter parameters were obtained by preparing sources of several isotopes of interest on Formvar film, the mass thickness of which was 0.3 to $0.5 \mathrm{mg} / \mathrm{cm}^{2}$ (Healy et al. 1950). The film was supported on an open aluminum ring to aid in accurate positioning of the backing plates. An aliquot of carrier-free isotope was evaporated on the film. After drying, the source was counted on a holder which ensured that the ring position was reproducible. Backing material was then put into position just under the film and a second count was taken. The ratio of the second count to the first was the backscatter parameter. Because the backscatter parameter was expected to vary by 3 percent for a single type of measurement, several sources were prepared so that an average could be obtained (Schwendiman 1954).

A second method of determining the backscatter parameter was also mentioned by Schwendiman (1954). In this method, which was used less commonly, the counting rate of an aliquot evaporated directly on the backing material was then compared with the counting rate of an identical aliquot dried on the thin Formvar film. Backscatter parameters determined by this less common method were about the same as those determined by the first method.

From a figure in Thomas et al. (1956, p. 9) for a maximum beta energy of $\sim 0.6 \mathrm{MeV}$, the backscatter parameter for shelf 1 is about 1.10 for $\mathrm{H}-70$ filter paper.

\section{A.3 Historical Technique of Determining $F_{a}$}

Historically, absorption parameters were determined using Equation (4.3). The 1950s calibration research involved determining individual beta absorption coefficients for the isotopes being analyzed. Beta absorption coefficients for iodine-131 were determined in 1950, 1954, and 1956 and differed only slightly. Healy et al. (1950) and Schwendiman (1954) reported their methods for determining the iodine-131 beta absorption coefficient. No technique was reported by Thomas et al. (1956).

Beta absorption coefficients were determined by placing various mass thicknesses in $\mathrm{mg} / \mathrm{cm}^{2}$ of aluminum between the source and the mica-window GM counter (Healy et al. 1950; Schwendiman 1954). For thin absorbers, the relationship between absorption and counting rate followed an exponential curve. Thus, plotting the counting rate versus mass thickness on semi-logarithmic paper resulted in a straight line. The slope of this line was defined as the beta-absorption coefficient for the radionuclide being measured. However, the slope of the line was dependent on the relative geometries of the source, detector, and absorber, meaning the measurement technique could affect the beta-absorption coefficient. If the absorber were placed directly on the source, the counting rate would have been higher because of backscatter from parts of the absorber outside the solid angle. This effect was 
noted in both the 1950 and the 1954 reports. To counteract this problem, the 1950 and 1954 determinations were made with the absorber as close as possible to the detector rather than the source.

In addition to the relative geometries, inert material associated with the source could also affect the beta-absorption coefficient (Schwendiman 1954). Schwendiman (1954) observed that when inert material was associated with the source, the beta absorption coefficient was higher. It was, therefore, critical that sources contain as little residue as possible and preferably none.

\section{A.4 Historical Technique of Determining $\mathbf{F}_{\text {cel }}$}

Schwendiman (1954) observed that counting rate increased when the cellophane covering used to block the weak $\mathrm{RaD}$ (lead- 210) beta and $\mathrm{RaF}$ (polonium-210) alpha particles was placed directly above the RaDEF standard as opposed to just below the window. He measured the ratio of counts per minute with cellophane at $0.0,0.06,0.12$, and 0.18 inches from the source relative to counts per minute with the cellophane at the window. These measurements were made for all five shelves. Schwendiman (1954) concluded that the counting rate increased because beta particles that had initially been moving at angles far outside the geometry cone between the source and counter window were deflected by the cellophane. The measurements made by Schwendiman (1954) are relevant to the present analysis because historically cellophane was placed directly on top of vegetation pellets to aid in securing them.

\section{A.5 Historical Technique of Determining $G_{p}$}

Schwendiman (1954) has described in detail how $G_{p}$ was determined for shelves 1 through 5. Both RaDEF and iodine-131 standards were used, and all the other parameters that affected counting rate were factored out. The USBS RaDEF standards have been cited as having an accuracy of \pm 5 percent. However, by 1954 , the activity of all standards was always verified at Hanford by using 4- $\pi$ counting techniques. Four- $\pi$ counting techniques were much more accurate because the standard was placed inside the du.ector's sensitive volume and, therefore, no losses would have occurred as a result of geometry or absorption outside of the sample itself. Nonetheless, the 4- $\pi$ counting techniques should have provided an accurate determination of activity.

In addition, iodine-131 standards were used to determine the iodine-131 mass absorption coefficient (used in $F_{2}$ ) and to empirically determine $F_{s a}$. In the present analysis, both of these parameters are based on equations using a value for the iodine-131 beta absorption coefficient determined in 1977 (Baltakmens 1977). 
Historically, $G_{p}$ was calculated using the equation (Schwendiman 1954)

$$
G_{p}=c p m /\left(d p m \times F_{b s} \times F_{d} \times F_{d} \times F_{s a} \times F_{c e l} \times F_{\text {decay }}\right)
$$

where dpm refers to the disintegration rate for the RaE standard (bismuth -210), not iodine-131. The historical parameters $F_{b s}, F_{d}, F_{a}, F_{c e l}$, and $F_{s a}$ are discussed in Section 4.0 of this report. Historically, $\mathrm{F}_{\mathrm{sa}}$ included a factor of 1.05 to account for scattering from the lead oxide carrier in the USBS RaDEF sources. The $F_{\text {decay }}$ factor was the decay correction for the 22.2-year half-life of $\operatorname{RaD}$ (lead-210). The beta particles emitted by $\operatorname{RaD}$ (lead-210) were too low in energy to penetrate the cellophane covering, and RaF (polonium-210) emitted only an alpha particle which could not penetrate the cellophane, air, and mica window. The error in $F_{\text {decay }}$ was $<1$ percent if the original activity was decay-corrected every 3 months. All of the parameters in Equation (A.1) had been determined empirically. The result was the $G_{p}$ for a given shelf (Healy et al. 1950).

The average $G_{p}$ calculated for shelf 1 for all mica-window beta counters was 0.22 with a standard deviation of 0.01. Schwendiman (1954) found that the error introduced by assuming this average for all beta counters was less than the error arising from other sources and, therefore, felt it was justifiable to use these average $G_{p}$ values for every mica-window GM detector in the counting laboratory.

\section{A.6 Historical Technique of Determining $F_{d}$}

An empirical method of determining $F_{d}$ was reported by Healy et al. (1950). Schwendiman (1954) and Thomas et al. (1956) also used this same method. In 1950 and 1954 (Healy et al. 1950; Schwendiman 1954), $F_{d}$ was determined empirically by first measuring the counting rate of a point source at various distances along a radius perpendicular to the axis of the detector. This measurement was repeated at each shelf distance. The relative counting rates (counts per minute at the radial distance to counts per minute at the origin where radial distance refers to the distance from the center to the circumference of the ring) were then integrated graphically after the counting rates at the radial distances had been adjusted to the area represented by an annular ring at that radius. Then $F_{d}$ was the ratio of the graphically integrated counting rate of a uniform circular source of a given diameter (equalling two times the radial distance) to the counting rate of a point source of the same activity centered directly under the detector.

Healy et al. (1950) presented a figure with the vertical axis as relative counting rate (the ratio of the rate at a given distance to the rate at the center) using the RaDEF source and the horizontal axis as distance from the center in inches. The curve included both the measured points (the relative counting rate at radial distance versus distance) and values calculated using an equation that considered the difference in solid angles between a point source centered directly under the detector and a point source located at given radial distances (given the shelf 
distances and diameter of the beta detector). They found excellent agreement for the RaDEF source between the empirical results and the values derived using their equation.

Kalmon (1953) confirmed the $F_{d}$ data reported by Schwendiman (1954) for flat circular sources with maximum beta energies that were $>0.3 \mathrm{MeV}$. Schwendiman's data include $F_{d}$ values for diameters at increments of $1.27 \mathrm{~cm}(0.5 \mathrm{in}),. 2.54 \mathrm{~cm}(1.0 \mathrm{in}),. 3.81 \mathrm{~cm}(1.5 \mathrm{in}$.$) ,$ and $5.08 \mathrm{~cm} \mathrm{(2.0} \mathrm{in.)} \mathrm{for} \mathrm{shelves} 1$ to 5 . In addition, Schwendiman (1954) compared the 1950 method (called the point source traverse method) with a method in which sources were carefully prepared to be uniformly spread. The source used was ruthenium-rhodium-106, and these two methods also compared favorably. 
Appendix B

\section{Reconstructed Pellet Data and Results for M}




\section{Appendix B}

\section{Reconstructed Pellet Data and Results for M}

This appendix contains tables of the dimensions of reconstructed hand-formed and pressformed sagebrush pellets and the values for parameters in $\mathbf{M}$ calculated for these pellets.

Table B.1. Dimensions for 1-Gram Hand-Formed Pellets

\begin{tabular}{|c|c|c|c|c|c|}
\hline \multirow[b]{2}{*}{ Pellet } & \multicolumn{5}{|c|}{ Surface } \\
\hline & $\begin{array}{c}\text { Date } \\
\text { Collected } \\
\end{array}$ & $\begin{array}{l}\text { Thickness } \\
\text { (cm) }\end{array}$ & $\begin{array}{l}\text { Diameter } \\
(\mathrm{cm})\end{array}$ & $\begin{array}{l}\text { Area } \\
\left(\mathrm{cm}^{2}\right)\end{array}$ & $\begin{array}{r}\text { Density } \\
\left(\mathrm{mg} / \mathrm{cm}^{3}\right)\end{array}$ \\
\hline $1-\mathrm{H}$ & $9 / 11 / 89$ & 0.64 & $\begin{array}{l}4.06 \\
4.37 \\
3.86 \\
3.96\end{array}$ & 13.0 & 121 \\
\hline $2-\mathrm{H}$ & $9 / 11 / 89$ & 0.66 & $\begin{array}{l}4.22 \\
4.01 \\
3.76 \\
3.86\end{array}$ & 12.3 & 123 \\
\hline $3-\mathrm{H}$ & $9 / 11 / 89$ & 0.51 & $\begin{array}{l}3.91 \\
3.81 \\
5.18 \\
3.56\end{array}$ & 13.3 & 148 \\
\hline $4-\mathrm{H}$ & $9 / 11 / 89$ & 0.64 & $\begin{array}{l}3.96 \\
3.35 \\
4.06 \\
3.66\end{array}$ & 11.1 & 142 \\
\hline $5-\mathrm{H}$ & $9 / 11 / 89$ & 0.61 & $\begin{array}{l}4.67 \\
4.98 \\
4.37 \\
4.57\end{array}$ & 17.0 & 97 \\
\hline 6-H & $9 / 11 / 89$ & 0.66 & $\begin{array}{l}4.52 \\
3.45 \\
4.83 \\
4.52\end{array}$ & 14.7 & 103 \\
\hline $7-\mathrm{H}$ & $9 / 11 / 89$ & 0.64 & $\begin{array}{l}4.01 \\
4.52 \\
4.01 \\
3.61\end{array}$ & 12.8 & 123 \\
\hline
\end{tabular}

B. 1 
Table B.1. (contd)

\begin{tabular}{|c|c|c|c|c|c|}
\hline \multirow[b]{2}{*}{ Pellet } & \multicolumn{5}{|c|}{ Surface } \\
\hline & $\begin{array}{c}\text { Date } \\
\text { Collected }\end{array}$ & $\begin{array}{l}\text { Thickness } \\
(\mathrm{cm})\end{array}$ & $\begin{array}{l}\text { Diameter } \\
(\mathrm{cm})\end{array}$ & $\begin{array}{l}\text { Area'(a) } \\
\left(\mathrm{cm}^{2}\right)\end{array}$ & $\begin{array}{c}\text { Density } \\
\left(\mathrm{mg} / \mathrm{cm}^{3}\right)\end{array}$ \\
\hline $8-\mathrm{H}$ & $9 / 11 / 89$ & 0.61 & $\begin{array}{l}4.11 \\
4.22 \\
3.81 \\
5.08\end{array}$ & 14.6 & 113 \\
\hline 9-H & 9/11/89 & 0.64 & $\begin{array}{l}3.86 \\
3.20 \\
3.76 \\
4.67\end{array}$ & 11.8 & 134 \\
\hline $10-\mathrm{H}$ & $9 / 11 / 89$ & 0.58 & $\begin{array}{l}3.66 \\
4.42 \\
4.62 \\
4.27\end{array}$ & 14.1 & 121 \\
\hline $11-\mathrm{H}$ & $10 / 16 / 89$ & 0.58 & $\begin{array}{l}3.56 \\
4.06 \\
4.06 \\
4.32\end{array}$ & 12.6 & 137 \\
\hline $12-\mathrm{H}$ & $10 / 16 / 89$ & 0.62 & $\begin{array}{l}3.30 \\
4.32 \\
4.57 \\
3.05\end{array}$ & 11.4 & 142 \\
\hline $13-\mathrm{H}$ & $10 / 16 / 89$ & 0.67 & $\begin{array}{l}3.81 \\
4.06 \\
3.30 \\
4.06\end{array}$ & 11.4 & 132 \\
\hline $14-\mathrm{H}$ & $10 / 16 / 89$ & & $\begin{array}{l}4.06 \\
4.06 \\
3.81 \\
4.57\end{array}$ & 13.4 & 110 \\
\hline $15-\mathrm{H}$ & $10 / 16 / 89$ & 0.63 & $\begin{array}{l}4.06 \\
3.56 \\
4.06 \\
4.06\end{array}$ & 12.2 & 130 \\
\hline $16-\mathrm{H}$ & $11 / 30 / 89$ & 0.51 & $\begin{array}{l}3.30 \\
3.56 \\
4.32 \\
4.57\end{array}$ & 12.2 & 162 \\
\hline
\end{tabular}

B. 2 
Table B.1. (contd)

\begin{tabular}{|c|c|c|c|c|c|}
\hline \multirow[b]{2}{*}{ Pellet } & \multicolumn{5}{|c|}{ Surface } \\
\hline & $\begin{array}{c}\text { Date } \\
\text { Collected }\end{array}$ & $\begin{array}{l}\text { Thickness } \\
\text { (cm) }\end{array}$ & $\begin{array}{l}\text { Diameter } \\
(\mathrm{cm})\end{array}$ & $\begin{array}{l}\text { Area }{ }^{(a)} \\
\left(\mathrm{cm}^{2}\right)\end{array}$ & $\begin{array}{c}\text { Density } \\
\left(\mathrm{mg} / \mathrm{cm}^{3}\right)\end{array}$ \\
\hline $17-\mathrm{H}$ & $11 / 30 / 89$ & 0.56 & $\begin{array}{l}4.06 \\
5.33 \\
5.08 \\
5.59\end{array}$ & 19.8 & 91 \\
\hline 18-H & $11 / 30 / 89$ & 0.51 & $\begin{array}{l}4.06 \\
4.57 \\
4.06 \\
4.57\end{array}$ & 14.6 & 134 \\
\hline $19-\mathrm{H}$ & $11 / 30 / 89$ & 0.46 & $\begin{array}{l}4.57 \\
5.08 \\
3.81 \\
4.83\end{array}$ & 16.4 & 133 \\
\hline $20-\mathrm{H}$ & $11 / 30 / 89$ & 0.51 & $\begin{array}{l}3.81 \\
4.83 \\
4.57 \\
4.06\end{array}$ & 14.6 & 134 \\
\hline 21-H & $12 / 28 / 89$ & 0.33 & $\begin{array}{l}6.05 \\
4.14 \\
3.66 \\
5.08\end{array}$ & 17.6 & 172 \\
\hline $22-\mathrm{H}$ & $12 / 28 / 89$ & 0.41 & $\begin{array}{l}4.14 \\
4.45 \\
4.14 \\
4.45\end{array}$ & 14.5 & 170 \\
\hline $23-\mathrm{H}$ & $12 / 28 / 89$ & 0.56 & $\begin{array}{l}4.45 \\
4.78 \\
4.78 \\
4.14\end{array}$ & 16.1 & 111 \\
\hline $24-H$ & $12 / 28 / 89$ & 0.48 & $\begin{array}{l}3.66 \\
4.78 \\
5.08 \\
4.45\end{array}$ & 15.8 & 131 \\
\hline $25-\mathrm{H}$ & $12 / 28 / 89$ & 0.48 & $\begin{array}{l}4.14 \\
4.93 \\
5.41 \\
4.45\end{array}$ & 17.6 & 118 \\
\hline
\end{tabular}


Table B.1. (contd)

\begin{tabular}{|c|c|c|c|c|c|}
\hline \multirow[b]{2}{*}{ Pellet } & \multicolumn{5}{|c|}{ Surface } \\
\hline & $\begin{array}{c}\text { Date } \\
\text { Collected }\end{array}$ & $\begin{array}{l}\text { Thickness } \\
\text { (cm) }\end{array}$ & $\begin{array}{c}\text { Diameter } \\
(\mathrm{cm})\end{array}$ & $\begin{array}{l}\text { Area } \\
\left(\mathrm{cm}^{2}\right)\end{array}$ & $\begin{array}{c}\text { Density } \\
\left(\mathrm{mg} / \mathrm{cm}^{3}\right)\end{array}$ \\
\hline $26-\mathrm{H}$ & $1 / 24 / 90$ & 0.61 & $\begin{array}{l}3.81 \\
3.30 \\
3.81 \\
4.06\end{array}$ & 11.0 & 149 \\
\hline $27-\mathrm{H}$ & $1 / 24 / 90$ & 0.61 & $\begin{array}{l}3.81 \\
4.32 \\
3.81 \\
3.81\end{array}$ & 12.2 & 135 \\
\hline $28-\mathrm{H}$ & $1 / 24 / 90$ & 0.58 & $\begin{array}{l}3.56 \\
4.32 \\
3.56 \\
3.81\end{array}$ & 11.4 & 150 \\
\hline $29-\mathrm{H}$ & $1 / 24 / 90$ & 0.58 & $\begin{array}{l}3.81 \\
3.56 \\
3.81 \\
3.56\end{array}$ & 10.7 & 161 \\
\hline $30-\mathrm{H}$ & $1 / 24 / 90$ & 0.56 & $\begin{array}{l}3.30 \\
4.32 \\
4.32 \\
3.30\end{array}$ & 11.4 & 157 \\
\hline $31-\mathrm{H}$ & $2 / 26 / 90$ & 0.64 & $\begin{array}{l}3.81 \\
4.57 \\
3.81 \\
4.06\end{array}$ & 13.0 & 121 \\
\hline $32-\mathrm{H}$ & $2 / 26 / 90$ & 0.66 & $\begin{array}{l}4.83 \\
4.32 \\
3.81 \\
3.81\end{array}$ & 13.8 & 110 \\
\hline $33-\mathrm{HI}$ & $2 / 26 / 90$ & 0.61 & $\begin{array}{l}4.06 \\
4.32 \\
3.56 \\
4.32\end{array}$ & 15.1 & 126 \\
\hline $34-\mathrm{H}$ & $2 / 26 / 90$ & 0.71 & $\begin{array}{l}4.32 \\
4.06 \\
4.06 \\
5.08\end{array}$ & 15.1 & 93 \\
\hline
\end{tabular}

B. 4 
Table B.1. (contd)

\begin{tabular}{|c|c|c|c|c|c|}
\hline \multirow[b]{2}{*}{ Pellet } & \multicolumn{5}{|c|}{ Surface } \\
\hline & $\begin{array}{c}\text { Date } \\
\text { Collected }\end{array}$ & $\begin{array}{c}\text { Thickness } \\
\text { (cm) }\end{array}$ & $\begin{array}{c}\text { Diameter } \\
(\mathrm{cm})\end{array}$ & $\begin{array}{l}\text { Area } \\
\left(\mathrm{cm}^{2}\right)\end{array}$ & $\begin{array}{r}\text { Density } \\
\left(\mathrm{mg} / \mathrm{cm}^{3}\right) \\
\end{array}$ \\
\hline $35-\mathrm{H}$ & $2 / 26 / 90$ & 0.56 & $\begin{array}{l}3.81 \\
4.57 \\
4.06 \\
4.83\end{array}$ & 14.6 & 122 \\
\hline $36-\mathrm{H}$ & $4 / 12 / 90$ & 0.48 & $\begin{array}{l}4.57 \\
3.56 \\
4.32 \\
4.83\end{array}$ & 14.6 & 142 \\
\hline $37-\mathrm{H}$ & $4 / 12 / 90$ & 0.56 & $\begin{array}{l}4.06 \\
5.33 \\
4.32 \\
4.32\end{array}$ & 16.0 & 112 \\
\hline $38-\mathrm{H}$ & $4 / 12 / 90$ & 0.66 & $\begin{array}{l}3.81 \\
4.06 \\
3.30 \\
4.06\end{array}$ & 11.4 & 133 \\
\hline $39-\mathrm{H}$ & $4 / 12 / 90$ & 0.51 & $\begin{array}{l}3.81 \\
5.08 \\
4.57 \\
4.06\end{array}$ & 15.1 & 131 \\
\hline $40-\mathrm{H}$ & $4 / 12 / 90$ & 0.56 & $\begin{array}{l}4.32 \\
4.57 \\
4.06 \\
5.08\end{array}$ & 16.0 & 112 \\
\hline $41-\mathrm{H}$ & $5 / 24 / 90$ & 0.58 & $\begin{array}{l}4.32 \\
4.57 \\
4.57 \\
3.56\end{array}$ & 14.2 & 120 \\
\hline $42-\mathrm{H}$ & $5 / 24 / 90$ & 0.56 & $\begin{array}{l}4.06 \\
3.56 \\
4.57 \\
4.57\end{array}$ & 13.8 & 130 \\
\hline $43-\mathrm{H}$ & $5 / 24 / 90$ & 0.53 & $\begin{array}{l}4.32 \\
4.57 \\
4.06 \\
4.06 \\
4.57\end{array}$ & 14.2 & 132 \\
\hline
\end{tabular}


Table B.1. (contd)

\begin{tabular}{|c|c|c|c|c|c|}
\hline \multirow[b]{2}{*}{ Pellet } & \multicolumn{5}{|c|}{ Surface } \\
\hline & $\begin{array}{c}\text { Date } \\
\text { Collected }\end{array}$ & $\begin{array}{l}\text { Thickness } \\
\text { (cm) }\end{array}$ & $\begin{array}{l}\text { Diameter } \\
(\mathrm{cm})\end{array}$ & $\begin{array}{l}\text { Area } \\
\left(\mathrm{cm}^{2}\right)\end{array}$ & $\begin{array}{c}\text { Density } \\
\left(\mathrm{mg} / \mathrm{cm}^{3}\right)\end{array}$ \\
\hline $44-\mathrm{H}$ & $5 / 24 / 90$ & 0.64 & $\begin{array}{l}4.57 \\
3.56 \\
5.33 \\
4.06\end{array}$ & 15.1 & 104 \\
\hline $45-\mathrm{H}$ & $5 / 24 / 90$ & 0.56 & $\begin{array}{l}4.32 \\
5.08 \\
4.32 \\
4.57\end{array}$ & 16.4 & 109 \\
\hline $46-\mathrm{H}$ & $6 / 18 / 90$ & 0.58 & $\begin{array}{l}4.06 \\
4.57 \\
4.57 \\
4.06\end{array}$ & 14.6 & 117 \\
\hline $47-\mathrm{H}$ & $6 / 18 / 90$ & 0.66 & $\begin{array}{l}3.30 \\
4.57 \\
3.56 \\
4.32\end{array}$ & 12.2 & 124 \\
\hline 48-H & $6 / 18 / 90$ & 0.53 & $\begin{array}{l}4.83 \\
3.56 \\
4.06 \\
4.57\end{array}$ & 14.2 & 132 \\
\hline 49-H & $6 / 18 / 90$ & 0.56 & $\begin{array}{l}4.32 \\
4.32 \\
4.32 \\
4.57\end{array}$ & 15.1 & 119 \\
\hline $50-\mathrm{H}$ & $6 / 18 / 90$ & 0.56 & $\begin{array}{l}4.57 \\
5.08 \\
3.81 \\
4.32\end{array}$ & 15.5 & 115 \\
\hline $51-\mathrm{H}$ & $7 / 20 / 90$ & 0.61 & $\begin{array}{l}3.56 \\
3.81 \\
4.57 \\
3.56\end{array}$ & 11.8 & 139 \\
\hline $52-\mathrm{i} !$ & $7 / 20 / 90$ & 0.64 & $\begin{array}{l}4.32 \\
3.81 \\
3.81 \\
4.57\end{array}$ & 13.4 & 118 \\
\hline
\end{tabular}

B. 6 
Table B.1. (contd)

\begin{tabular}{|c|c|c|c|c|c|}
\hline \multirow[b]{2}{*}{ Pellet } & \multicolumn{5}{|c|}{ Surface } \\
\hline & $\begin{array}{c}\text { Date } \\
\text { Collected }\end{array}$ & $\begin{array}{l}\text { Thickness } \\
\text { (cm) }\end{array}$ & $\begin{array}{l}\text { Diametèr } \\
(\mathrm{cm})\end{array}$ & $\begin{array}{l}\text { Area }{ }^{(a)} \\
\left(\mathrm{cm}^{2}\right)\end{array}$ & $\begin{array}{c}\text { Density } \\
\left(\mathrm{mg} / \mathrm{cm}^{3}\right)\end{array}$ \\
\hline 53-H & $7 / 20 / 90$ & 0.58 & $\begin{array}{l}3.30 \\
4.06 \\
4.32 \\
4.32\end{array}$ & 12.6 & 136 \\
\hline 54-H & $7 / 20 / 90$ & 0.56 & $\begin{array}{l}3.56 \\
3.81 \\
4.32 \\
3.81\end{array}$ & 11.8 & 152 \\
\hline $55-\mathrm{H}$ & 7/20/90 & 0.61 & $\begin{array}{r}3.30 \\
4.57 \\
4.32 \\
4.83 \\
\end{array}$ & 14.2 & 115 \\
\hline Average & & 0.58 & 4.19 & 13.9 & 128 \\
\hline
\end{tabular}

B. 7 
Table B.2. Dimensions for 1-Gram Press-Formed Pellets

\begin{tabular}{|c|c|c|c|c|c|}
\hline \multirow[b]{2}{*}{ Pellet } & \multicolumn{5}{|c|}{ Surface } \\
\hline & $\begin{array}{c}\text { Date } \\
\text { Collected }\end{array}$ & $\begin{array}{l}\text { Thickness } \\
\text { (cm) }\end{array}$ & Diameter $(\mathrm{cm})$ & $\begin{array}{l}\text { Area }{ }^{(a)} \\
\left(\mathrm{cm}^{2}\right)\end{array}$ & $\begin{array}{c}\text { Density } \\
\left(\mathrm{mg} / \mathrm{cm}^{3}\right)\end{array}$ \\
\hline $1-P$ & $9 / 11 / 89$ & 0.58 & $\begin{array}{l}3.71 \\
3.40 \\
3.96 \\
4.22\end{array}$ & 11.5 & 150 \\
\hline $2-P$ & $9 / 11 / 89$ & 0.56 & $\begin{array}{l}3.96 \\
3.96 \\
4.42 \\
4.01\end{array}$ & 13.1 & 136 \\
\hline 3-P & 9/11/89 & 0.58 & $\begin{array}{l}3.76 \\
3.76 \\
3.25 \\
4.06\end{array}$ & 10.8 & 160 \\
\hline 4-P & $9 / 11 / 89$ & 0.53 & $\begin{array}{l}3.61 \\
3.30 \\
3.05 \\
3.51\end{array}$ & 8.9 & 212 \\
\hline 5-P & $9 / 11 / 89$ & 0.56 & $\begin{array}{l}3.56 \\
4.27 \\
3.35 \\
3.91\end{array}$ & 11.2 & 160 \\
\hline 6-P & $9 / 11 / 89$ & 0.51 & $\begin{array}{l}3.81 \\
3.76 \\
3.35 \\
3.76\end{array}$ & 10.6 & 185 \\
\hline 7-P & $9 / 11 / 89$ & 0.53 & $\begin{array}{l}3.76 \\
3.96 \\
3.71 \\
3.76\end{array}$ & 11.3 & 167 \\
\hline 8-P & $9 / 11 / 89$ & 0.51 & $\begin{array}{l}3.81 \\
3.71 \\
3.51 \\
3.56\end{array}$ & 10.5 & 188 \\
\hline 9-P & $9 / 11 / 89$ & 0.51 & $\begin{array}{l}3.91 \\
3.76 \\
3.66 \\
3.66\end{array}$ & 11.0 & 178 \\
\hline
\end{tabular}


Table B.2. (contd)

\begin{tabular}{|c|c|c|c|c|c|}
\hline \multirow[b]{2}{*}{ Pellet } & \multicolumn{5}{|c|}{ Surface } \\
\hline & $\begin{array}{c}\text { Date } \\
\text { Collected }\end{array}$ & $\begin{array}{c}\text { Thickness } \\
(\mathrm{cm})\end{array}$ & Diameter $(\mathrm{cm})$ & $\begin{array}{l}\text { Area }{ }^{(\mathrm{a})} \\
\left(\mathrm{cm}^{2}\right)\end{array}$ & $\begin{array}{r}\text { Density } \\
\left(\mathrm{mg} / \mathrm{cm}^{3}\right)\end{array}$ \\
\hline $10-\mathrm{P}$ & $9 / 11 / 89$ & 0.53 & $\begin{array}{l}3.61 \\
3.76 \\
3.66\end{array}$ & 11.3 & 168 \\
\hline $11-\mathrm{P}$ & $10 / 16 / 89$ & 0.70 & $\begin{array}{l}3.56 \\
3.81 \\
3.81 \\
3.30\end{array}$ & 10.3 & 139 \\
\hline 12-P & $10 / 16 / 89$ & 0.63 & $\begin{array}{l}3.30 \\
3.81 \\
3.81 \\
3.56\end{array}$ & 10.3 & 154 \\
\hline 13-P & $10 / 16 / 89$ & 0.48 & $\begin{array}{l}4.06 \\
3.81 \\
4.06 \\
3.81\end{array}$ & 12.2 & 171 \\
\hline i4-P & $10 / 16 / 89$ & 0.52 & $\begin{array}{l}4.06 \\
3.81 \\
3.81 \\
3.81\end{array}$ & 11.8 & 163 \\
\hline $15-\mathrm{P}$ & $10 / 19 / 89$ & 0.62 & $\begin{array}{l}3.81 \\
3.30 \\
3.56 \\
3.81\end{array}$ & 10.3 & 157 \\
\hline $16-\mathrm{P}$ & $11 / 30 / 89$ & 0.51 & $\begin{array}{l}3.81 \\
4.06 \\
3.81 \\
3.81\end{array}$ & 11.8 & 166 \\
\hline $17-\mathrm{P}$ & $11 / 30 / 89$ & 0.51 & $\begin{array}{l}4.32 \\
4.06 \\
4.32 \\
4.83\end{array}$ & 15.1 & 130 \\
\hline $18-\mathrm{P}$ & $11 / 30 / 89$ & 0.58 & $\begin{array}{l}3.56 \\
4.06 \\
3.81 \\
4.32\end{array}$ & 12.2 & 142 \\
\hline
\end{tabular}

B. 9 
Table B.2. (contd)

\begin{tabular}{|c|c|c|c|c|c|}
\hline \multirow[b]{2}{*}{ Pellet } & \multicolumn{5}{|c|}{ Surface } \\
\hline & $\begin{array}{c}\text { Date } \\
\text { Collected }\end{array}$ & $\begin{array}{l}\text { Thickness } \\
\text { (cm) }\end{array}$ & Diameter $(\mathrm{cm})$ & $\begin{array}{l}\operatorname{Arsa} a^{(a)} \\
\left(\mathrm{cm}^{2}\right)\end{array}$ & $\begin{array}{l}\text { Density } \\
\left(\mathrm{mg} / \mathrm{cm}^{3}\right)\end{array}$ \\
\hline $19-\mathrm{P}$ & $11 / 30 / 89$ & 0.53 & $\begin{array}{l}4.06 \\
4.06 \\
3.81 \\
4.06\end{array}$ & 12.6 & 150 \\
\hline 20-P & $11 / 30 / 89$ & 0.53 & $\begin{array}{l}4.06 \\
4.06 \\
3.81 \\
3.81\end{array}$ & 12.2 & 179 \\
\hline 21-P & $12 / 28 / 89$ & 0.56 & $\begin{array}{l}3.51 \\
4.14 \\
3.81 \\
3.33\end{array}$ & 10.7 & 166 \\
\hline $22-\mathrm{P}$ & $12 / 28 / 89$ & 0.56 & $\begin{array}{l}3.81 \\
3.66 \\
3.81 \\
3.66\end{array}$ & 11.0 & 163 \\
\hline 23-P & $12 / 28 / 89$ & 0.56 & $\begin{array}{l}4.45 \\
4.14 \\
3.66 \\
3.96\end{array}$ & 12.9 & 138 \\
\hline 24-P & $12 / 28 / 89$ & 0.41 & $\begin{array}{l}4.78 \\
4.78 \\
3.81 \\
3.81\end{array}$ & 14.5 & 168 \\
\hline 25-P & $12 / 28 / 89$ & 0.41 & $\begin{array}{l}3.96 \\
3.81 \\
3.66 \\
3.33\end{array}$ & 10.7 & 228 \\
\hline $26-P$ & 1/9/90 & 0.61 & $\begin{array}{l}3.56 \\
3.81 \\
3.56 \\
3.81\end{array}$ & 10.7 & 154 \\
\hline 27-P & $1 / 9 / 90$ & 0.53 & $\begin{array}{l}3.81 \\
3.81 \\
3.30 \\
4.06\end{array}$ & 11.0 & 171 \\
\hline
\end{tabular}

B. 10 
Table B.2. (contd)

\begin{tabular}{|c|c|c|c|c|c|}
\hline \multirow[b]{2}{*}{ Pellet } & \multicolumn{5}{|c|}{ Surface } \\
\hline & $\begin{array}{c}\text { Date } \\
\text { Collected }\end{array}$ & $\begin{array}{l}\text { Thickness } \\
(\mathrm{cm})\end{array}$ & Diameter $(\mathrm{cm})$ & $\begin{array}{l}\text { Area } \\
\left(\mathrm{cm}^{2}\right)\end{array}$ & $\begin{array}{c}\text { Density } \\
\left(\mathrm{mg} / \mathrm{cm}^{3}\right)\end{array}$ \\
\hline 28-P & $1 / 9 / 90$ & 0.56 & $\begin{array}{l}4.06 \\
4.06 \\
3.30 \\
3.81\end{array}$ & 11.4 & 157 \\
\hline 29-P & $1 / 24 / 90$ & 0.56 & $\begin{array}{l}3.81 \\
4.32 \\
4.06 \\
4.06\end{array}$ & 13.0 & 138 \\
\hline 30-P & $1 / 24 / 90$ & 0.66 & $\begin{array}{l}3.81 \\
3.81 \\
4.83 \\
4.06\end{array}$ & 13.4 & 113 \\
\hline 31-P & $2 / 26 / 90$ & 0.53 & $\begin{array}{l}3.81 \\
3.81 \\
4.06 \\
4.06\end{array}$ & 12.2 & 155 \\
\hline 32-P & $2 / 26 / 90$ & 0.56 & $\begin{array}{l}3.56 \\
3.81 \\
3.56 \\
4.06\end{array}$ & 11.0 & 162 \\
\hline 33-P & $2 / 26 / 90$ & 0.56 & $\begin{array}{l}4.06 \\
3.81 \\
3.56 \\
4.06\end{array}$ & 11.8 & 152 \\
\hline 34-P & $2 / 26 / 90$ & 0.53 & $\begin{array}{l}3.81 \\
3.81 \\
3.56 \\
3.56\end{array}$ & 10.7 & 177 \\
\hline 35-P & $2 / 26 / 90$ & 0.58 & $\begin{array}{l}4.32 \\
4.32 \\
4.32 \\
3.56\end{array}$ & 13.4 & 129 \\
\hline 36-P & $4 / 12 / 90$ & 0.48 & $\begin{array}{l}3.81 \\
3.81 \\
3.81 \\
4.06\end{array}$ & 11.8 & 177 \\
\hline
\end{tabular}

B. 11 
Table B.2. (contd)

\begin{tabular}{|c|c|c|c|c|c|}
\hline \multirow[b]{2}{*}{ Peilet } & \multicolumn{5}{|c|}{ Surface } \\
\hline & $\begin{array}{c}\text { Date } \\
\text { Collected } \\
\end{array}$ & $\begin{array}{l}\text { Thickness } \\
\text { (cm) }\end{array}$ & Diameter $(\mathrm{cm})$ & $\begin{array}{l}\text { Area }{ }^{(a)} \\
\left(\mathrm{cm}^{2}\right)\end{array}$ & $\begin{array}{r}\text { Density } \\
\left(\mathrm{mg} / \mathrm{cm}^{3}\right)\end{array}$ \\
\hline $37-\mathrm{P}$ & $4 / 12 / 90$ & 0.48 & $\begin{array}{l}3.81 \\
4.32 \\
4.06 \\
4.06\end{array}$ & 13.0 & 161 \\
\hline 38-P & $4 / 12 / 90$ & $0 . .3$ & $\begin{array}{l}3.81 \\
4.06 \\
3.81 \\
3.81\end{array}$ & 11.8 & 160 \\
\hline 39-P & $4 / 12 / 90$ & 0.48 & $\begin{array}{l}3.81 \\
3.81 \\
4.32 \\
3.81\end{array}$ & 12.2 & 171 \\
\hline 40-P & $4 / 12 / 90$ & 0.48 & $\begin{array}{l}4.57 \\
4.32 \\
4.06 \\
4.06\end{array}$ & 14.2 & 147 \\
\hline 41-P & $5 / 24 / 90$ & 0.58 & $\begin{array}{l}4.06 \\
3.81 \\
3.81 \\
4.06\end{array}$ & 12.2 & 142 \\
\hline $42-\mathrm{P}$ & $5 / 24 / 90$ & 0.53 & $\begin{array}{l}4.06 \\
3.81 \\
4.06 \\
4.06\end{array}$ & 12.6 & 150 \\
\hline 43-P & $5 / 24 / 90$ & 0.56 & $\begin{array}{l}4.06 \\
4.32 \\
4.06 \\
4.06\end{array}$ & 13.4 & 134 \\
\hline 44-P & $5 / 24 / 90$ & 0.48 & $\begin{array}{l}4.06 \\
4.06 \\
3.81 \\
3.56\end{array}$ & 11.8 & 177 \\
\hline $45-\mathrm{P}$ & $5 / 24 / 90$ & 0.51 & $\begin{array}{l}4.06 \\
4.06 \\
4.06 \\
3.81\end{array}$ & 12.6 & 156 \\
\hline
\end{tabular}

B. 12 
Table B.2. (contd)

\begin{tabular}{|c|c|c|c|c|c|}
\hline \multirow[b]{2}{*}{ Pellet } & \multicolumn{5}{|c|}{ Surface } \\
\hline & $\begin{array}{c}\text { Date } \\
\text { Collected }\end{array}$ & $\begin{array}{l}\text { Thickness } \\
\text { (cm) }\end{array}$ & Diameter $(\mathrm{cm})$ & $\begin{array}{l}\text { Area }{ }^{(a)} \\
\left(\mathrm{cm}^{2}\right)\end{array}$ & $\begin{array}{r}\text { Density } \\
\left(\mathrm{mg} / \mathrm{cm}^{3}\right)\end{array}$ \\
\hline $46-\mathrm{P}$ & $6 / 18 / 90$ & 0.53 & $\begin{array}{l}3.56 \\
4.06 \\
3.81 \\
4.06\end{array}$ & 11.8 & 160 \\
\hline 47-P & $6 / 18 / 90$ & 0.53 & $\begin{array}{l}4.06 \\
4.06 \\
3.81 \\
4.06\end{array}$ & 12.6 & 150 \\
\hline $48 \cdot \mathrm{P}$ & $6 / 18 / 90$ & 0.56 & $\begin{array}{l}3.81 \\
3.81 \\
3.81 \\
3.56\end{array}$ & 11.0 & 162 \\
\hline $49-\mathrm{P}$ & $6 / 18 / 90$ & 0.53 & $\begin{array}{l}3.81 \\
3.81 \\
3.81 \\
4.06\end{array}$ & 11.8 & 160 \\
\hline 50-P & $6 / 18 / 90$ & 0.56 & $\begin{array}{l}4.06 \\
4.06 \\
3.81 \\
3.81\end{array}$ & 12.2 & 147 \\
\hline $51-\mathrm{P}$ & $7 / 20 / 90$ & 0.58 & $\begin{array}{l}4.06 \\
3.30 \\
3.56 \\
3.81\end{array}$ & 10.7 & 162 \\
\hline $52-\mathrm{P}$ & $7 / 20 / 90$ & 0.58 & $\begin{array}{l}3.81 \\
3.30 \\
4.06 \\
3.81\end{array}$ & 11.0 & 157 \\
\hline 53-P & $7 / 20 / 90$ & 0.53 & $\begin{array}{l}4.06 \\
3.56 \\
4.32 \\
3.56\end{array}$ & 11.8 & 160 \\
\hline 54-P & $7 / 20 / 90$ & 0.58 & $\begin{array}{l}3.56 \\
3.81 \\
4.06 \\
4.32\end{array}$ & 12.2 & 142 \\
\hline
\end{tabular}


Table B.2. (contd)

\begin{tabular}{|c|c|c|c|c|c|}
\hline \multirow{2}{*}{ Pellet } & \multicolumn{5}{|c|}{ Surface } \\
\cline { 2 - 6 } & $\begin{array}{c}\text { Date } \\
\text { Collected }\end{array}$ & $\begin{array}{c}\text { Thickness } \\
(\mathrm{cm})\end{array}$ & Diameter $(\mathrm{cm})$ & $\begin{array}{c}\text { Area } \\
\left(\mathrm{cm}^{2}\right)\end{array}$ & $\begin{array}{c}\text { Density } \\
\left(\mathrm{mg} / \mathrm{cm}^{3}\right)\end{array}$ \\
\hline $55-\mathrm{P}$ & $7 / 20 / 90$ & 0.61 & 3.81 & 11.8 & 139 \\
& & & 3.81 & & \\
& & & 3.81 & & \\
\hline Average & & 0.06 & 3.87 & 11.8 & 159 \\
\hline
\end{tabular}

(a) Surface aree of the top of the pellet only. 
Table B.3. Parameters in M for 1-Gram Reconstructed Hand-Formed Pellets

\begin{tabular}{|c|c|c|c|c|c|c|c|c|c|}
\hline Pellet & $G_{p}$ & $F_{d}$ & $F_{b o}$ & $F_{\mathrm{cel}}$ & $F_{s a}$ & $\mathrm{~F}_{2}$ & $\mathrm{E}_{\mathrm{c}}$ & $\begin{array}{c}\mathrm{M} \\
(\mathrm{dpm} / \\
\mathrm{cpm})\end{array}$ & $\begin{array}{r}1 / \mathrm{M} \\
(\mathrm{cpm} / \\
\mathrm{dpm}) \\
\end{array}$ \\
\hline $1-\mathrm{r}^{\mathrm{r}}$ & 0.084 & 0.67 & 1.10 & 1.04 & 0.33 & 0.73 & 1.00 & 63.5 & 0.016 \\
\hline $2-\mathrm{H}$ & 0.085 & 0.68 & 1.10 & 1.04 & 0.32 & 0.73 & 1.00 & 64.6 & 0.015 \\
\hline $3-\mathrm{H}$ & 0.080 & 0.67 & 1.10 & 1.04 & 0.34 & 0.73 & 1.00 & 65.4 & 0.015 \\
\hline 4-H & 0.084 & 0.70 & 1.10 & 1.04 & 0.29 & 0.73 & 1.00 & 69.1 & 0.014 \\
\hline 5-H & 0.083 & 0.62 & 1.10 & 1.04 & 0.41 & 0.73 & 1.00 & 56.7 & 0.018 \\
\hline $6-\mathrm{H}$ & 0.085 & 0.64 & 1.10 & 1.04 & 0.37 & 0.73 & 1.00 & 59.2 & 0.017 \\
\hline $7-\mathrm{H}$ & 0.084 & 0.67 & 1.10 & 1.04 & 0.33 & 0.73 & 1.00 & 63.9 & 0.016 \\
\hline 8-H & 0.083 & 0.65 & 1.10 & 1.04 & 0.37 & 0.73 & 1.00 & 60.5 & 0.016 \\
\hline $9-\mathrm{H}$ & 0.084 & 0.69 & 1.10 & 1.04 & 0.31 & 0.73 & 1.00 & 66.8 & 0.015 \\
\hline $10-\mathrm{H}$ & 0.082 & 0.66 & 1.10 & 1.04 & 0.36 & 0.73 & 1.00 & 61.9 & 0.016 \\
\hline $11-\mathrm{H}$ & 0.082 & 0.68 & 1.10 & 1.04 & 0.32 & 0.73 & 1.00 & 65.7 & 0.015 \\
\hline $12-\mathrm{H}$ & 0.083 & 0.70 & 1.10 & 1.04 & 0.30 & 0.73 & 1.00 & 68.4 & 0.015 \\
\hline $13-\mathrm{H}$ & 0.085 & 0.70 & 1.10 & 1.04 & 0.30 & 0.73 & 1.00 & 67.3 & 0.015 \\
\hline $14-\mathrm{H}$ & 0.085 & 0.66 & 1.10 & 1.04 & 0.34 & 0.73 & 1.00 & 61.6 & 0.016 \\
\hline $15-\mathrm{H}$ & 0.084 & 0.68 & 1.10 & 1.04 & 0.32 & 0.73 & 1.00 & 65.6 & 0.015 \\
\hline $16-\mathrm{H}$ & 0.080 & 0.69 & 1.10 & 1.04 & 0.32 & 0.73 & 1.00 & 68.5 & 0.015 \\
\hline $17-\mathrm{H}$ & 0.081 & 0.59 & 1.10 & 1.04 & 0.46 & 0.73 & 1.00 & 54.6 & 0.018 \\
\hline $18-\mathrm{H}$ & 0.080 & 0.65 & 1.10 & 1.04 & 0.37 & 0.73 & 1.00 & 62.3 & 0.016 \\
\hline $19-\mathrm{H}$ & 0.078 & 0.64 & 1.10 & 1.04 & 0.40 & 0.73 & 1.00 & 60.2 & 0.017 \\
\hline $20-\mathrm{H}$ & 0.080 & 0.65 & 1.10 & 1.04 & 0.37 & 0.73 & 1.00 & 62.3 & 0.016 \\
\hline $21-\mathrm{H}$ & 0.075 & 0.63 & 1.10 & 1.04 & 0.42 & 0.72 & 1.00 & 60.9 & 0.016 \\
\hline $22-\mathrm{H}$ & 0.077 & 0.66 & 1.10 & 1.04 & 0.37 & 0.73 & 1.00 & 64.8 & 0.015 \\
\hline $23-\mathrm{H}$ & 0.081 & 0.63 & 1.10 & 1.04 & 0.40 & 0.73 & 1.00 & 58.8 & 0.017 \\
\hline $24-\mathrm{H}$ & 0.079 & 0.64 & 1.10 & 1.04 & 0.39 & 0.73 & 1.00 & 60.7 & 0.016 \\
\hline $25-\mathrm{H}$ & 0.079 & 0.62 & 1.10 & 1.04 & 0.42 & 0.73 & 1.00 & 58.2 & 0.017 \\
\hline $26-\mathrm{H}$ & 0.083 & 0.70 & 1.10 & 1.04 & 0.29 & 0.73 & 1.00 & 70.0 & 0.014 \\
\hline $27-\mathrm{H}$ & 0.083 & 0.68 & 1.10 & 1.04 & 0.32 & 0.73 & 1.00 & 66.2 & 0.015 \\
\hline $28-\mathrm{H}$ & 0.082 & 0.70 & 1.10 & 1.04 & 0.30 & 0.73 & 1.00 & 69.2 & 0.014 \\
\hline 29-H & 0.082 & 0.71 & 1.10 & 1.04 & 0.28 & 0.73 & 1.00 & 72.0 & 0.014 \\
\hline
\end{tabular}


Table B.3. (contd)

\begin{tabular}{|c|c|c|c|c|c|c|c|c|c|}
\hline Pellet & $G_{p}$ & $F_{d}$ & $F_{b e}$ & $F_{\infty o l}$ & $F_{\mathbf{a}}$ & $F_{a}$ & $E_{o}$ & $\begin{array}{c}\mathrm{M} \\
(\mathrm{dpm} / \\
\mathrm{cpm})\end{array}$ & $\begin{array}{c}1 / \mathrm{M} \\
(\mathrm{cpm} / \\
\mathrm{dpm})\end{array}$ \\
\hline $30-\mathrm{H}$ & 0.081 & 0.70 & 1.10 & 1.04 & 0.30 & 0.73 & 1.00 & 69.8 & 0.014 \\
\hline $31-H$ & 0.084 & 0.67 & 1.10 & 1.04 & 0.33 & 0.73 & 1.00 & 63.5 & 0.016 \\
\hline $32-\mathrm{H}$ & 0.085 & 0.66 & 1.10 & 1.04 & 0.35 & 0.73 & 1.00 & 61.0 & 0.016 \\
\hline $33-\mathrm{H}$ & 0.083 & 0.67 & 1.10 & 1.04 & 0.33 & 0.73 & 1.00 & 64.0 & 0.016 \\
\hline 34-H & 0.087 & 0.63 & 1.10 & 1.04 & 0.38 & 0.74 & 1.00 & 57.6 & 0.017 \\
\hline $35-\mathrm{H}$ & 0.081 & 0.65 & 1.10 & 1.04 & 0.37 & 0.73 & 1.00 & 61.3 & 0.016 \\
\hline 36-H & 0.079 & 0.66 & 1.10 & 1.04 & 0.37 & 0.73 & 1.00 & 62.8 & 0.016 \\
\hline $37-\mathrm{H}$ & 0.081 & 0.63 & 1.10 & 1.04 & 0.39 & 0.73 & 1.00 & 59.0 & 0.017 \\
\hline 38-H & 0.085 & 0.70 & 1.10 & 1.04 & 0.30 & 0.73 & 1.00 & 67.4 & 0.015 \\
\hline $39-H$ & 0.080 & 0.65 & 1.10 & 1.04 & 0.38 & 0.73 & 1.00 & 61.5 & 0.016 \\
\hline $40-\mathrm{H}$ & 0.081 & 0.63 & 1.10 & 1.04 & 0.39 & 0.73 & 1.00 & 59.0 & 0.017 \\
\hline $41-H$ & 0.082 & 0.66 & 1.10 & 1.04 & 0.36 & 0.73 & 1.00 & 61.7 & 0.016 \\
\hline $42-\mathrm{H}$ & 0.081 & 0.66 & 1.10 & 1.04 & 0.35 & 0.73 & 1.00 & 63.1 & 0.016 \\
\hline $43-\mathrm{H}$ & 0.081 & 0.66 & 1.10 & 1.04 & 0.36 & 0.73 & 1.00 & 62.7 & 0.016 \\
\hline 44-H & 0.084 & 0.64 & 1.10 & 1.04 & 0.38 & 0.73 & 1.00 & 59.1 & 0.017 \\
\hline $45-\mathrm{H}$ & 0.081 & 0.63 & 1.10 & 1.04 & 0.40 & 0.73 & 1.00 & 58.4 & 0.017 \\
\hline $46-\mathrm{H}$ & 0.082 & 0.65 & 1.10 & 1.04 & 0.37 & 0.73 & 1.00 & 60.8 & 0.016 \\
\hline $47-\mathrm{H}$ & 0.085 & 0.68 & 1.10 & 1.04 & 0.32 & 0.73 & 1.00 & 65.0 & 0.015 \\
\hline $48-\mathrm{H}$ & 0.081 & 0.66 & 1.10 & 1.04 & 0.36 & 0.73 & 1.00 & 62.7 & 0.016 \\
\hline 49-H & 0.081 & 0.64 & 1.10 & 1.04 & 0.38 & 0.73 & 1.00 & 60.5 & 0.016 \\
\hline 50-H & 0.081 & 0.64 & 1.10 & 1.04 & 0.38 & 0.73 & 1.00 & 59.8 & 0.017 \\
\hline $51-H$ & 0.083 & 0.69 & 1.10 & 1.04 & 0.31 & 0.73 & 1.00 & 67.4 & 0.015 \\
\hline $52-\mathrm{H}$ & 0.084 & 0.66 & 1.10 & 1.04 & 0.34 & 0.73 & 1.00 & 62.5 & 0.016 \\
\hline 53-H & 0.082 & 0.68 & 1.10 & 1.04 & 0.32 & 0.73 & 1.00 & 65.6 & 0.015 \\
\hline 54-H & 0.081 & 0.70 & .1 .10 & 1.04 & 0.31 & 0.73 & 1.00 & 68.6 & 0.014 \\
\hline 55-H & 0.083 & 0.65 & 1.10 & 1.04 & 0.36 & 0.73 & 1.00 & 61.2 & 0.016 \\
\hline Average & 0.082 & 0.66 & 1.10 & 1.04 & 0.35 & 0.73 & 1.00 & 63.2 & 0.016 \\
\hline Min & 0.075 & 0.59 & 1.10 & 1.04 & 0.28 & 0.72 & 1.00 & 54.6 & 0.014 \\
\hline Max & 0.087 & 0.71 & 1.10 & 1.04 & 0.46 & 0.74 & 1.00 & 72.0 & 0.018 \\
\hline
\end{tabular}

B. 16 
Table B.4. Parameters in M for 1-Gram Reconstructed Press-Formed Pellets

\begin{tabular}{|c|c|c|c|c|c|c|c|c|c|}
\hline Pellet & $G_{p}$ & $F_{d}$ & $F_{b}$ & $F_{\infty 11}$ & $F_{a}$ & $\mathrm{~F}_{\mathrm{a}}$ & $\mathrm{E}_{0}$ & $\begin{array}{c}\mathrm{M} \\
(\mathrm{dpm} / \\
\mathrm{cpm})\end{array}$ & $\begin{array}{c}1 / \mathrm{M} \\
(\mathrm{cpm} / \\
\mathrm{dpm})\end{array}$ \\
\hline $1-P$ & 0.083 & 0.70 & 1.10 & 1.04 & 0.30 & 0.73 & 1.00 & 68.7 & 0.014 \\
\hline $2-P$ & 0.082 & 0.67 & 1.10 & 1.04 & 0.34 & 0.73 & 1.00 & 64.4 & 0.016 \\
\hline 3-P & 0.083 & 0.71 & 1.10 & 1.04 & 0.29 & 0.73 & 1.00 & 71.2 & 0.014 \\
\hline 4-P & 0.081 & 0.75 & 1.10 & 1.04 & 0.24 & 0.73 & 1.00 & 81.8 & 0.012 \\
\hline 5-P & 0.082 & 0.70 & 1.10 & 1.04 & 0.30 & 0.73 & 1.00 & 70.3 & 0.014 \\
\hline 6-P & 0.080 & 0.72 & 1.10 & 1.04 & 0.28 & 0.73 & 1.00 & 73.9 & 0.014 \\
\hline 7-P & 0.081 & 0.70 & 1.10 & 1.04 & 0.30 & 0.73 & 1.00 & 70.5 & 0.014 \\
\hline 8-P & 0.080 & 0.72 & 1.10 & 1.04 & 0.28 & 0.73 & 1.00 & 74.5 & 0.013 \\
\hline 9-P & 0.080 & 0.71 & 1.10 & 1.04 & 0.29 & 0.73 & 1.00 & 72.1 & 0.014 \\
\hline $10-\mathrm{P}$ & 0.081 & 0.70 & 1.10 & 1.04 & 0.30 & 0.73 & 1.00 & 70.8 & 0.014 \\
\hline 11-P & 0.087 & 0.71 & 1.10 & 1.04 & 0.27 & 0.74 & 1.00 & 70.1 & 0.014 \\
\hline 12-P & 0.084 & 0.72 & 1.10 & 1.04 & 0.27 & 0.73 & 1.00 & 71.9 & 0.014 \\
\hline 13-P & 0.079 & 0.69 & 1.10 & 1.04 & 0.32 & 0.73 & 1.00 & 68.9 & 0.014 \\
\hline 14-P & 0.081 & 0.70 & 1.10 & 1.04 & 0.31 & $0.7 \vdots$ & 1.00 & 69.2 & 0.014 \\
\hline $15-\mathrm{P}$ & 0.084 & 0.72 & 1.10 & 1.04 & 0.27 & 0.73 & 1.00 & 72.2 & 0.014 \\
\hline $16-\mathrm{P}$ & 0.080 & 0.70 & 1.10 & 1.04 & 0.31 & 0.73 & 1.00 & 69.4 & 0.014 \\
\hline 17-P & 0.080 & 0.65 & 1.10 & 1.04 & 0.38 & 0.73 & 1.00 & 61.2 & 0.016 \\
\hline 18-P & 0.083 & 0.69 & 1.10 & 1.04 & 0.32 & 0.73 & 1.00 & 66.5 & 0.015 \\
\hline $19-\mathrm{P}$ & 0.081 & 0.68 & 1.10 & 1.04 & 0.32 & 0.73 & 1.00 & 66.6 & 0.015 \\
\hline 20-P & 0.079 & 0.69 & 1.10 & 1.04 & 0.32 & 0.73 & 1.00 & 69.4 & 0.014 \\
\hline 21-P & 0.082 & 0.71 & 1.10 & 1.04 & 0.28 & 0.73 & 1.00 & 72.0 & 0.014 \\
\hline 22-P & 0.082 & 0.71 & 1.10 & 1.04 & 0.29 & 0.73 & 1.00 & 71.1 & 0.014 \\
\hline 23-P & 0.082 & 0.68 & 1.10 & 1.04 & 0.33 & 0.73 & 1.00 & 65.0 & 0.015 \\
\hline 24-P & 0.077 & 0.66 & 1.10 & 1.04 & 0.36 & 0.73 & 1.00 & 64.4 & 0.016 \\
\hline 25-P & 0.077 & 0.72 & 1.10 & 1.04 & 0.28 & 0.73 & 1.00 & 76.1 & 0.013 \\
\hline 26-P & 0.084 & 0.71 & 1.10 & 1.04 & 0.28 & 0.73 & 1.00 & 70.9 & 0.014 \\
\hline 27-P & 0.081 & 0.71 & 1.10 & 1.04 & 0.29 & 0.73 & 1.00 & 71.6 & 0.014 \\
\hline 28-P & 0.082 & 0.70 & 1.10 & 1.04 & 0.30 & 0.73 & 1.00 & 69.5 & 0.014 \\
\hline 29-P & 0.082 & 0.67 & 1.10 & 1.04 & 0.33 & 0.73 & 1.00 & 64.8 & 0.015 \\
\hline
\end{tabular}

B. 17 
Table B.4. (cont)

\begin{tabular}{|c|c|c|c|c|c|c|c|c|c|}
\hline Pellet & $G_{p}$ & $F_{d}$ & $F_{b}$ & $F_{\infty \infty 1}$ & $F_{s u}$ & $F_{a}$ & $\mathrm{E}_{0}$ & $\begin{array}{c}\mathrm{M} \\
(\mathrm{dpm} / \\
\mathrm{cpm})\end{array}$ & $\begin{array}{r}1 / \mathrm{M} \\
(\mathrm{cpm} / \\
\mathrm{dpm}) \\
\end{array}$ \\
\hline 30-P & 0.085 & 0.66 & 1.10 & 1.04 & 0.34 & 0.73 & 1.00 & 61.6 & 0.016 \\
\hline 31-P & 0.081 & 0.69 & 1.10 & 1.04 & 0.32 & 0.73 & 1.00 & 67.7 & 0.015 \\
\hline 32-P & 0.082 & 0.71 & 1.10 & 1.04 & 0.29 & 0.73 & 1.00 & 70.8 & 0.014 \\
\hline 33-P & 0.082 & 0.69 & 1.10 & 1.04 & 0.31 & 0.73 & 1.00 & 68.2 & 0.015 \\
\hline 34-P & 0.081 & 0.72 & 1.10 & 1.04 & 0.28 & 0.73 & 1.00 & 73.0 & 0.014 \\
\hline $35-\mathrm{P}$ & 0.083 & 0.67 & 1.10 & 1.04 & 0.34 & 0.73 & 1.00 & 63.3 & 0.016 \\
\hline $36-P$ & 0.079 & 0.70 & 1.10 & 1.04 & 0.31 & 0.73 & 1.00 & 70.1 & 0.014 \\
\hline 37-P & 0.079 & 0.68 & 1.10 & 1.04 & 0.33 & 0.73 & 1.00 & 66.6 & 0.015 \\
\hline 38-P & 0.081 & 0.70 & 1.10 & 1.04 & 0.31 & 0.73 & 1.00 & 68.9 & 0.014 \\
\hline 39-P & 0.079 & 0.69 & 1.10 & 1.04 & 0.32 & 0.73 & 1.00 & 68.9 & 0.014 \\
\hline 40-P & 0.079 & 0.66 & 1.10 & 1.04 & 0.36 & 0.73 & 1.00 & 63.6 & 0.016 \\
\hline 41-P & 0.083 & 0.69 & 1.10 & 1.04 & 0.32 & 0.73 & 1.00 & 66.6 & 0.015 \\
\hline 42-P & 0.081 & 0.68 & 1.10 & 1.04 & 0.32 & 0.73 & 1.00 & 66.8 & 0.015 \\
\hline 43-P & 0.082 & 0.67 & 1.10 & 1.04 & 0.34 & 0.73 & 1.00 & 63.8 & 0.016 \\
\hline 44-P & 0.079 & 0.70 & 1.10 & 1.04 & 0.31 & 0.73 & 1.00 & 70.1 & 0.014 \\
\hline 45-P & 0.080 & 0.68 & 1.10 & 1.04 & 0.32 & 0.73 & 1.00 & 67.0 & 0.015 \\
\hline 46-P & 0.081 & 0.70 & 1.10 & 1.04 & 0.31 & 0.73 & 1.00 & 68.9 & 0.014 \\
\hline 47-P & 0.081 & 0.68 & 1.10 & 1.04 & 0.32 & 0.73 & 1.00 & 66.6 & 0.015 \\
\hline 48-P & 0.082 & 0.71 & 1.10 & 1.04 & 0.29 & 0.73 & 1.00 & 70.8 & 0.014 \\
\hline 49-P & 0.081 & 0.70 & 1.10 & 1.04 & 0.31 & 0.73 & 1.00 & 68.9 & 0.014 \\
\hline 50-P & 0.082 & 0.69 & 1.10 & 1.04 & 0.32 & 0.73 & 1.00 & 67.0 & 0.015 \\
\hline $51-P$ & 0.083 & 0.71 & 1.10 & 1.04 & 0.28 & 0.73 & 1.00 & 71.8 & 0.014 \\
\hline 52-P & 0.083 & 0.71 & 1.10 & 1.04 & 0.29 & 0.73 & 1.00 & 70.4 & 0.014 \\
\hline 53-P & 0.081 & 0.70 & 1.10 & 1.04 & 0.31 & 0.73 & 1.00 & 68.9 & 0.014 \\
\hline 54-P & 0.083 & 0.69 & 1.10 & 1.04 & 0.32 & 0.73 & 1.00 & 67.0 & 0.015 \\
\hline 55-P & 0.084 & 0.69 & 1.10 & 1.04 & 0.31 & 0.73 & 1.00 & 67.0 & 0.015 \\
\hline Average & 0.081 & 0.70 & 1.10 & 1.04 & 0.31 & 0.73 & 1.00 & 68.9 & 0.014 \\
\hline Min & 0.077 & 0.65 & 1.10 & 1.04 & 0.24 & 0.73 & 1.00 & 61.2 & 0.012 \\
\hline $\operatorname{Max}$ & 0.087 & 0.75 & 1.10 & 1.04 & 0.38 & 0.74 & 1.00 & 81.8 & 0.016 \\
\hline
\end{tabular}

B. 18 


\section{Distribution}

No. of

Copies

\section{OFFSITE}

\section{Technical Steering Panel}

D. S. Barth

University of Nevada

4505 Maryland Parkway

Las Vegas, NV 89154

W. A. Bishop

2503 Wedgewood Court S.E.

Olympia, WA 98501

M. L. Blazek

Oregon Department of Energy

625 Marion Street N.E.

Salem, OR 97310

G. G, Caldwell

Tulsa City-County Health Dept.

4616 East 15th Street

Tulsa, OK 74112

S. N. Davis

Dept. of Hydrology and Water

Resources

Building 11

University of Arizona

Tucson, AZ 85721

N. J. Germond

224 Iron Mountain Blvd.

Lake Oswego, OR 97034
No. of

Copies

P. C. Klingeman

Civil Engineering Dept.

Apperson Hail 202

Oregon State University

Corvallis, OR 97331-2302

K. J. Kopecky

Fred Hutchinson Cancer

Research Center

1124 Columbia Street

Seattle, WA 98104

P. D. McGavran

Dept. of Health and Welfare $450 \mathrm{~W}$. State Street, 4th Floor

Boise, ID 83720-5450

R. L. Morrill

Dept. of Geography, DP-10

University of Washington

Seattle, WA 98195

A. H. Murphy

3115 NW McKinley Drive

Corvallis, OR 97330

D. W. Price

Agricultural Economics

Hulbert Hall Room 211

Washington State University

Pullman, WA 99164-6210

Distr. 1 
No. of

Copies

M. A. Robkin

Radiological Sciences, SB-75

University of Washington

Seattle, WA 98195

G. S. Roessler

Route 1, Box $139 \mathrm{H}$

Elysian, MN 56028

B. Shleien

2421 Homestead Drive

Silver Springs, MD 20902

A. P. Slickpoo, Sr.

809 N.z Perce Lane

P.O. Box 331

Kamiah, ID 83536

J. E. Till

Route 2 Box 122

Neeses, SC 29107

D. E. Walker, Jr.

P.O. Box 4147

Boulder, CO 80306

Other

2 DOE Office of Scientific and

Technical Information

Technical Information Center

P.O. Box 62

Oak Ridge, TN 37830

B. G. Brooks, EH-421

Room J-112

Department of Energy

Germantown, MD 20545
No. of

Copies

Z. E. Carey

32 Vista Court

Richland, WA 99352

18 K. CharLee

Office of Nuclear Waste Mgmt.

Department of Ecology

719 Sleater Kinney Road, S.E.

Suite 200

Olympia, WA 98504

M. R. Donnelly

Public Health Service

Centers for Disease Control and Prevention

2201 Sixth Avenue, RX-22

Seattle, WA 98121

C. C. Gamertsfelder

4728 Santala Drive

Knoxville, TN 37909

H. A. Haerer

Golden Associates, Inc.

4104 148th N.E.

Redmond, WA 98052

J. W. Healy

51 Grand Cannon Drive

Los Alamos, NM 87544

5 E. I. Mart

20512 S.E. Whitstone

Bend, OR 97702

R. W. Perkins

1413 Sunset

Richland, WA 99352

Distr. 2 
No. of

Copies

K. R. Price

1329 Goethals, \#3

Richland, WA 99352

D. L. Reid

1910 Harris Street

Richland, WA 99352

L. E. Sewell

Centers for Disease Control and Prevention

4770 Buford Highway N.E., F-35

Atlanta, GA 30341-3724

J. P. Thomas

HEAL

1720 N. Ash

Spokane, WA 99205

R. C. Thorburn

132 Sandhill Circle

Menlo Park, CA 94025

L. D. Turner

303 Comstock

Richland, WA 99352

\section{ONSITE}

6 DOE Richland Operations Office

R. F. Brich, TSD

Public Reading Room (5)
No. of

Copies

54 Battelle, Pacific Northwest Laboratories

G. L. Black (5)

K $1-25$

S. D. Cannon

K1-25

D. H. Denham (5)

$\mathrm{K} 3-56$

D. E. Deonigi

K6-54

P. W. Eslinger

K6-96

W. T. Farris

K3-54

N. D. Foote

M. D. Freshiey

K7-70

K6-77

R. O. Gilbert

K7-34

W. A. Glass (14)

K4-13

R. H. Gray

K1-33

L. K. Grove

K6-86

S. P. Gydesen

P8-55

G. L. Harvey

K1-77

C. M. Heeb

K6-42

K3-54

P7-07

P. O. Jackson

K3-54

B. A. Napier

J. V. Ramsdell

K6-03

J. A. Shaw

D. B. Shipler

K1-25

K $1-25$

K7-34

K3-54

B1-40

K1-30

K6-13

P8-08

K6-09

K1-06

K3-70

P8-55

Distr. 3 

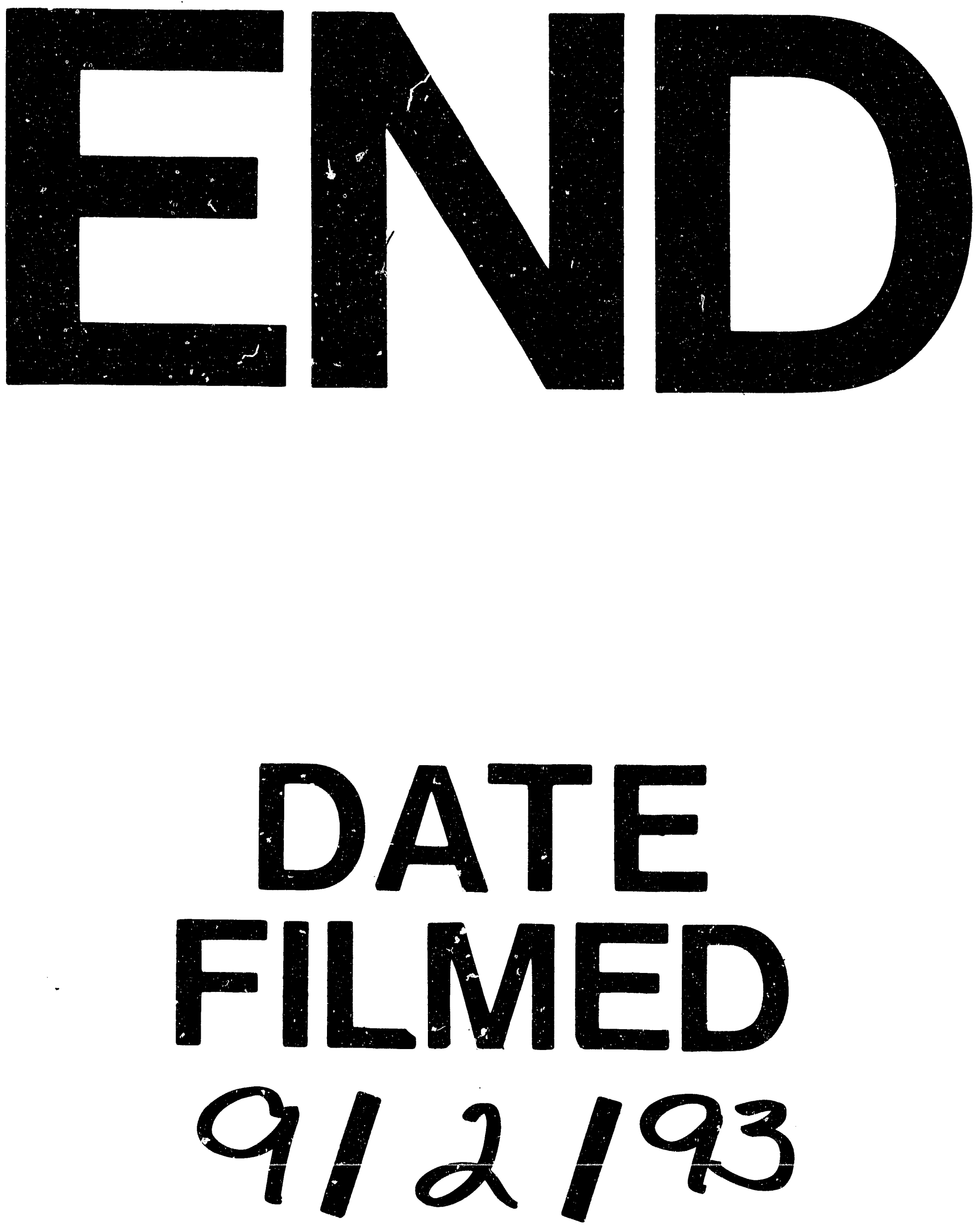
